\title{
WestVirginiaUniversity
}

THE RESEARCH REPOSITORY @ WVU

Graduate Theses, Dissertations, and Problem Reports

2019

\section{Lead exposure of North American raptors}

Vincent A. Slabe

vaslabe@mix.wvu.edu

Follow this and additional works at: https://researchrepository.wvu.edu/etd

Part of the Ornithology Commons

\section{Recommended Citation}

Slabe, Vincent A., "Lead exposure of North American raptors" (2019). Graduate Theses, Dissertations, and Problem Reports. 4037.

https://researchrepository.wvu.edu/etd/4037

This Dissertation is protected by copyright and/or related rights. It has been brought to you by the The Research Repository @ WVU with permission from the rights-holder(s). You are free to use this Dissertation in any way that is permitted by the copyright and related rights legislation that applies to your use. For other uses you must obtain permission from the rights-holder(s) directly, unless additional rights are indicated by a Creative Commons license in the record and/ or on the work itself. This Dissertation has been accepted for inclusion in WVU Graduate Theses, Dissertations, and Problem Reports collection by an authorized administrator of The Research Repository @ WVU.

For more information, please contact researchrepository@mail.wvu.edu. 


\title{
Lead exposure of North American raptors
}

\author{
Vincent A. Slabe
}

Dissertation submitted to the Davis College of Agriculture, Natural Resources and Design at West Virginia University

in partial fulfillment of the requirements for the degree of

Doctor of Philosophy in

Forest Resources Science

\author{
James T. Anderson, Ph.D., Chair \\ Todd Katzner, Ph.D., Co-Chair \\ Jonathan Hall, Ph.D. \\ John Buchweitz, Ph.D. \\ Mike Strager, Ph.D.
}

School of Natural Resources

\author{
Morgantown, West Virginia \\ 2019
}

Keywords: Lead Poisoning, Raptors, Birds of Prey, Toxicant Exposure

Copyright 2019 Vincent A. Slabe 


\section{ABSTRACT \\ Lead exposure of North American Raptors}

Vincent A. Slabe

Lead is an anthropogenic threat to terrestrial wildlife, has no physiological benefits, and is considered a neurotoxin. Legislation adopted in many developed countries restricts the uses of lead in consumer and industrial products such as pipe fittings, petrol, paint, and shot for use in waterfowl hunting. However, lead is currently categorized by the United States (US) government as a critical metal and common uses of lead still persist in North America. These include the use of rifle ammunition, shot in upland gamebird hunting, and fishing sinkers. Lead is also a byproduct of multiple industrial operations including smelters, coal power plants, oil refineries, and battery production facilities. As a consequence, there is regular deposition of potentially toxic amounts of lead in the environment.

Anthropogenic lead influences the ecology and demography of multiple wildlife taxa, including a large number of avian species. Elevated lead concentrations are documented in avian scavengers as a result of ingesting lead fragments from hunter harvested animal carcasses. However, multiple forms of lead deposition exist in eastern North America, making the region ideal to study the pathways of lead exposure in wildlife. I documented the sources and pathways of lead exposure of raptors by studying novel species, seasons, regions and spatial scales. During the breeding season in the Chesapeake region of Maryland and Virginia, I found differences in blood lead concentrations among age groups of bald eagles but no difference between age groups of osprey. In the central Appalachians, I found that territorial red-shouldered hawks had higher blood lead concentrations in urban settings when compared to non-urban settings during the breeding season. I found that a community of facultative avian scavengers in eastern North America exhibited higher blood and liver lead concentrations during the fall and winter months compared to the spring and summer months when they scavenge to a lesser degree. On a nationwide scale, I found that $47 \%$ of bald eagles and $46 \%$ of golden eagles had femur lead concentrations above the threshold commonly accepted to indicate clinical lead poisoning. This work will provide information useful to the management of lead-influenced wildlife and identify potential opportunities for mitigation of environmental lead exposure and, using wildlife as sentinel species, help to understand potential human health hazards of lead exposure. 


\section{DEDICATION}

For Mosey, Frances and Sonny -

Thank you for providing me with the two most essential tools to succeed-Love and Motivation. 


\section{ACKNOWLEDGMENTS}

I thank my mentors, Dr. Todd Katzner and Dr. Jim Anderson. Todd, thank you for giving me this chance and teaching me the way of a scientist. Jim, thank you for always being present and going to bat for me. I will be forever grateful for your role in my attendance at the RRF conference in South Africa - a trip of a lifetime.

I thank Jeff Cooper. Jeff, thank you for requesting an experienced field biologist over an exemplary student to conduct this research. By doing this, you gave me an amazing opportunity that I will never forget.

To Rob Domenech, I am forever grateful to you for hiring me 15 years ago to study golden eagles and for passing along your passion for birds of prey.

To Bracken Brown, Ania Wrona and Meghan Jensen, thanks a million for your countless hours in the field, especially when I was home for the birth of my son.

To the many people who provided samples for this work, I appreciate you all. I wish I had the space to acknowledge all of you individually.

To my parents, siblings and extended family, thanks for always being there and providing me with the confidence to succeed.

I thank the Virginia Department of Game and Inland Fisheries, United States Fish and Wildlife Service, United States Geological Survey and the American Eagle Foundation for funding my research. Also, I thank Davis College for awarding me a fellowship that funded essential writing time for this dissertation. 


\section{TABLE OF CONTENTS}

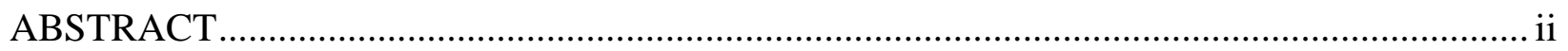

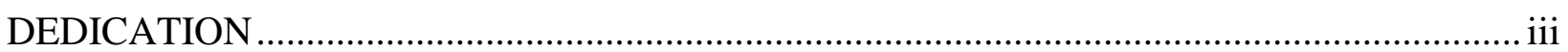

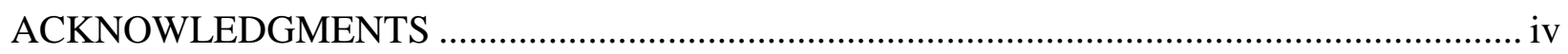

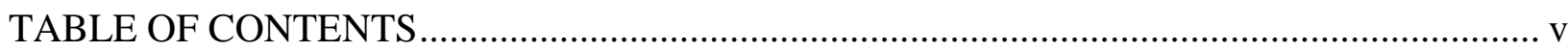

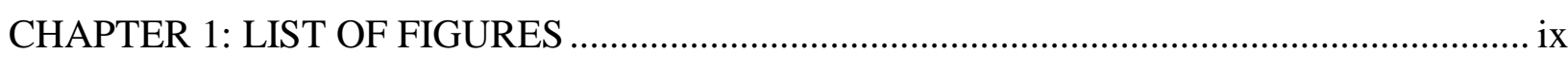

CHAPTER 2: LIST OF TABLES........................................................................................

CHAPTER 3: LIST OF FIGURES ......................................................................................

CHAPTER 3: LIST OF TABLES....................................................................................

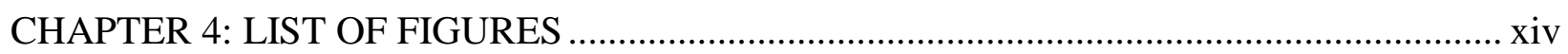

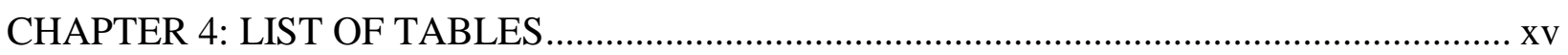

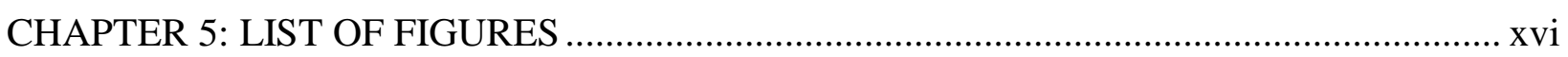

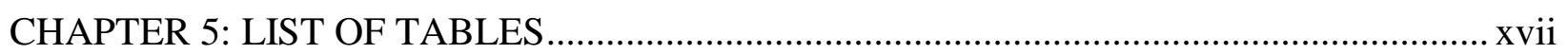

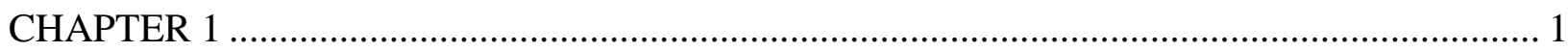

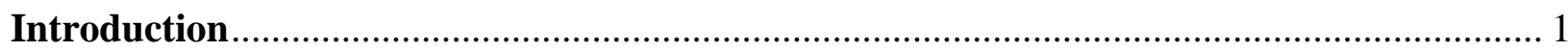

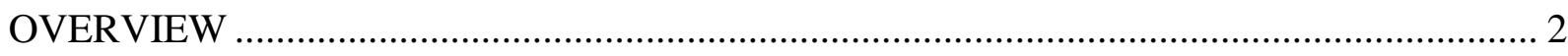

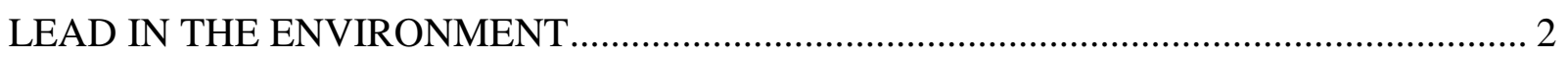

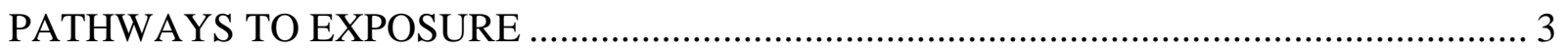

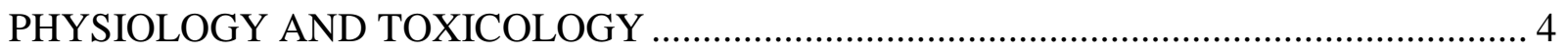

EXAMPLES OF LEAD EXPOSURE IN WILDLIFE ....................................................... 5

AVIAN SCAVENGERS AND AMMUNITION …………................................................ 7

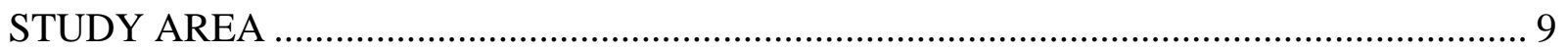

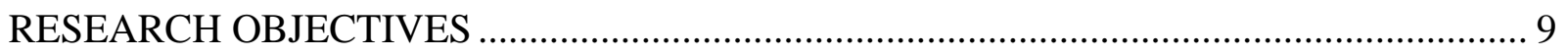

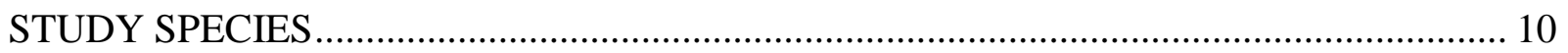

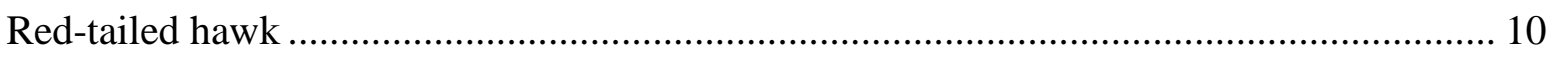

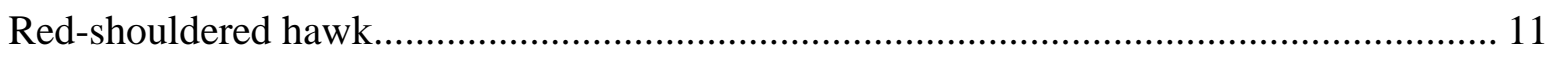

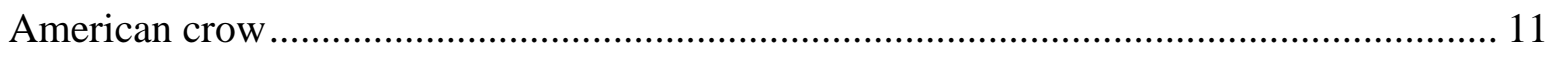

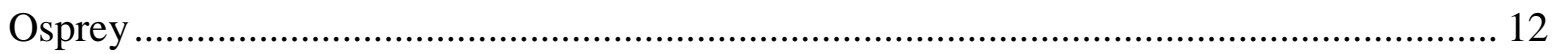

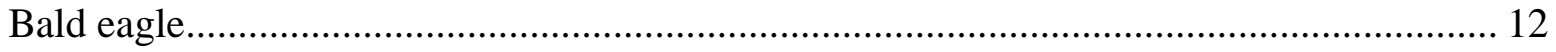

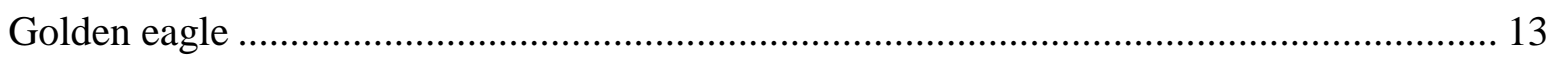

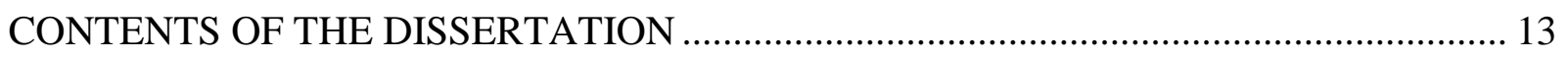

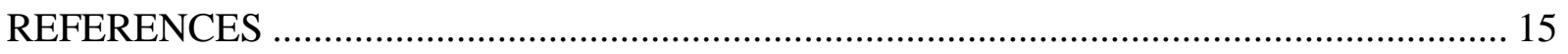


Lead in piscivorous raptors during breeding season in the Chesapeake Bay region of Maryland and Virginia, $\mathbf{U S A}^{\mathbf{1}}$.

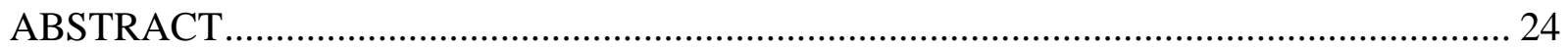

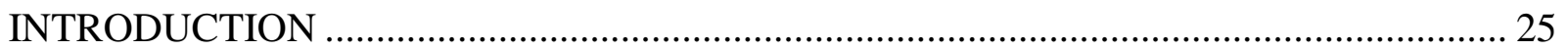

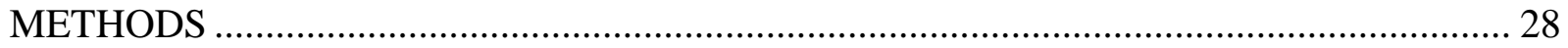

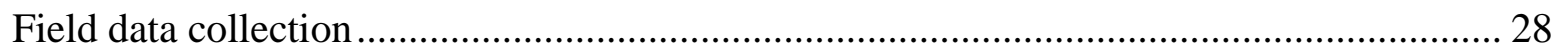

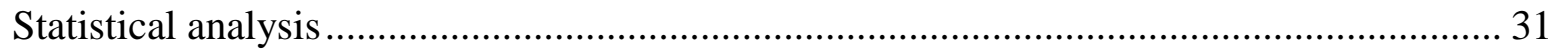

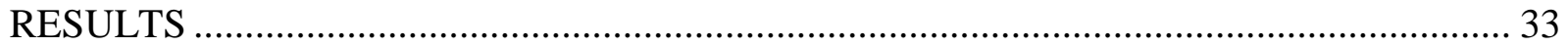

Age- and region-specific lead exposure of osprey and bald eagles ................................. 33

Environmental lead piscivorous raptors encounter in the Chesapeake Bay watershed ........ 35

Correspondence of lead exposure of parent-offspring dyads ........................................ 36

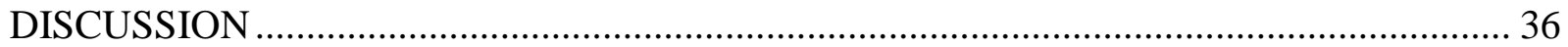

Spatial and demographic patterns of lead exposure .................................................. 36

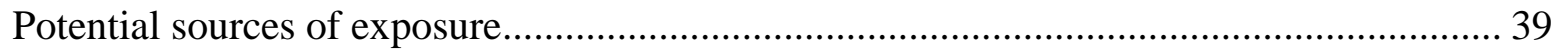

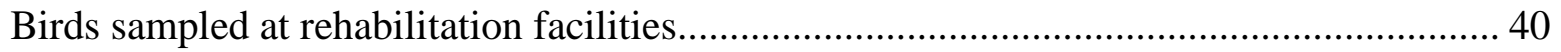

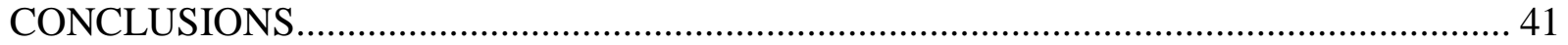

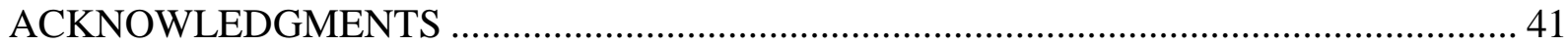

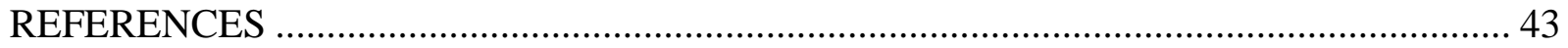

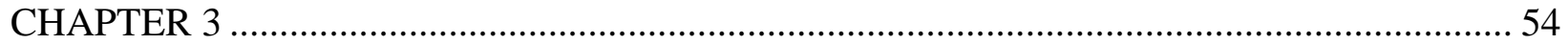

Lead exposure of red-shouldered hawks during the breeding season in the central

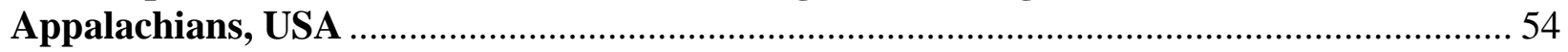

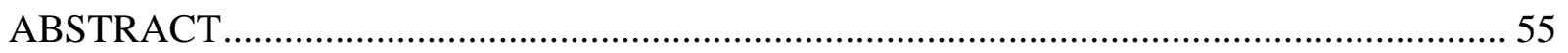

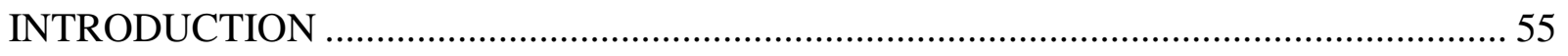

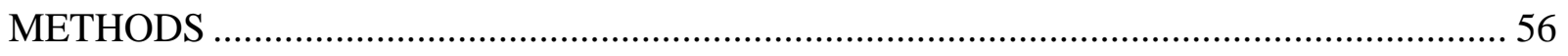

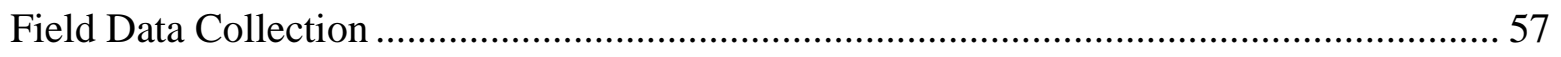

Sample Processing and Laboratory Analysis............................................................ 58

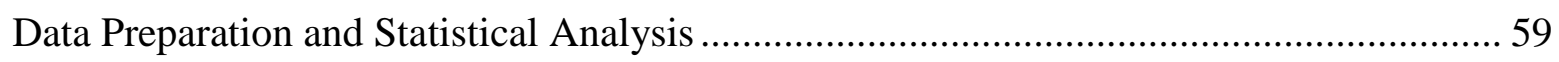

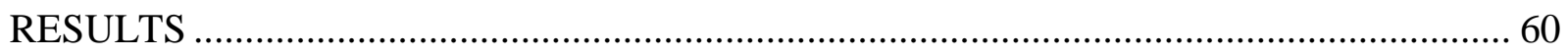

Lead exposure of red-shouldered hawks by region and age class ................................. 61

Comparison of urban and non-urban blood lead concentrations of red-shouldered hawks.. 61

Environmental lead in red-shouldered hawk habitat ................................................. 61

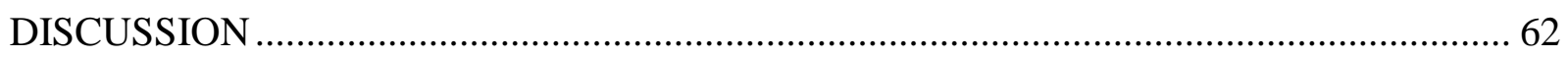

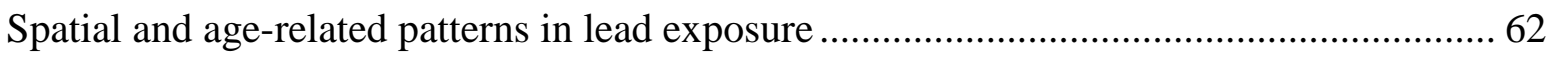

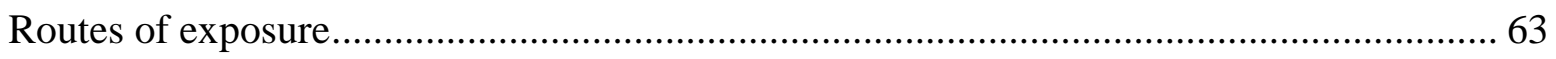




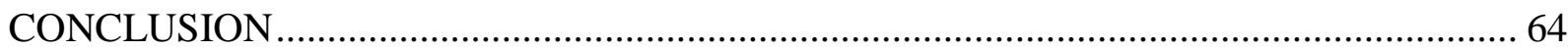

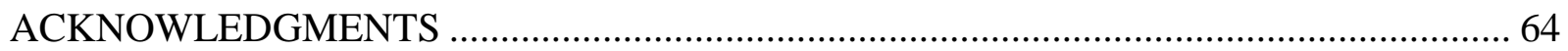

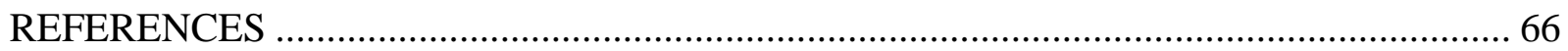

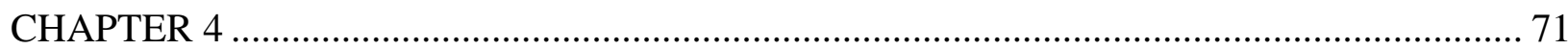

Foraging ecology drives lead exposure of facultative and obligate avian scavengers in eastern North America ..................................................................................................... 71

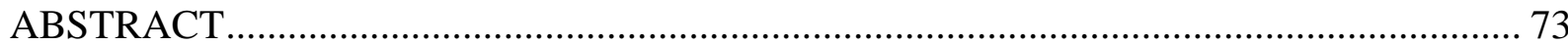

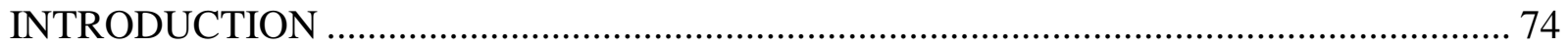

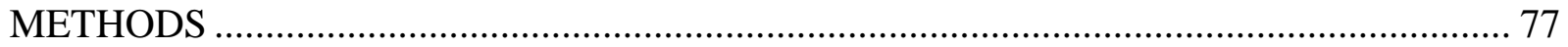

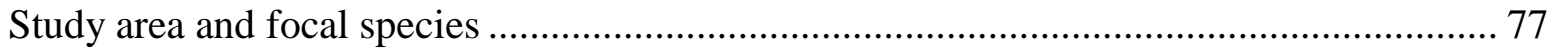

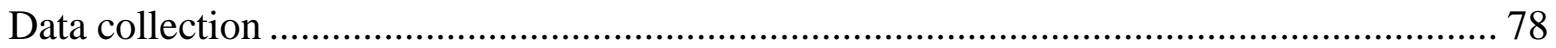

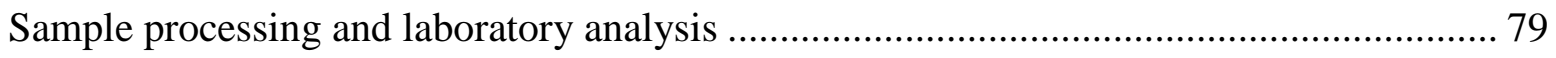

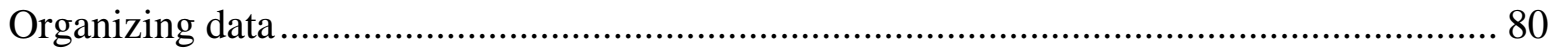

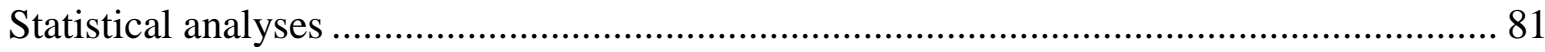

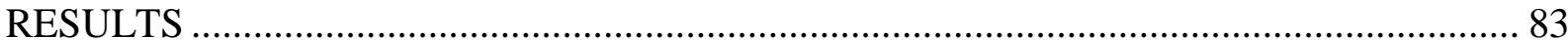

Season and species-specific differences of lead exposure of facultative avian scavengers . 84

Within season comparison of lead exposure of obligate and facultative avian scavengers.. 86

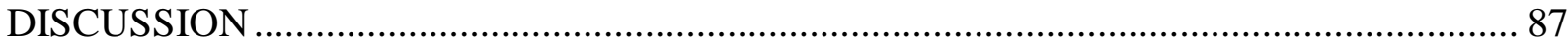

Lead exposure response of facultative scavengers to seasonal and ecological variation ..... 87

Response of lead exposure to behavioral variation among types of scavengers .................. 89

Lead exposure of free flying birds vs. birds sampled at rehabilitation facilities .................. 90

Conclusions - ecological and behavioral drivers of lead exposure...................................... 90

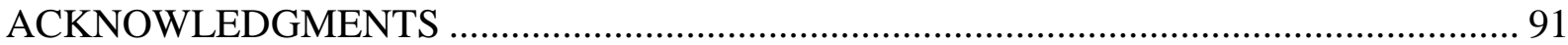

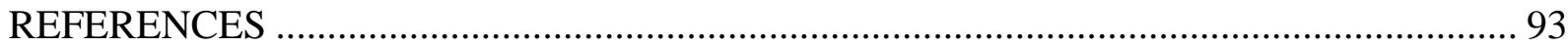

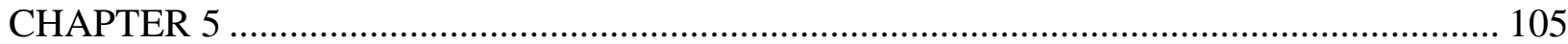

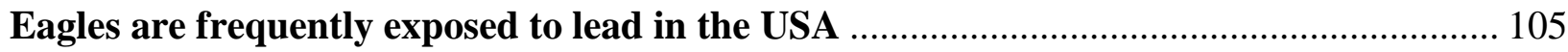

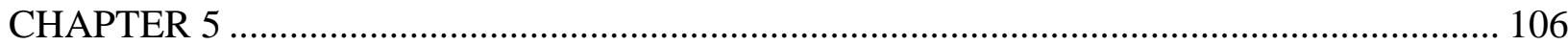

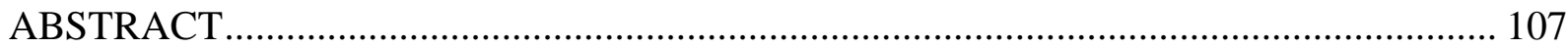

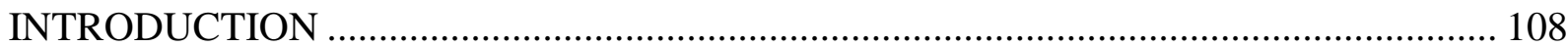

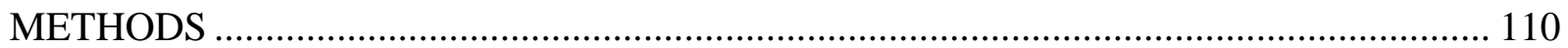

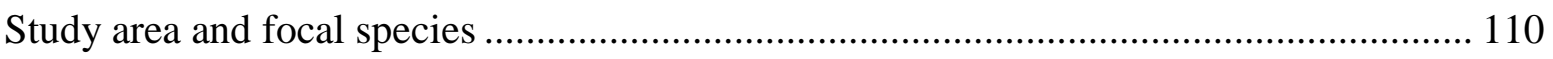

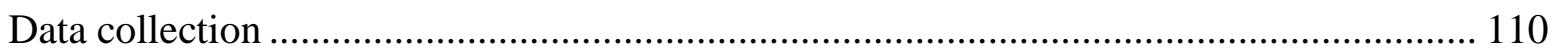

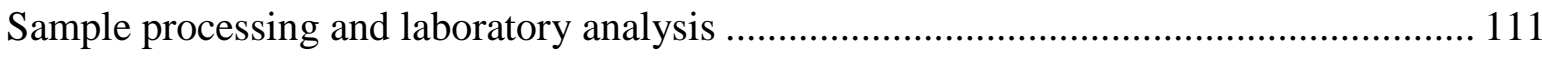

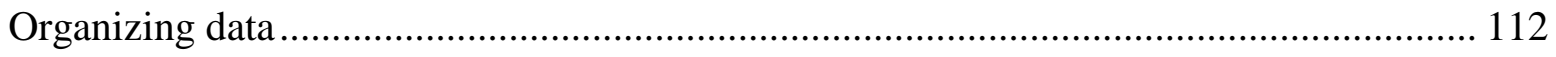

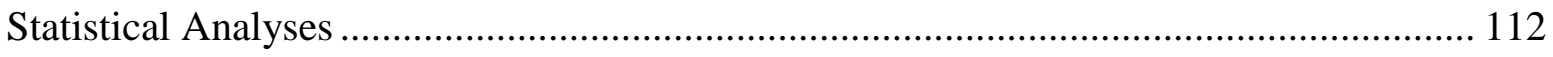


RESULTS

Temporal, age-related, regional, and species-specific differences of lead exposure of bald and golden eagles.

Among region comparison of threshold-specific lead exposure of bald and golden eagles116

Temporal trends in the lead exposure of bald and golden eagles ................................... 118

Spatial trends in the lead exposure of bald and golden eagles....................................... 119

Age-related trends in the lead exposure of bald and golden eagles ................................. 119

Species-specific patterns of lead exposure of eagles ................................................ 120

Threshold specific variation of lead exposure between eagle species ............................. 121

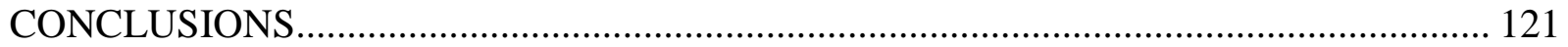

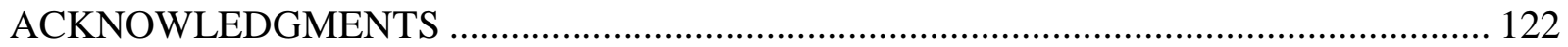

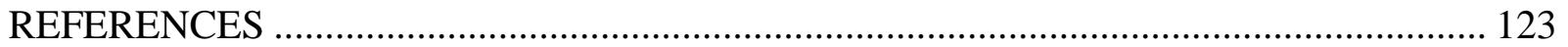

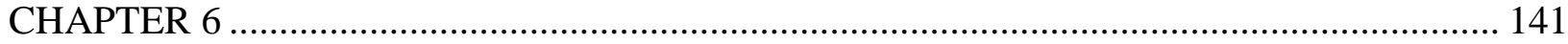

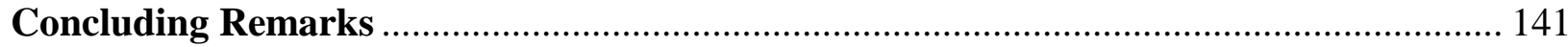

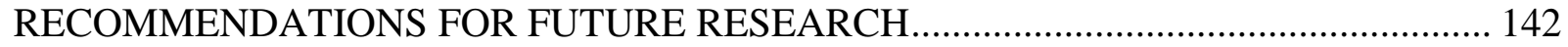

MANAGEMENT RECOMMENDATIONS ........................................................... 143 


\section{CHAPTER 1: LIST OF FIGURES}

Figure 1. (a) Bracken Brown and Vincent Slabe with red-shouldered hawks, West Virginia. (b) Osprey nestlings, Virginia. (c) Vincent Slabe with golden eagle, Montana. (d) Mosey Hardin, Frances Slabe, and Vincent Slabe with rehabilitated bald eagle fledgling, Avian Conservation Center of Appalachia, West Virginia. 


\section{CHAPTER 2: LIST OF FIGURES}

Figure 1. Chesapeake Bay, Eastern Shore, and Coastal Plain of Maryland and Virginia including the, Potomac (P), Rappahannock (R), York (Y), and James (J) Rivers. 


\section{CHAPTER 2: LIST OF TABLES}

Table 1. Age-specific statistics describing central tendencies and distributions of blood lead concentrations (WW, $\mu \mathrm{g} / \mathrm{dL}$ ) of (a) bald eagle and (b) osprey from the Chesapeake Bay region. Birds were sampled from $2014-2017$.

Table 2. Salinity-specific statistics describing central tendencies and distributions of blood lead concentrations (WW, $\mu \mathrm{g} / \mathrm{dL}$ ) for (a) bald eagle and (b) osprey, by salinity, from the Chesapeake Bay region. Birds were sampled from 2012 - 2017, see text for details.

Table 3. Region-specific statistics describing central tendencies and distributions of blood lead concentrations (WW, $\mu \mathrm{g} / \mathrm{dL}$ ) for nestling osprey from the Coastal Plain and Eastern Shore of the Chesapeake Bay region. Birds were sampled from 2015 - 2017.

Table 4. Statistics describing central tendencies and distributions of lead concentrations (DW, ppm) of blue catfish livers, gizzard shad livers, sediment and paint from the Chesapeake Bay region of Maryland and Virginia. Samples were collected from 2015-2017. 


\section{CHAPTER 3: LIST OF FIGURES}

Figure 1. Physiographic provinces in Virginia and West Virginia including the Coastal Plain, Piedmont, Blue Ridge, Valley and Ridge, and Appalachian Plateau. In this study, we compared samples collected in the Coastal Plain, the Piedmont, and the mountains (Blue Ridge, Valley and Ridge, and Appalachian Plateau).

Figure 2. Censored boxplots of blood lead concentrations of red-shouldered hawks from the central Appalachians, USA; (a) adults and nestlings (b) urban and non-urban settings. Boxplots are presented on a log scale to limit the y axis for graphical representation of the data. The line running perpendicular to the y axis represents the censoring threshold for the dataset. Whiskers are extended to include extreme data points. 


\section{CHAPTER 3: LIST OF TABLES}

Table 1. Blood lead concentrations (WW, $\mu \mathrm{g} / \mathrm{dL}$ ) for red-shouldered hawks from the central Appalachians. Data are organized by age class, physiographic region, and land use. Birds were sampled from 2012 - 2018. See text for details on age classification; ASY = "after second year", always adult territory holders.

Table 2. Lead concentrations (DW, ppm) for earthworms and soil from the central Appalachians. Samples were collected from 2016 - 2018 within known red-shouldered hawk territories and always near nests that were being used. Because all lead concentrations were above the LOD, we present minimum and maximum rather than confidence intervals. 


\section{CHAPTER 4: LIST OF FIGURES}

Figure 1. Boxplots of (a) blood (eastern North America) and (b) liver (Virginia) lead concentrations of American crows (AMCR), bald eagles (BAEA), golden eagles (GOEA), redshouldered hawks (RSHA), and red-tailed hawks (RTHA). Seasons (post-hatching (PH) and scavenge (SC) are based on mean hatching dates and earliest scavenging dates from game camera images. Boxplots are presented on a log scale to limit the y axis for graphical representation of the data.

Figure 2. Boxplots of liver lead concentrations of facultative (American crows (AMCR), bald eagles (BAEA), golden eagles (GOEA), red-shouldered hawks (RSHA), and red-tailed hawks (RTHA) and obligate (black vultures (BLVU) and turkey vultures (TUVU) avian scavengers that were culled or euthanized between the months of April and July in Virginia, USA. Boxplots are presented on a log scale to limit the y axis for graphical representation of the data. 


\section{CHAPTER 4: LIST OF TABLES}

Table 1. Statistics describing central tendencies of lead concentrations of scavenger blood (a) $(\mu \mathrm{g} / \mathrm{dL})$ from eastern North America and liver (b) ( $\mathrm{ppm})$ from Virginia. Samples were collected from 2010-2018

Table 2. Statistics describing central tendencies of lead concentrations of avian scavengers from eastern North America by (a) season, (b) disposition, and (c) scavenging behavior. Samples were collected from 2010-2018.

Table 3. Beta coefficients, standard errors, $\mathrm{z}$-scores and $\mathrm{p}$ values for the final tobit models including (a) blood and liver lead concentrations of facultative obligate scavengers and (b) liver lead concentrations of obligate and facultative scavengers during the summer months. 


\section{CHAPTER 5: LIST OF FIGURES}

Figure 1. Continental US with blood, liver, and femur sample locations by county and USFWS administrative Flyway.

Figure 2. Boxplots of blood lead concentrations by (a) month (bald eagle) and (b) Flyway (golden eagle). Boxplots are presented on a log scale to limit the y axis for graphical representation of the data.

Figure 3. Boxplots of liver lead concentrations of bald eagles by age group. Boxplots are presented on a log scale to limit the $y$ axis for graphical representation of the data.

Figure 4. Boxplots comparing (a) blood and (b) liver lead concentrations of North American eagle species. Boxplots are presented on a log scale to limit the y axis for graphical representation of the data. 


\section{CHAPTER 5: LIST OF TABLES}

Table 1. Statistics describing Central tendencies of blood lead concentrations ( $\mu \mathrm{g} / \mathrm{dL})$ of (a) golden eagles and (b) bald eagles from North America by (a) age, (b) month, (c) Flyway, and (d) disposition. Samples were collected from 2010-2018.

Table 2. Statistics describing Central tendencies of liver lead concentrations (ppm DW) of (a) bald eagles and (b) golden eagles from North America by age, month, Flyway, and disposition. Samples were collected from 2010-2018.

Table 3. Statistics describing Central tendencies of femur lead concentrations (ppm DW) of (a) bald eagles and (b) golden eagles by age, Flyway, and disposition. Samples were collected from 2010-2018.

Table 4. Beta coefficients, standard errors, z-scores and $\mathrm{p}$ values for the significant predictor variables in the final tobit models describing blood, liver, and femur lead concentrations of (a) bald eagles and (b) golden eagles. 


\section{CHAPTER 1}

Introduction

Vincent A. Slabe ${ }^{1}$

${ }^{1}$ Division of Forestry and Natural Resources, West Virginia University, Morgantown WV 26506 U.S.A. 


\section{OVERVIEW}

The use of lead dates back 8,000 years to ancient Greece, China, and Rome (Kendler 1994, Mao et al. 2008). The Romans used lead for their complex plumbing systems, as a flavor additive in wine, and as an ingredient in ornamental paint (Kendler 1994). Abnormally high lead levels were subsequently present in the bones of Romans, leading one researcher to hypothesize that lead poisoning contributed to the fall of the Roman Empire (Nriagu 1983). Some of the chronic effects of lead poisoning include decreased fertility, cardiovascular disease, renal failure, and in some cases, death (Pokras and Kneeland 2008). Unborn children have a high absorption rate of lead in the blood stream and consequently are particularly susceptible to the resulting neurological effects including delayed cognitive development, behavioral problems, and mental impairment (Huang et al. 2012, Sowers et al. 2002). A drastic reduction in violent crime rates in U.S. urban areas has been correlated to the gradual elimination of lead in gasoline and paint (Carpenter and Nevin 2010).

There are many characteristics of lead that make it favorable for a variety of uses in modern society. Lead has a low melting point, is highly versatile, is corrosion resistant, and is cost effective to mine when compared with other industrial metals (Kendler 1994). The process of mining lead entails the extraction of lead ore, followed by the refining process, and finally the distribution of a product that is $99 \%$ pure.

\section{LEAD IN THE ENVIRONMENT}

Industrialization in the modern world has resulted in a much higher incidence of lead contamination in water, soil, plants, and the atmosphere (Irwin et al. 1997). The primary impetus to manufacture lead worldwide and the subsequent leading cause of atmospheric lead continues to be the combustion of leaded fuel (Mao et al. 2008). Manufacturing storage batteries and the 
subsequent recycling of the lead from these batteries for use in the production of ammunition are the two largest commercial forms of lead production in the US (USGS 2013). As of 2007, the US ranked third in the world in total commercial lead production behind China and Australia.

Emission sources including exhaust from airplanes and automobiles, lead smelters, and coal fired power plants are the leading causes of airborne lead (Irwin et al. 1997). Atmospheric lead from these sources eventually settles in surface soils and causes ecological damage (Derome and Nieminen 1998, Irwin et al. 1997, Lukkari et al. 2004). Additionally, elevated lead levels exist in sediment washed downstream from mining operations (Beyer et al. 2000). Because of its resistance to corrosion and low mobility, lead can exist in host environments, such as topsoil in upland environments, for several millennia (Davies et al. 1990, Jørgensen and Willems 1987).

The Environmental Protection Agency in the US sets regulations on the amount of lead allowable in drinking water (US EPA 2009). Water, soil, and air can all contribute to the amount of lead found in aquatic and terrestrial plant life (Cheng and $\mathrm{Hu} 2010)$. Potential factors determining the amount of lead in roots, stems, and leaves of plants are dependent on, but not limited to, environmental factors such as soil acidity, plant species and distance to industrial lead pollution, etc. (Sorvari et al. 2006).

\section{PATHWAYS TO EXPOSURE}

The two most common pathways by which lead enters the body are via ingestion and inhalation. Incidental ingestion of lead particles in the form of paint chips and dust can occur by children and various species of wildlife (Sileo and Fefer 1987, Wadanambi et al. 2008). Lead exposure through ingestion also occurs through the consumption of hunter harvested food sources (Iqbal et al. 2009). 
Inhalation of lead has been greatly reduced in the US by the restrictions placed on the use of leaded fuel (US EPA 2013). Occupational hazards of lead inhalation continue to persist within fine dust particles at mining operations, construction sites, factories, and in buildings with degraded lead-based paint. However, workplace standards in the US regulate potentially harmful conditions for the inhalation of lead (OSHA 2015). In countries with more lenient restrictions on emissions, such as China, the inhalation of lead particles can occur in individuals living within close proximity of industrial locations such as smelters and coking plants (Cao et al. 2014, Cheng and Hu 2010).

\section{PHYSIOLOGY AND TOXICOLOGY}

Lead replaces vital metals such as zinc, iron and calcium in the bodies of vertebrates (Rabinowitz et al. 1976). Absorption rates of lead ions are higher in species with deficiencies in essential metals (Goyer 1995). Calcium is an essential nutrient for birds and females actively select for food items high in calcium prior to egg laying. As a result, in some species, females can exhibit higher bone lead concentrations than males (Scheuhammer and Norris 1996). Also, females of lead exposed avian species are thought to release lead through egg production potentially limiting the viability of eggs (Pokras and Kneeland 2008).

Lead has been recognized for well over a century as a neurotoxin with sub-lethal and lethal effects to wildlife (Calvert 1876, Grinnell 1894). Exposure to lead is reported in a variety of wildlife species in the US including, but not limited to, neotropical migrant songbirds (Lewis et al. 2001), carnivores (Rogers et al. 2012), and the critically endangered California condor (Gymnogyps californianus) (Cade 2007). Over 120 bird species have been documented with measurable blood or tissue lead concentrations and the resulting consequences vary amongst species (Haig et al. 2014). Symptoms of chronic lead exposure that birds exhibit include wing 
droop, crop stasis, kidney failure, weight loss, and delayed motor skills (Mateo et al. 1998, Scheuhammer and Norris 1996).

In avian species, the majority of ingested lead is eventually deposited in bone after it enters the body (Hoppin et al. 2000, Sheuhammer et al. 1999). Before the deposition of lead in bone, it can exist for weeks in kidney and liver (Ethier et al. 2007). The pathways for lead to exit the avian body are through defecating, regurgitating, and feather growth. Blood is considered a short-term representation of recent lead exposure (Craighead and Bedrosian 2008); feathers, kidney, and liver are a moderate-term indicators of lead exposure (Finkelstein et al. 2010, Kenntner et al. 2001, Kreager et al. 2008) and lead in bone can be representative of long-term or a lifetime of exposure (Ethier et al. 2007 Pattee and Pain 2003). Lead within the bones of chronically exposed vertebrates' releases back to the bloodstream causing temporary spikes in blood lead levels (Rabinowitz et al. 1976). Consequently, elevated blood lead levels can be representative of short-term acute exposure or of long-term chronic exposure (Langner et al. 2015).

Response to lead poisoning of obligate scavenging birds illustrates the variability of symptoms across species. For example, turkey vultures (Cathartes aura) are tolerant of repetitive lead exposure (Carpenter et al. 2003), whereas California condors experience high mortality rates from lead poisoning (Finkelstein et al. 2010). Recently, a chronic lead exposure epidemic has been revealed in the bones of vulture species in eastern North America with potential adverse ecological implications (Behmke et al. 2015).

\section{EXAMPLES OF LEAD EXPOSURE IN WILDLIFE}

Due to high mortality rates and critically endangered status, the California condor is the highest profile avian scavenger affected by lead poisoning (Church et al. 2006). Lead exposure 
lowers reproductive rates in this species. This adverse effect is particularly troublesome in a species with delayed sexual maturity and a tendency to lay only one egg every two years (Cade 2007). Mortality of the California condor, as a result of lead exposure, led to the ban of lead rifle ammunition throughout the California range of this species (Thomas 2009). A high participation rate in the use of non-lead hunting ammunition in Arizona has increased restoration efforts of this species (Cade 2007, Hunt et al. 2009, Finkelstein et al. 2010). However, lead toxicosis remains the primary cause of death in wild populations of adult condors (Rideout et al. 2012) and long-term monitoring will be needed to determine the overall effects of the decrease in lead availability throughout this species' range (Finkelstein et al. 2012).

Elevated blood lead concentrations and acute toxicity of golden eagles (Aquila chrysaetos) was most likely resultant from consumption of lead contaminated offal piles (Harmata and Restani 2013, Wayland et al. 2003). Within the range of the California condor, lead levels in golden eagles declined after the ban on lead ammunition (Kelly et al. 2011). In west central Montana, elevated blood lead levels were present in over 50\% of 178 golden eagles captured during fall migration (Langner et al. 2015). Furthermore, golden eagles captured on ungulate carcasses had statistically higher blood lead levels than those captured with live lures, suggesting increased risk in targeting carrion as a food source.

Secondary lead poisoning of bald eagles (Haliaeetus leucocephalus) was attributed to the consumption of dead and wounded lead poisoned waterfowl (Feierabend and Myers 1984). Multiple species of waterfowl and wading birds experience high rates of lead poisoning in waterfowl hunting areas due to the ingestion of sediment containing lead shot. Consequently, the US banned lead shot in waterfowl hunting in an effort to protect waterfowl, a group of valuable game species; and bald eagles, a national emblem (USFWS 1986). 
Since the ban of lead shot in waterfowl hunting, lead poisoned bald eagles continue to be admitted at rehabilitation facilities at the same rate, indicating a pervasive landscape level issue (Kramer and Redig 1997). Furthermore, temporal associations between lead poisoned bald eagles and deer hunting season suggest lead-contaminated offal as a source of exposure (CruzMartinez et al. 2012). Harmata (2011) reported higher blood lead levels of wild caught bald eagles than that of birds admitted to a rehabilitation facility in Montana. Migrant bald eagles feeding on vast amounts of offal in the Teton Valley, Wyoming exhibit a spike in blood lead levels during elk hunting season (Bedrosian et al. 2012).

\section{AVIAN SCAVENGERS AND AMMUNITION}

Hunting seasons offer wildlife an abundance of scavenging opportunities in the form of offal piles, carcasses, and mortally wounded game animals. Raptors and corvids risk lead exposure via consumption of wounded or dead upland game birds, doves, rabbits, and big game animals (Craighead and Bedrosian 2008, Hunt et al. 2009, Pain et al. 2009). Lead poisoning is reported in 33 raptor species worldwide (Pain et al. 2009).

Evidence suggests the likely source of ingested lead in eagles, corvids, and vultures is ammunition (Craighead and Bedrosian 2008, Finkelstein et al. 2010, Harmata and Restani 2013, Kelly et al. 2011). Radiographs of deer remains voluntarily submitted by big game hunters revealed a high occurrence of lead fragments and subsequent availability to scavenging species (Hunt et al. 2009). Furthermore, the presence of elevated blood lead concentrations in avian scavengers is more likely to occur during the hunting seasons (Bedrosian et al. 2012, CruzMartinez et al. 2012, Elliott et al. 1996, Pain et al. 1997). Similarly, raptors have a higher incidence of lead exposure if there is extensive hunting in their foraging areas (Mateo et al. 1998, Wayland and Bollinger 1999). 
The use of non-lead ammunition has been positively correlated with a decrease in lead poisoning of bald eagles, golden eagles, and turkey vultures (Bedrosian et al. 2012, Kelly et al. 2011). Accordingly, these studies and others recommend the use of non-lead ammunition as a management directive (Craighead and Bedrosian 2008, Hunt et al. 2009). A ban of lead ammunition in the California range of the California condor and high participation in the volunteer use of non-lead ammunition within the Arizona range of this species are two examples of different management directives in action (Finkelstein et al. 2012).

Lead shot for the use of waterfowl hunting was outlawed in the US in 1991 due to elevated lead concentrations discovered in waterfowl, bald eagles, and wetland soils in the vicinity of waterfowl hunting (USFWS 1986). Bald eagles are the focus of research because of their tendency to opportunistically prey on crippled waterfowl with embedded lead shotgun pellets during and after hunting seasons (Pattee 1983). In captive bald eagles, lead shot is often regurgitated within 24 hours and does not make it from the proventriculus to the gizzard; however, multiple ingestions result in mortality, regardless of how quickly lead shot is expelled through pellets (Pattee et al. 1981).

Lead shotgun ammunition is legally employed for upland gamebird, waterfowl, and big game hunting in many regions of the world. Consequently, lead pellet ingestion continues to be documented in waterfowl in areas without a ban on lead shot (Ferreyra et al. 2014), in gallinaceous birds (Bingham 2011, Kreager et al. 2008), and in raptors (Mateo et al. 1998, Mateo et al. 1999). In the US alone, around 2,000 metric tons of lead shot are deposited and made available as a potential contaminant in the environment each year (Schulz et al. 2006). 


\section{STUDY AREA}

My dissertation research focused on the collection and analysis of blood and tissue lead concentrations of raptors and corvids at multiple spatial scales including the Chesapeake region of Maryland and Virginia, the central Appalachian Mountains in eastern North America, the eastern US and the continental US (Figure 1). For a further description of the geographic extent of my sampling, please refer to the detailed study area descriptions included in each of the following four chapters.

\section{RESEARCH OBJECTIVES}

The goal of my research was to understand sources and pathways of lead exposure of raptors by studying novel species, seasons, regions and spatial scales. I will address these research objectives with the following questions.

1. What are the age-related and species specific lead exposure patterns of piscivorous raptors in the Chesapeake Bay during the breeding season?

2. How does localized land use affect lead concentrations of red-shouldered hawks in the central Appalachians during the breeding season?

3. How do lead concentrations of a suite of avian scavengers in eastern North America vary by season and species?

4. How do lead concentrations of bald and golden eagles vary by season, region and species in the continental US? 


\section{STUDY SPECIES}

A subgroup of documented lead exposed species, avian scavengers, may be particularly susceptible to lead poisoning when they opportunistically feed on carcasses of animals harvested with shotgun and rifle ammunition (Fisher et al. 2006). Seasonal scavenging occurs during times of the year when increased amounts of biomass are available via big game hunting seasons, winter kill, or the acquisition of prey items from species competing for the same food source. Foraging on dead prey may be a necessity for survival under some circumstances for seasonal avian scavengers, although this topic is mostly under-reported (Jachowski et al. 2015).

Seasonal avian scavengers are an ideal subset of wildlife in which to investigate demographic lead exposure patterns. I collected blood from free-flying birds and birds admitted to rehabilitation facilities. Additionally, I collected liver and femur from dead birds found in the wild or at rehabilitation facilities. In an effort to investigate the source of lead within territorial raptors, I collected environmental and biological samples from potential sources of lead.

\section{Red-tailed hawk}

The red-tailed hawk is one of the most common hawks in eastern North America. Redtailed hawks are year-round residents in Virginia and populations increase during the winter months with an influx of northern migrants increasing competition for foraging habitat. Redtailed hawks are normally found along edges, but utilize a variety of habitats including closed canopy forest in the tropics. Suburban development has created more open wooded parkland possibly adding to increasing populations of red-tailed hawks through much of its range. The red-tailed hawk is a generalist and prey items include mammals, birds, reptiles, and carrion. The estimated range-wide population size of this species is thought to be 2,000,000 individuals with stable populations across its range with the exception of eastern Canada, where populations may be declining (Preston and Beane 2009). Previous research on environmental contaminants in this 
species is limited, although low tissue lead concentrations are reported (Stansley and Murphy 2011). Red-tailed hawks are the most abundant raptor species during winter months in eastern North America (Preston and Beane 2009) and readily feed on deer carcasses (Jachowski et al. 2015).

\section{Red-shouldered hawk}

The red-shouldered hawk is a common species and year-round resident in eastern North America. They exhibit variability in nest site selection ranging from urban forests to remote tracts of bottomland deciduous forests. Prey selection is correlated to prey availability in this species (Bednarz and Dinsmore 1982) and documented prey items include small mammals, earthworms, snakes, and frogs (Townsend 2006). A remote camera study in the eastern US recorded evidence of red-shouldered hawks feeding on deer carcasses (Jachowski et al. 2015). Populations in the eastern US appear to be stable; however, red-shouldered hawks are listed as a species of concern due to apparent population declines in the Great Lakes region (Henneman and Andersen 2009). Despite the red-shouldered hawk's tolerance of urban habitats, investigations of environmental contaminant exposure within this species are limited (Deem et al. 1998).

\section{American crow}

American crows have continent-wide distribution and thrive in urban environments due to their preference and adaptation as a commensal. American crows are found in a variety of habitats including urban parks, agricultural settings, and forest clearcuts. Prey selection includes an omnivorous diet of small insects, human refuse, and carrion. During the non-breeding season, numbers of American crow at roosts can be in the thousands. American crows are an intelligent and notoriously difficult species to harvest or capture for scientific study. Virginia Department of Game and Inland Fisheries (VDGIF) biologists have reported carcass feeding by American 
crows during attempts to capture bald and golden eagles (J. Cooper pers com). No previous research on contaminants in this species has been conducted, although a similar species, the common raven (Corvus corax) exhibits elevated blood lead levels with increased availability of offal on the landscape (Craighead and Bedrosian 2008).

Osprey

Since the ban of dichlorodiphenyltrichloroethane (DDT) in the US, breeding populations of osprey in the Chesapeake Bay and tributaries have steadily increased to the largest breeding population in the world (Watts and Paxton 2007). The osprey is the only North American raptor that focuses exclusively on live fish (Glass and Watts 2009) and therefore, the only raptor included in this study that is not considered a seasonal scavenger. Osprey use manmade nesting structures, are highly tolerant to human activity, and are considered sentinels of environmental contamination in aquatic systems (Grove et al. 2009, Hopkins et al. 2007, Langner et al. 2012).

\section{Bald eagle}

The bald eagle is the national symbol of the US and is a significant symbol of Native American cultures. Bald eagle populations in the eastern US have experienced major fluctuations since colonial settlement. Since the ban of DDT, the year-round Chesapeake Bay bald eagle nesting population increased from 73 breeding pairs in 1977 to 601 breeding pairs in 2001 (Watts et al. 2008). Additionally, influxes of wintering individuals to the Chesapeake Bay region have been reported at communal roost locations (Buehler et al. 1991). Over 95\% of the food resources fed to chicks during the breeding season in the Chesapeake Bay region are fish (Markham 2004). Bald eagles focus on a much wider variety of prey outside of the breeding season including waterfowl and carrion. A camera study along the migration route of golden 
eagles in the eastern US has documented frequent carcass feeding by bald eagles (Jachowski et al. 2015).

\section{Golden eagle}

The golden eagle (Aquila chrysaetos) is a circumpolar apex predator mostly found at northern latitudes. During the breeding season, golden eagles select for a wide variety of terrestrial prey items including ground squirrels (Urocitellus spp.), prairie dogs (Cynomys spp.), rabbits (Lepus americanus, Lepus spp., Sylvilagus spp.), and in some cases young of the year ungulates, turkeys (Meleagris gallopavo), striped skunks (Mephitis mephitis), and greater sagegrouse (Centrocercus urophasianus) (Watson et al. 2010). Furthermore, in the US, golden eagles will opportunistically scavenge on carcasses within breeding territories during the pre-egg laying period, while on wintering grounds, and during migration (Langner et al. 2015, Katzner et al. 2012).

\section{CONTENTS OF THE DISSERTATION}

In addition to this introductory chapter, my dissertation consists of four research-based chapters and a concluding chapter. The introductory chapter is designed to provide a literature review of lead poisoning of humans and wildlife, a brief description of study species and to state my research questions.

In Chapter 2, I evaluated lead exposure of osprey and bald eagles in the Coastal Plain of Maryland and Virginia during the breeding season. For this chapter, I collected blood lead concentration data of birds in the major tributaries of the Chesapeake Bay. In the manuscript, I test for spatial and age-related patterns in the data. 
In Chapter 3, I evaluated lead exposure of red-shouldered hawks in the central Appalachians during the breeding season. More specifically, I tested for spatial and age-related differences in the blood lead concentrations of red-shouldered hawks in this region.

In Chapter 4, I evaluated lead exposure of a suite of avian scavengers in eastern North America including eagle, buteo, corvid and vulture species. For this chapter, I tested for seasonal, species specific and age-related patterns in the data.

In Chapter 5, I studied lead exposure of bald and golden eagles in the continental US. For this chapter, I tested for temporal, spatial, species-specific and age-related patterns in the data. Additionally, I tested for spatial patterns in clinically relevant lead exposure of these two species. Finally, in Chapter 6, I present some global conclusions from this study, management recommendations and suggestions for future research. 


\section{REFERENCES}

Bednarz, J. C., and J. J. Dinsmore. 1982. Nest-sites and habitat of red-shouldered and red-tailed hawks in Iowa. The Wilson Bulletin 31-45.

Bedrosian, B., D. Craighead, and R. Crandall. 2012. Lead exposure in bald eagles from big game hunting, the continental implications and successful mitigation efforts. C. J. Johnson, editor. PLoS ONE 7:e51978.

Behmke, S., J. Fallon, A. E. Duerr, A. Lehner, J. Buchweitz, and T. Katzner. 2015. Chronic lead exposure is epidemic in obligate scavenger populations in eastern North America. Environment International 79:51-55.

Beyer, W. N., D. J. Audet, G. H. Heinz, D. J. Hoffman, and D. Day. 2000. Relation of waterfowl poisoning to sediment lead concentrations in the Coeur d'Alene River Basin. Ecotoxicology 9:207-218.

Bingham, R. 2011. Causes, extent, and consequences of lead-pellet ingestion by chukars (Alectoris chukar) in western Utah: Examining habitat, search images, and toxicology. All Graduate Theses and Dissertations. 1038. https://digitalcommons.usu.edu/etd/1038

Buehler, D. A., T. J. Mersmann, J. D. Fraser, and J. K. Seegar. 1991. Nonbreeding bald eagle communal and solitary roosting behavior and roost habitat on the northern Chesapeake Bay. Journal of Wildlife Management 273-281.

Cade, T. J. 2007. Exposure of California condors to lead from spent ammunition. Journal of Wildlife Management 71:2125-2133.

Calvert, J. H. 1876. Pheasants poisoned by swallowing shots. The Field 47:189.

Cao, J., Li, M., Wang, Y., Yu, G. and Yan, C., 2014. Environmental lead exposure among preschool children in Shanghai, China: blood lead levels and risk factors. PloS one, 9(12), p.e113297.

Carpenter, D. O., and R. Nevin. 2010. Environmental causes of violence. Physiology \& Behavior 99:260-268.

Carpenter, J. W., O. H. Pattee, S. H. Fritts, B. A. Rattner, S. N. Wiemeyer, J. A. Royle, and M. R. Smith. 2003. Experimental lead poisoning in turkey vultures (Cathartes aura). Journal of Wildlife Diseases 39:96-104.

Cheng, H., and Y. Hu. 2010. Lead (Pb) isotopic fingerprinting and its applications in lead pollution studies in China: A review. Environmental Pollution 158:1134-1146.

Church, M. E., R. Gwiazda, R. W. Risebrough, K. Sorenson, C. P. Chamberlain, S. Farry, W. Heinrich, B. A. Rideout, and D. R. Smith. 2006. Ammunition is the principal source of lead accumulated by California condors re-introduced to the wild. Environmental Science \& Technology 40:6143-6150.

Craighead, D., and B. Bedrosian. 2008. Blood lead levels of common ravens with access to biggame offal. Journal of Wildlife Management 72:240-245.

Cruz-Martinez, L., Redig, P.T. and Deen, J., 2012. Lead from spent ammunition: a source of exposure and poisoning in bald eagles. Human-Wildlife Interactions, 6:11.

Davies, D. J. A., I. Thornton, J. M. Watt, E. B. Culbard, P. G. Harvey, H. T. Delves, J. C. Sherlock, G. A. Smart, J. F. A. Thomas, and M. J. Quinn. 1990. Lead intake and blood lead in two-year-old UK urban children. Science of the Total Environment 90:13-29.

Deem, S. L., S. P. Terrell, and D. J. Forrester. 1998. A retrospective study of morbidity and mortality of raptors in Florida: 1988-1994. Journal of Zoo and Wildlife Medicine 160164.

Derome, J., and T. Nieminen. 1998. Metal and macronutrient fluxes in heavy-metal polluted 
Scots pine ecosystems in SW Finland. Environmental Pollution 103:219-228.

Elliott, J. E., K. M. Langelier, P. Mineau, and L. K. Wilson. 1996. Poisoning of bald eagles and red-tailed hawks by carbofuran and fensulfothion in the Fraser Delta of British Columbia, Canada. Journal of Wildlife Diseases 32:486-491.

Ethier, A., B. Braune, A. Scheuhammer, and D. Bond. 2007. Comparison of lead residues among avian bones. Environmental Pollution 145:915-919.

Feierabend, J. S., and O. Myers. 1984. A national summary of lead poisoning in bald eagles and waterfowl. National Wildlife Federation. Washington D.C., USA.

Ferreyra, H., M. Romano, P. Beldomenico, A. Caselli, A. Correa, and M. Uhart. 2014. Lead gunshot pellet ingestion and tissue lead levels in wild ducks from Argentine hunting hotspots. Ecotoxicology and Environmental Safety 103:74-81.

Finkelstein, M. E., D. F. Doak, D. George, J. Burnett, J. Brandt, M. Church, J. Grantham, and D. R. Smith. 2012. Lead poisoning and the deceptive recovery of the critically endangered California condor. Proceedings of the National Academy of Sciences 109:11449-11454.

Finkelstein, M. E., D. George, S. Scherbinski, R. Gwiazda, M. Johnson, J. Burnett, J. Brandt, S. Lawrey, A. P. Pessier, M. Clark, and others. 2010. Feather lead concentrations and $207 \mathrm{~Pb} / 206 \mathrm{~Pb}$ ratios reveal lead exposure history of California Condors (Gymnogyps californianus). Environmental Science \& Technology 44:2639-2647.

Fisher, I.J., D.J. Pain, and V.G. Thomas. 2006. A review of lead poisoning from ammunition sources in terrestrial birds. Biological Conservation 131:421-432.

Glass, K. A., and B. D. Watts. 2009. Osprey diet composition and quality in high- and lowsalinity areas of lower Chesapeake Bay. Journal of Raptor Research 43:27-36.

Goyer, R. A. 1995. Nutrition and metal toxicity. The American Journal of Clinical Nutrition 61:646S-650S.

Grinnell, G. B. 1894. Lead poisoning. Forest and Stream 42:117-118.

Grove, R. A., C. J. Henny, and J. L. Kaiser. 2009. Osprey: worldwide sentinel species for assessing and monitoring environmental contamination in rivers, lakes, reservoirs, and estuaries. Journal of Toxicology and Environmental Health, Part B 12:21-44.

Haig, S. M., J. D’Elia, C. Eagles-Smith, J. M. Fair, J. Gervais, G. Herring, J. W. Rivers, and J. H. Schulz. 2014. The persistent problem of lead poisoning in birds from ammunition and fishing tackle. The Condor 116:408-428.

Harmata, A.R., 2011. Environmental contaminants in tissues of bald eagles sampled in southwestern Montana, 2006-2008. Journal of Raptor Research 45:119-136.

Harmata, A. R., and M. Restani. 2013. Lead, mercury, selenium, and other trace elements in tissues of golden eagles from southwestern Montana, USA. Journal of Wildlife Diseases 49:114-124.

Henneman, C., and D. E. Andersen. 2009. Occupancy models of nesting-season habitat associations of red-shouldered hawks in central Minnesota. The Journal of Wildlife Management 73:1316-1324.

Hopkins, W. A., L. B. Hopkins, J. M. Unrine, J. Snodgrass, and J. D. Elliot. 2007. Mercury concentrations in tissues of osprey from the Carolinas, USA. The Journal of Wildlife Management 71:1819-1829.

Hoppin, J. A., A. Aro, H. Hu, and P. B. Ryan. 2000. Measurement variability associated with KXRF bone lead measurement in young adults. Environmental Health Perspectives 108:239-242.

Huang, P.-C., P.-H. Su, H.-Y. Chen, H.-B. Huang, J.-L. Tsai, H.-I. Huang, and S.-L. Wang. 
2012. Childhood blood lead levels and intellectual development after ban of leaded gasoline in Taiwan: A 9-year prospective study. Environment International 40:88-96.

Hunt, W. G., C. N. Parish, K. Orr, and R. F. Aguilar. 2009. Lead poisoning and the reintroduction of the California condor in northern Arizona. Journal of Avian Medicine and Surgery 23:145-150.

Iqbal, S., W. Blumenthal, C. Kennedy, F. Y. Yip, S. Pickard, W. D. Flanders, K. Loringer, K. Kruger, K. L. Caldwell, and M. Jean Brown. 2009. Hunting with lead: Association between blood lead levels and wild game consumption. Environmental Research 109:952-959.

Irwin, R. J., M. V. Mouwerik, S. Stevens, M. D. Seese, and W. Basham. 1997. Environmental contaminants encyclopedia-PAHs entry. National Parks Service Report, Water Resources Division.

Jachowski, D.S., T. Katzner, J.L. Rodrigue, W.M. Ford. 2015. Monitoring landscape-level distribution and migration Phenology of Raptors using a volunteer camera-trap network: Raptor camera-trapping. Wildlife Society Bulletin. 39:553-563.

Jørgensen, S. S., and M. Willems. 1987. The fate of lead in soils: The transformation of lead pellets in shooting-range soils. Ambio 16:11-15.

Katzner, T., Smith, B.W., Miller, T.A., Brandes, D., Cooper, J., Lanzone, M., Brauning, D., Farmer, C., Harding, S., Kramar, D.E. and Koppie, C., 2013. Status, biology, and conservation priorities for North America's eastern Golden Eagle (Aquila chrysaetos) population, 2012. The Auk 129:168-176.

Kelly, T. R., P. H. Bloom, S. G. Torres, Y. Z. Hernandez, R. H. Poppenga, W. M. Boyce, and C. K. Johnson. 2011. Impact of the California lead ammunition ban on reducing lead exposure in golden eagles and turkey vultures. A. Iwaniuk, editor. PLoS ONE 6:e17656.

Kendler, B. S. 1994. Environmental lead contamination: a metaphor for destructive industrial practices; lead abatement: a model for ineffective societal responses. Structural Survey 12:13-23.

Kenntner, N., F. Tataruch, and O. Krone. 2001. Heavy metals in soft tissue of white-tailed eagles found dead or moribund in Germany and Austria from 1993 to 2000. Environmental Toxicology and Chemistry 20:1831-1837.

Kramer, J. L., and P. T. Redig. 1997. Sixteen years of lead poisoning in eagles, 1980-95: an epizootiologic view. Journal of Raptor Research 31:327-332.

Kreager, N., B. C. Wainman, R. K. Jayasinghe, and L. J. S. Tsuji. 2008. Lead pellet ingestion and liver-lead concentrations in upland game birds from southern Ontario, Canada. Archives of Environmental Contamination and Toxicology 54:331-336.

Langner, H. W., E. Greene, R. Domenech, and M. F. Staats. 2012. Mercury and other miningrelated contaminants in ospreys along the upper Clark Fork River, Montana, USA. Archives of Environmental Contamination and Toxicology 62:681-695.

Langner, H. W., R. Domenech, V. A. Slabe, and S. P. Sullivan. 2015. Lead and mercury in fall migrant golden eagles from western North America. Archives of Environmental Contamination and Toxicology 69:54-61.

Lewis, A. R., J. Poppenga, W. R. Davies. 2001. Lead toxicosis and trace element levels in wild birds and mammals at a firearms training facility. Archives of Environmental Contamination and Toxicology 41:208-214.

Lukkari, T., M. Taavitsainen, A. Väisänen, and J. Haimi. 2004. Effects of heavy metals on earthworms along contamination gradients in organic rich soils. Ecotoxicology and 
Environmental Safety 59:340-348.

Mao, J. S., J. Dong, and T. E. Graedel. 2008. The multilevel cycle of anthropogenic lead. Resources, Conservation and Recycling 52:1058-1064.

Markham, A. C. 2004. The influence of salinity on diet composition, provisioning patterns, and nestling growth in bald eagles in the lower Chesapeake Bay. https://dspace.swem.wm.edu/handle/10288/9081. Accessed 28 May 2015.

Mateo, R., J. Belliure, J. C. Dolz, J. A. Serrano, and R. Guitart. 1998. High prevalences of lead poisoning in wintering waterfowl in Spain. Archives of Environmental Contamination and Toxicology 35:342-347.

Mateo, R., J. Estrada, J.-Y. Paquet, X. Riera, L. Domínguez, R. Guitart, and A. Martínez-Vilalta. 1999. Lead shot ingestion by marsh harriers (Circus aeruginosus) from the Ebro delta, Spain. Environmental Pollution 104:435-440.

Nriagu, J. O. 1983. Lead and lead poisoning in antiquity. In Green History, D. Wall (ed) London:Routledge.

OSHA. 2015. Safety and Health Topics | Lead - Health Effects. https://www.osha.gov/SLTC/lead/healtheffects.html. Accessed 3 May 2015.

Pain, D. J., C. Bavoux, and G. Burneleau. 1997. Seasonal blood lead concentrations in marsh harriers (Circus aeruginosus) from Charente-Maritime, France: relationship with the hunting season. Biological 81:1-7.

Pain, D. J., I. J. Fisher, and V. G. Thomas. 2009. A global update of lead poisoning in terrestrial birds from ammunition sources. The Peregrine Fund, Boise, Idaho, 99-118.

Pattee, O. H. 1983. Bald eagles and waterfowl: the lead shot connection. Transactions of the North American Wildlife and Natural Resources Conference 48:230-237.

Pattee, O. H., S. N. Wiemeyer, B. M. Mulhern, L. Sileo, and J. W. Carpenter. 1981. Experimental lead-shot poisoning in bald eagles. The Journal of Wildlife Management 45:806-810.

Pattee, O. H., and D. J. Pain. 2003. Lead in the environment. Handbook of Ecotoxicology. 2:373-399.

Pokras, M. A., and M. R. Kneeland. 2008. Lead poisoning: using transdisciplinary approaches to solve an ancient problem. EcoHealth 5:379-385.

Preston, C. R. and R. D. Beane. 2009. Red-tailed hawk (Buteo jamaicensis), version 2.0. In the Birds of North America (A. F. Poole, Editor). Cornell Lab of Ornithology, Ithaca, NY, USA. https://doi.org/10.2173/bna.52

Rabinowitz, M. B., G. W. Wetherill, and J. D. Kopple. 1976. Kinetic analysis of lead metabolism in healthy humans. Journal of Clinical Investigation 58:260-270.

Rideout, B. A., I. Stalis, R. Papendick, A. Pessier, B. Puschner, M. E. Finkelstein, D. R. Smith, M. Johnson, M. Mace, R. Stroud, and others. 2012. Patterns of mortality in free-ranging California condors (Gymnogyps californianus). Journal of Wildlife Diseases 48:95-112.

Rogers, T. A., B. Bedrosian, J. Graham, and K. R. Foresman. 2012. Lead exposure in large carnivores in the greater Yellowstone ecosystem. The Journal of Wildlife Management 76:575-582.

Scheuhammer, A. M., and S. L. Norris. 1996. The ecotoxicology of lead shot and lead fishing weights. Ecotoxicology 5:279-295.

Scheuhammer, A.M., Rogers, C.A. and Bond, D., 1999. Elevated lead exposure in American woodcock (Scolopax minor) in eastern Canada. Archives of Environmental Contamination and Toxicology, 36:334-340. 
Schulz, J. H., J. J. Millspaugh, A. J. Bermudez, X. Gao, T. W. Bonnot, L. G. Britt, and M. Paine. 2006. Acute lead toxicosis in mourning doves. Journal of Wildlife Management 70:413421.

Sileo, L., and S. I. Fefer. 1987. Paint chip poisoning of Laysan albatross at Midway Atoll. Journal of Wildlife Diseases 23:432-437.

Sorvari, J., R. Antikainen, and O. Pyy. 2006. Environmental contamination at Finnish shooting ranges - the scope of the problem and management options. Science of the Total Environment 366:21-31.

Sowers, M., M. Jannausch, T. Scholl, W. Li, F. W. Kemp, and J. D. Bogden. 2002. Blood lead concentrations and pregnancy outcomes. Archives of Environmental Health 57:489-495.

Stansley, W., and L. A. Murphy. 2011. Liver lead concentrations in raptors in New Jersey, USA, 2008-2010. Bulletin of Environmental Contamination and Toxicology 87:171-174.

Thomas, V. 2009. The policy and legislative dimensions of nontoxic shot and bullet use in North America. The Peregrine Fund. http://www.peregrinefund.org/Lead_conference/PDF/0311 Thomas.pdf. Accessed 28 Mar 2015.

Townsend, K. A. L. 2006. Nesting ecology and sibling behaviour of red-shouldered hawks at the St. Francis Sunken Lands Wildlife Management Area in northeastern Arkansas (Doctoral Dissertation, Arkansas State University).

USFWS. 1986. Final supplemental environmental impact statement. Use of lead shot for hunting migratory birds in the United States. Department of the Interior, Washington, DC, USA.

US EPA. 2009. Lead in Drinking Water. Accessed 28 May 2015. https://www.epa.gov/groundwater-and-drinking-water/basic-information-about-lead-drinking-water

US EPA. 2013. Alkyl-lead | Persistent Bioaccumulative and Toxic (PBT) Chemical Program. http://www.epa.gov/pbt/pubs/alkylaction.htm\#prog-base. Accessed 30 Mar 2015.

USGS. 2013. National Wildlife Health Center - Lead Poisoning. http://www.nwhc.usgs.gov/disease_information/lead_poisoning. Accessed 30 Mar 2015.

Wadanambi, L., B. Dubey, and T. Townsend. 2008. The leaching of lead from lead-based paint in landfill environments. Journal of Hazardous Materials 157:194-200.

Watson, J., 2010. The golden eagle. London: T. and A. D. Poyser.

Watts, B. D., and B. J. Paxton. 2007. Ospreys of the Chesapeake Bay: Population recovery, ecological requirements, and current threats. Waterbirds 30:39-49.

Watts, B. D., G. D. Therres, and M. A. Byrd. 2008. Recovery of the Chesapeake Bay bald eagle nesting population. The Journal of Wildlife Management 72:152-158.

Wayland, M., and T. Bollinger. 1999. Lead exposure and poisoning in bald eagles and golden eagles in the Canadian prairie provinces. Environmental Pollution 104:341-350.

Wayland, M., L. Wilson, J. Elliott, M. Miller, T. Bollinger, M. Mcadie, K. Langelier, J. Keating, and J. Froese. 2003. Mortality, morbidity, and lead poisoning of eagles in western Canada, 1986-98. Journal of Raptor Research 37:8-18. 
Figure 1. (a) Bracken Brown and Vincent Slabe with red-shouldered hawks, West Virginia. (b) Osprey nestlings, Virginia. (c) Vincent Slabe with golden eagle, Montana. (d) Mosey Hardin, Frances Slabe, and Vincent Slabe with rehabilitated bald eagle fledgling, Avian Conservation Center of Appalachia, West Virginia.

(a)

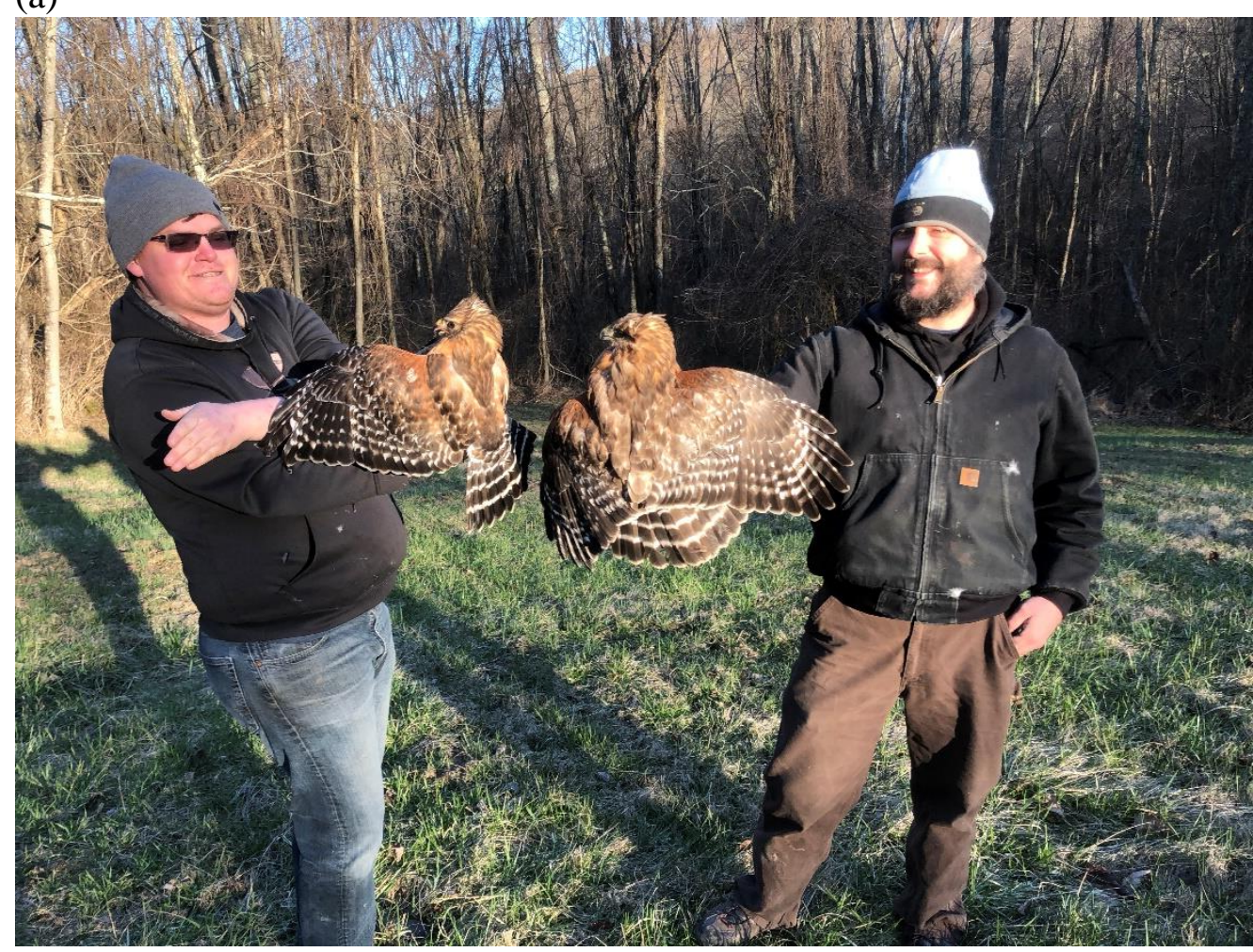

(b)

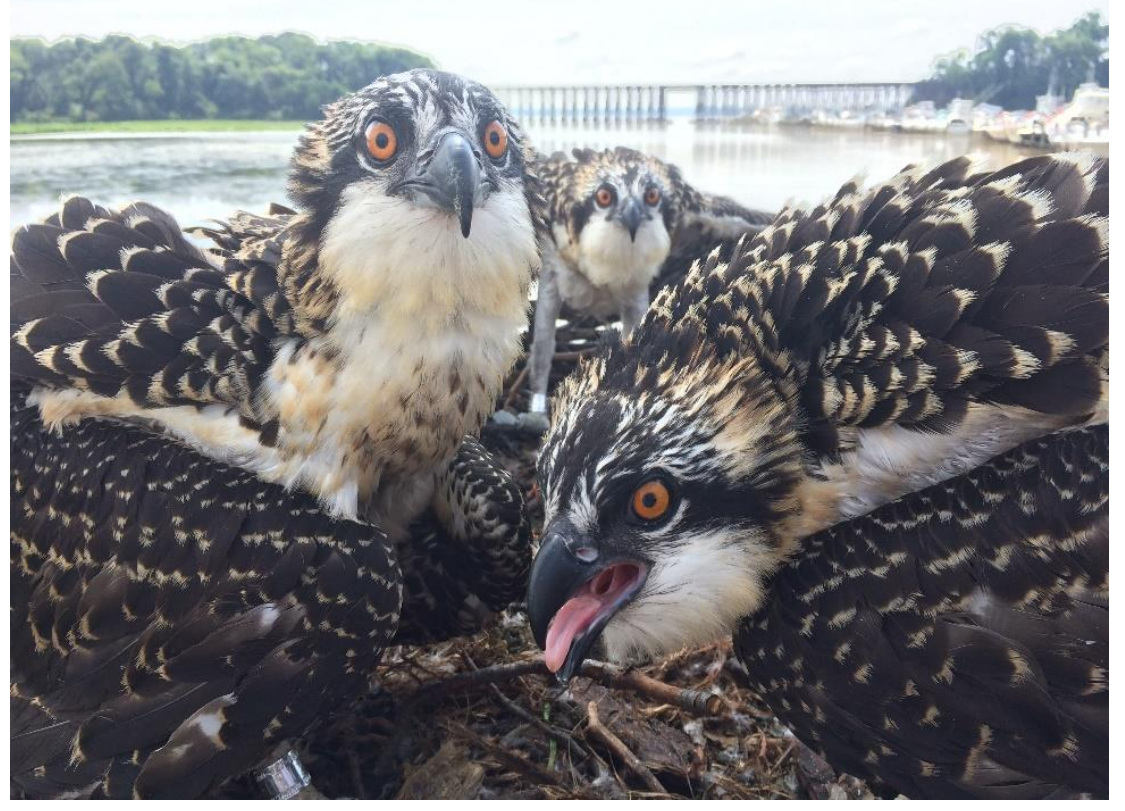


(c)

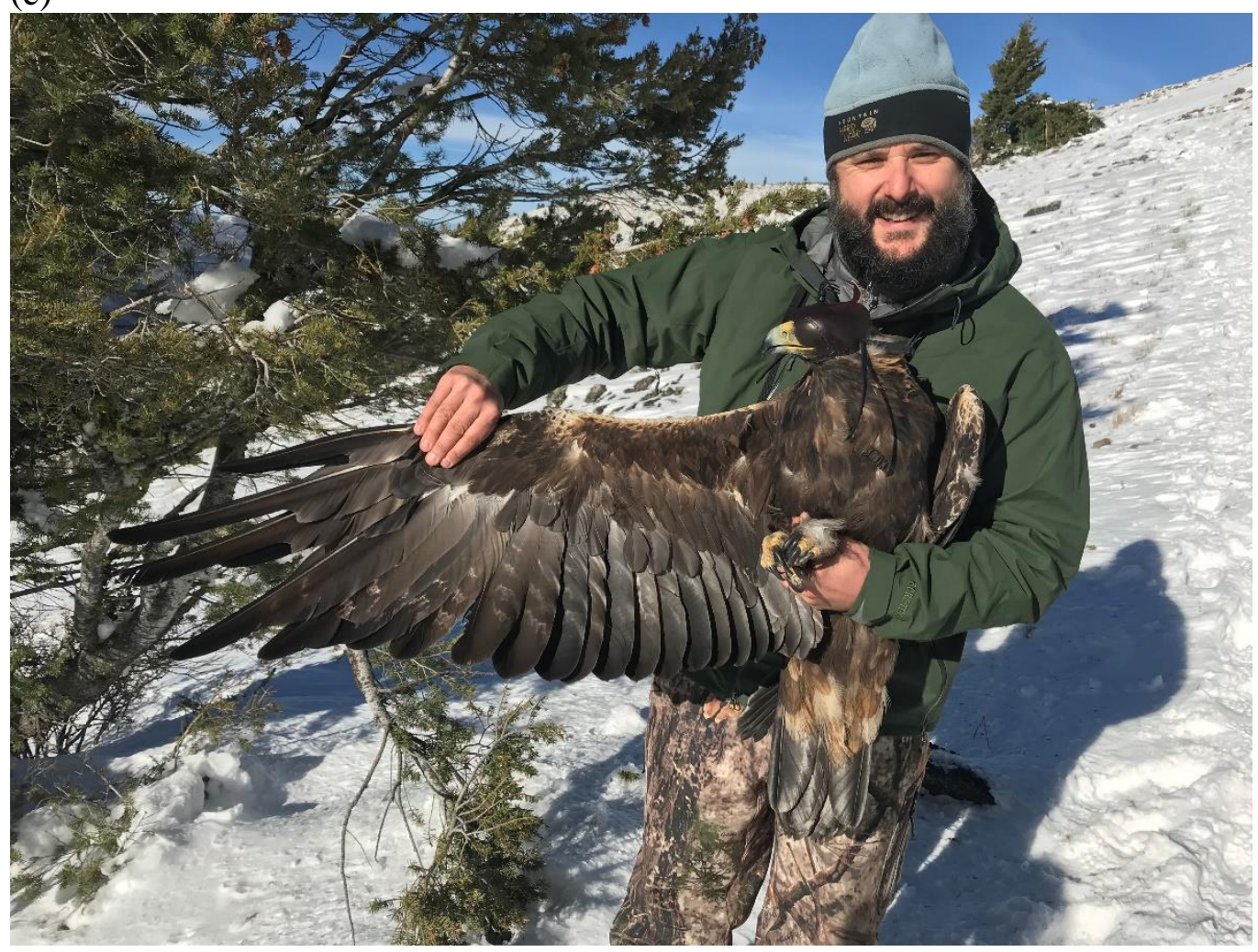

(d)

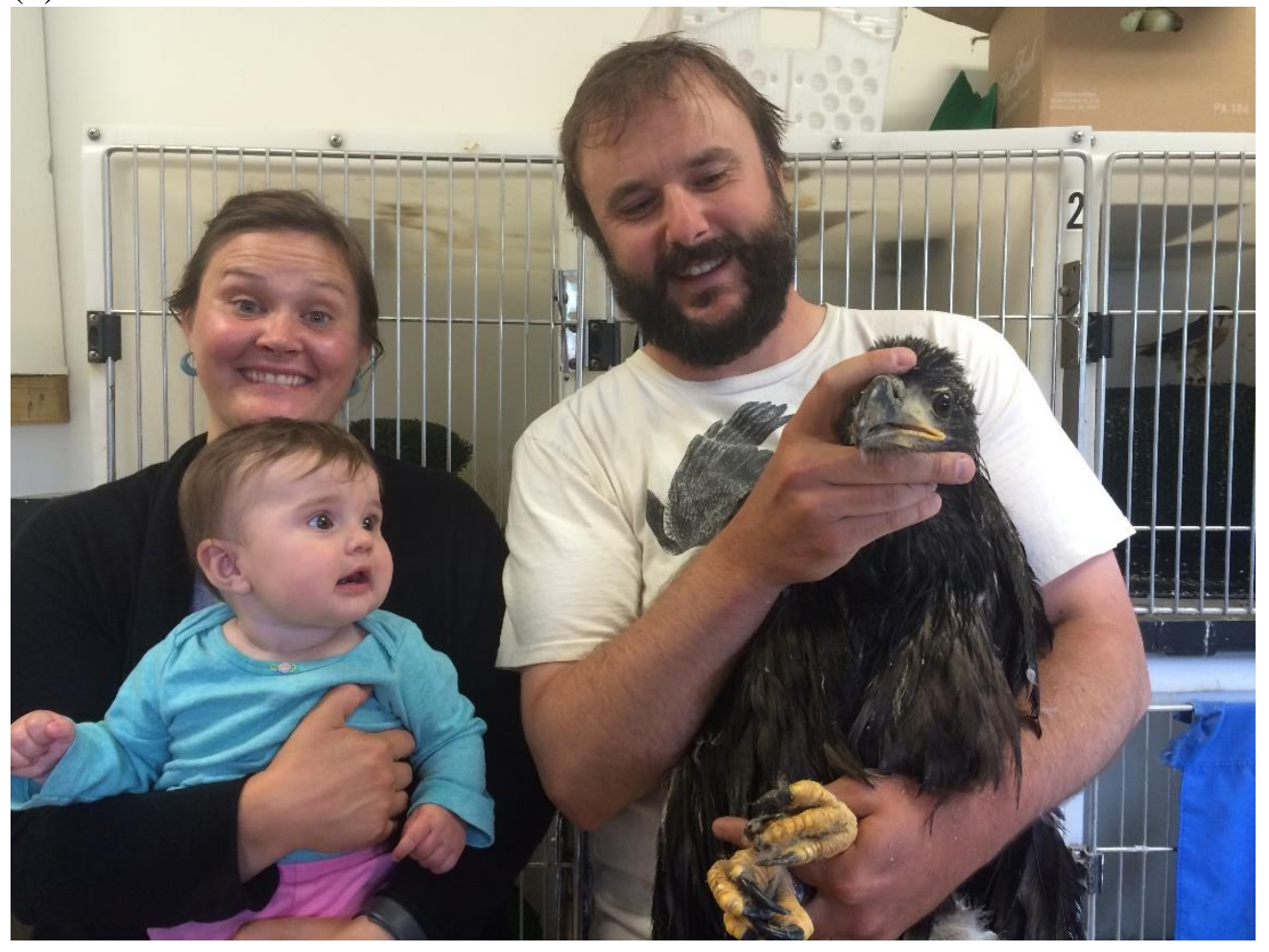




\title{
CHAPTER 2
}

Lead in piscivorous raptors during breeding season in the Chesapeake Bay region of Maryland and Virginia, USA

\author{
Vincent A. Slabe \\ vaslabe@mix.wvu.edu \\ West Virginia University \\ School of Natural Resources \\ PO Box 6125 \\ Morgantown, WV 26506-6125
}




\section{CHAPTER 2}

\section{Lead in piscivorous raptors during breeding season in the Chesapeake Bay region of Maryland and Virginia, $\mathrm{USA}^{1}$}

Vincent A. Slabe ${ }^{\mathrm{a}, *}$, James T. Anderson ${ }^{\mathrm{a}}$, Jeff Cooper ${ }^{\mathrm{b}}$, Bracken Brown ${ }^{\mathrm{a}}$, Patricia Ortiz ${ }^{\mathrm{c}}$, John Buchweitz $^{\mathrm{d}}$, Dave McRuer ${ }^{\mathrm{e}}$ and Todd Katzner ${ }^{\mathrm{c}}$

${ }^{a}$ Division of Forestry and Natural Resources, West Virginia University, Morgantown, WV, USA

${ }^{\mathrm{b}}$ Virginia Department of Game and Inland Fisheries, Richmond, VA, USA

${ }^{\mathrm{c}}$ US Geological Survey, Forest and Rangeland Ecosystem Science Center, Boise, ID, USA

${ }^{\mathrm{d}}$ Department of Pathobiology and Diagnostic Investigation, Michigan State University, East

Lansing, MI, USA

${ }^{\mathrm{e}}$ Wildlife Center of Virginia, Waynesboro, VA, USA

*Author correspondence to: vaslabe@mix.wvu.edu

Published: Slabe VA, Anderson JT, Cooper J, Brown B, Ortiz P, Buchweitz J, McRuer D, Katzner T. 2019. Lead in piscivorous raptors during breeding season in the Chesapeake Bay region of Maryland and Virginia, USA. Environmental Toxicology and Chemistry. 38:862-871. https://doi.org/10.1002/etc.4376 


\section{ABSTRACT}

Sources of lead exposure of many bird species are poorly understood. We analyzed blood lead concentrations from osprey $(\mathrm{n}=244 ;$ Pandion haliaetus $)$ and bald eagles $(\mathrm{n}=68$; Haliaeetus leucocephalus) and documented potential sources of lead they may encounter. Adult bald eagles had higher blood lead concentrations than did adult osprey. However, blood lead concentrations of nestlings were similar for both species. Although $62 \%$ of osprey had detectable lead concentrations $(\bar{x}=1.99 \mu \mathrm{g} / \mathrm{dL} \pm 4.02$; mean; $\pm \mathrm{SD})$, there was no difference in the detection frequency or lead concentrations between osprey adults and nestlings. Likewise, we found no differences in the detection frequency or lead concentrations in osprey adults and nestlings from high and low salinity areas. Of the bald eagle samples tested, 55\% had detectable lead levels $(\bar{x}=6.23 \mu \mathrm{g} / \mathrm{dL} \pm 10.74)$. Adult bald eagles had more detectable and higher lead concentrations than did nestlings or pre-adults. Among environmental samples, paint had the highest lead concentrations, followed by sediment, blue catfish (Ictalurus furcatus), and gizzard shad (Dorosoma cepedianum). There was no correlation between blood lead concentrations of osprey adults and their offspring. Our work indicates that, in the Chesapeake Bay region, there are multiple sources by which piscivorous raptors may be exposed to lead.

Key words: lead exposure, fish eating birds of prey, Chesapeake Bay 


\section{INTRODUCTION}

Lead is an anthropogenic threat to terrestrial wildlife, has no physiological benefits, and is considered a neurotoxin (Pattee and Pain 2003). Legislation adopted in many countries restricts the uses of lead in pipe fittings, gas, paint, and shot for use in waterfowl hunting (USFWS 1986). However, lead is currently categorized by the US government as a critical metal and common uses of lead still persist in North America (USGS 2012). As a consequence, there is anthropogenically-driven deposition of potentially toxic lead in the environment.

The Chesapeake Bay is the largest estuary in the US and is one of the most productive aquatic ecosystems in the world (Cooper 1995). The Potomac, Rappahannock, York, and James rivers flow east and terminate in the Chesapeake Bay. Tidal influences in these rivers affect salinity and aquatic habitats west to the fall line separating the Coastal Plain from the Piedmont. The Eastern Shore of Virginia and Maryland is part of the Delmarva Peninsula and is bordered by the Chesapeake Bay on the west and the Atlantic Ocean on the east. Sources of lead in this landscape include, but are not limited to, legacy lead paint on bridges and other industrial structures, lead acid battery storage facilities, coal fired power plants, leaded aviation fuel, and lead ammunition and fishing equipment (Ator 1998, Komárek et al. 2008). Once in the environment, potential pathways for lead exposure into humans and wildlife are through ingestion of contaminated prey items, inhalation, and endogenous transfer from parent to young (Iqbal et al. 2009, Wadanambi et al. 2008). Lead in prey items is of particular concern for avian predators and scavengers (Haig et al. 2014) and lead poisoning of terrestrial avian scavengers and nestling aquatic piscivorous raptors has been studied in the Chesapeake Bay region (Behmke et al. 2015, Rattner et al. 2008). However, there are virtually no studies quantifying blood lead concentrations of free-flying piscivorous raptors in this region (Rattner and McGowan 2007), in spite of their well-known exposure to lead in other regions (Henny et al. 1991). 
There are two species of piscivorous raptors in the Chesapeake Bay region, osprey (Pandion haliaetus) and bald eagle (Haliaeetus leucocephalus) (Buehler et al. 1991, Henny et al. 1974). In recent decades, both of these species have seen substantial population increases (Watts and Paxton 2007, Watts et al. 2008). Likewise, both are exposed to anthropogenic lead through multiple potential pathways and there is evidence of exposure for individuals of both species in this region (Rattner et al. 2008, Franzen-Klein et al. 2018).

Since the ban of dichlorodiphenyltrichloroethane (DDT) in 1972, the size of the breeding population of osprey in the Chesapeake Bay and rivers has increased substantially and it is now the largest such population in the world (Watts and Paxton 2007). Even at present levels though, numbers have not attained those observed during the pre-DDT era (Watts and Paxton 2007). The osprey is the only North American raptor whose diet is composed almost exclusively of live fish and its dietary preferences vary by location and fish assemblage (Glass and Watts 2009). Osprey often nest on structures made by humans, are highly tolerant of human activity, and, because of their dietary specialization, often are considered sentinels of environmental contamination in aquatic systems (Grove et al. 2009, Hopkins et al. 2007, Langner et al. 2012, Rattner and McGowan 2007).

Bald eagle populations in the eastern US also have experienced major fluctuations (USFWS 2007). Since the ban of DDT, the Chesapeake Bay bald eagle nesting population increased from 73 breeding pairs in 1977 to at least 1070 breeding pairs in 2016 (Watts 2005, Watts et al. 2008). In addition to this breeding population, most of whom are year-round residents, the Chesapeake Bay bald eagle population also includes migrants from the southeastern and northeastern US that are present during the local breeding season (Watts et al. 2007). Regardless of salinity levels, over $95 \%$ of the food items fed to chicks during the breeding 
season in this area are fish, especially catfish of several species (Watts et al. 2006). However, the diets of free flying eagles in the Chesapeake region include many items not fed to nestlings, such as birds, reptiles, mammals, and carrion (Mersmann 1989, Clark 1982). Bald eagles are a longlived apex predator with reproductive sensitivity to environmental contaminants and therefore also serve as powerful sentinels in aquatic ecosystems (Bowerman et al. 2002, Wierda et al. 2016).

Because of their recent population fluctuations and their tight relationship to the estuarine systems of the Chesapeake Bay, these piscivorous raptors are useful models to understand sources of exposure of wildlife to local environmental toxicants such as lead. Likewise, lead exposure of eagles and other raptors is a topic of increasing conservation concern, as lead poisoning has played a role in limiting the population growth of at least two raptor populations (Finkelstein et al. 2012, Millsap et al. 2016) and one regional population of piscivorous birds (Grade et al. 2018). That said, with a few notable exceptions, the vast majority of studies of lead exposure of raptors have evaluated response of birds during the non-breeding season, when these birds are known to eat hunter-killed ungulates harvested with lead bullets (Fisher et al. 2006, Hunt et al. 2006, Langner et al. 2015). In one prior study, feather and blood lead concentrations of nestling osprey were below toxic levels in rivers of the Chesapeake Bay (Rattner et al. 2008). However, lead concentrations of breeding-season adults of both species and of nestling bald eagles are unknown. Likewise, the relationships between lead concentrations of adults and the nestlings they feed are not documented. Thus, to understand the sources and ecology of lead exposure of piscivorous raptors in the Chesapeake Bay region, we (a) documented the detection frequency and lead concentrations of multiple age classes of osprey and bald eagles in the major rivers of the Coastal Plain and Eastern Shore of Virginia and Maryland and in systems ranging 
from tidal freshwater to polyhaline; (b) tested for age-specific differences in lead exposure rates of osprey and bald eagles; (c) tested for the presence of lead in food of these piscivorous raptors (blue catfish, Ictalurus furcatus and gizzard shad, Dorosoma cepedianum), in the environment they encounter (Chesapeake Bay sediment), and on their nesting structures (paint on channel markers and bridges); and, (d) evaluated relationships in lead exposure between osprey adults and their offspring.

\section{METHODS}

\section{Field data collection}

We collected blood samples from bald eagles and osprey during the breeding season. We collected bald eagle blood samples in $2014(\mathrm{n}=15), 2015(\mathrm{n}=8), 2016(\mathrm{n}=24)$ and $2017(\mathrm{n}=$ 21) from February through August and osprey blood samples in $2015(\mathrm{n}=90), 2016(\mathrm{n}=122)$ and $2017(n=53)$ from March through July. Bald eagles and osprey were captured on or near the major rivers in the Coastal Plain and Eastern Shore of Virginia and Maryland.

Bald eagle nests were accessed by technical climbers. All nestlings in a nest, always one to three birds, were lowered to the ground for blood collection and subsequently returned to the nest. Free flying bald eagles ( $n=6 ; 3$ adults and 3 pre-adults) were captured with rocket nets, net launchers, and noosed fish (Bloom et al. 2008). Bald eagles ( $\mathrm{n}=28: 17$ adults, 9 pre-adults, and 2 nestlings) were also sampled within 24 hours of admission to Wildlife Center of Virginia (WCV), a licensed raptor rehabilitation facility.

We accessed osprey nests by watercraft. Nestlings were brought in to the boat, where they were banded and a small blood sample was collected prior to returning them to the nest. Adult osprey were captured with a carpet-noose trap on the nest (Bloom et al. 2008). On a few occasions we captured both members of breeding pairs of osprey, but in most cases we obtained 
one adult blood sample per nest. We collected blood samples from all nestlings, again one to three per nest.

All birds of both species were banded with aluminum leg bands and bled from the brachial vein using 25-gauge needles with $3 \mathrm{ml}$ syringes. Two $\mathrm{mL}$ of blood was drawn and transferred to low lead BD Vacutainers (BD Vacutainer®), immediately placed in a cooler, and stored in a refrigerator upon return from the field. We described age of osprey as either nestling (age 8 weeks or younger) or adult (all "after second year", or at least 24 months, at age of capture) and we described age of bald eagle as nestling (age 8 weeks or younger), preadult (all immature eagles older than nestlings) or adult (after fifth year).

To understand potential sources of lead in the environment these birds experienced, we sampled lead present in human-built structures, including ones on which osprey nested, food of both species (fish), and sediment in the rivers where they were captured. River sediment directly below osprey platforms was sampled with a spade, placed in a plastic bag, and stored in a refrigerator. Paint was scraped from bridges, channel markers, and other structures and placed directly in to a plastic bag and stored at room temperature. Blue catfish (Ictalurus furcatus) and gizzard shad (Dorosoma cepedianum) were gill-netted in the James, Rappahannock, and York Rivers and tributaries in Virginia by employees of Virginia Department of Game and Inland Fisheries (VDGIF). Fish carcasses were placed in a conventional freezer at $-20^{\circ} \mathrm{F}$. The blue catfish, but not the gizzard shad, were later x-rayed for the presence of lead fishing equipment. Individuals of both species were thawed and liver tissue was harvested from each individual.

\section{Sample processing and laboratory analysis}

We measured lead concentrations of all biological and environmental samples collected. We prepared blood for laboratory analyses by drawing aliquots of 100-400 $\mu \mathrm{L}$ from whole blood 
samples and pipetted them into $1 \mathrm{~mL}$ microcentrifuge tubes. In cases when blood was clotted, we recorded wet weights, dried samples in an oven at $95^{\circ} \mathrm{C}$ (Fisher Scientific International Inc.), and recorded dry weights prior to digestion. Wet weight blood concentrations were calculated by multiplying the dry weight concentration by the dry:wet weight ratio for individual samples.

We removed a $1 \mathrm{~g}$ (wet weight) sample of liver tissue from each fish for subsequent analysis. Tissue samples were subsequently dried overnight in an oven at $95^{\circ} \mathrm{C}$. We also subsampled paint and sediment. These samples were weighed to $0.1 \mathrm{~g}( \pm 0.05 \mathrm{~g})$, dried in an oven overnight at $95^{\circ} \mathrm{C}$, and sent to Michigan State University Veterinary Diagnostic Laboratory (MSU-VDL) for further preparation prior to analysis.

We sent all blood, tissue and environmental samples to MSU-VDL for lead concentration analyses. Samples were sent pre-digested in 1:10 ratio of nitric acid to water. MSU-VDL determined lead concentrations by inductively coupled plasma mass spectrometry (ICP-MS) with an Agilent 7500ce ICP-MS (Agilent Technologies, Santa Clara, CA) fitted with a Cetac Auto Sampler (Cetac, Omaha, NE) and Micro Mist Nebulizer (Agilent Technologies 2008). Specific elemental calibrations were conducted with dilutions of Specpure $1000 \mu \mathrm{g} / \mathrm{ml}$ stock solutions (Alfa Aesar, Ward Hill, MA) in accordance with in-house generated standard operating procedures derived from Agilent Technologies (2008). Two levels of Bio-Rad Lypocheck whole blood standard reference material (SRM) were used for matrix matched quality control of metal concentrations. Initial instrument calibrations were performed with SRM in triplicate at a limit of detection of $0.5 \mathrm{ug} / \mathrm{dl} \pm 2.9 \%$ rsd; $95 \% \mathrm{CI}$ : $2.4 \%$ to $3.7 \%$. Run specific calibrations were similar and within the goals for precision listed by the manufacturer. Data on lead concentration in fish tissue and environmental samples are reported on a dry weight basis (DW) in parts per million 
(ppm). We report blood lead concentrations on a wet weight basis (WW) in micrograms per deciliter $(\mu \mathrm{g} / \mathrm{dL})$.

\section{Statistical analysis}

Our data included a significant number of samples for which lead concentrations were below the volume-determined limit of detection (LOD) of the ICP-MS (Table 1). Consequently, our sampled blood volumes varied widely with multiple LODs ranging from $0.04-7.56 \mu \mathrm{g} / \mathrm{dL}$. Similar to recent studies employing modern analytical methods, the LODs in this study were below predicted concentrations for subclinical effects (Lazarus et al. 2015). Due to the censored observations and a few outliers, the use of defined distributions for continuous data was not appropriate (Helsel 2012). These problems can be dealt with using substitution methods for samples below the LOD. However, substitution methods often perform poorly in concentrationbased datasets that are censored at semi-arbitrary lower limits (Helsel 2009). We chose to include sample lead concentrations below multiple LODs by calculating descriptive statistics based on a cumulative probability distribution of censored data using the Kaplan-Meier method for nonparametric censored datasets using package 'NADA' in program R (Lee 2017, R Core Team 2017).

Lead exposure of these piscivorous raptors can be thought of in terms either of the concentration, or level of exposure of the average individual, or in terms of the detection frequency or capability of the ICP-MS to detect quantifiable lead concentrations above LODs. To compare the concentrations of lead exposure among species and age classes of osprey and bald eagles, we grouped lead concentrations by species, region, salinity, and age. Regions were defined as the Eastern Shore, and the James, Potomac, Rappahannock, and York Rivers (Figure 1). We separated blood samples into categories for low (0 - $10 \mathrm{ppt})$ and high (>10 ppt) salinity. 
Salinity categories were modified from a GIS layer obtained from the Virginia Institute of Marine Sciences (Berman 2014). For low salinity, we combined the freshwater ( $0-1 \mathrm{ppt})$ and brackish (>1 - $10 \mathrm{ppt})$ categories defined in the layer file. For high salinity, we combined moderately salty $(>10-18 \mathrm{ppt})$ and salty categories $(>18-30 \mathrm{ppt})$. Due to sample size restrictions, we did not perform statistical tests to compare adult osprey between regions or to compare bald eagles between salinity levels or between regions. To evaluate if it was appropriate to pool data from free flying bald eagles with blood samples collected at WCV, we retained this information and compared data from these groups (see below for details).

Because our data did not meet the assumptions of parametric statistical tests, we analyzed them with the Peto and Peto modification of the Gehan Wilcoxon test for censored datasets with two or more groups using package 'NADA' in program R (Lee 2017). We tested for differences in adult blood lead concentrations among regions, among age classes, by salinity level, between disposition at time of capture (free flying or admitted) and between species $(\alpha=0.05)$. When Wilcoxon tests suggested differences among age classes, we sub-grouped the data and performed individual tests using package 'dplyr' to test for specific differences among age classes, species, salinity, and regions (Wickham et al. 2017). In cases where we evaluated nestlings, we used package 'survival' in program $\mathrm{R}$ to run semi-parametric cox proportional-hazards models to simultaneously assess the effects of region, age classes, salinity and species on blood lead concentrations while introducing a random effect for territory to account for non-independence among brood mates (Cox 1972, Therneau 2015).

To compare the detection frequency of lead exposure among the age classes, regions, and salinity level we created a binary contingency table of the number of individuals above and below the highest LOD for each species. We used a chi-square analysis to test for differences 
among age classes, regions, and salinity levels for both species $(\alpha=0.05)$ (package 'MASS'; Venables and Ripley 2002). When we detected differences amongst classes, we ran a post-hoc Fisher's exact test to characterize those differences among regions, age classes, and salinity level (package 'fifer', Fife 2014). Unlike the case for the lead concentration tests, we were unable to use a random effect to address the potential lack of independence among brood mates in the detection frequency tests because we know of no test that would allow us to do this.

To relate lead concentrations in osprey parents to those of their offspring, we used an Akritas-Thiel-Sen regression with a Kendall's tau correlation coefficient in R package 'NADA' (Lee 2017, R Core Team 2017). When multiple nestlings from a nest were compared to a single parent, we used the mean blood lead concentrations of the siblings. In calculating the mean, if concentrations of nestlings were below LODs, we estimated nestling blood lead concentrations with the Kaplan-Meier method for censored data using package 'NADA' in program R (Lee 2017, R Core Team 2017). We also used a paired Prentice-Wilcoxon test for censored datasets in R core package 'smwrQW' to evaluate differences in lead concentrations between adult and nestling osprey pairs (Lorenz 2017).

\section{RESULTS}

Age- and region-specific lead exposure of osprey and bald eagles

We tested blood lead concentrations of 244 osprey including 47 breeding adults $(\bar{x}=3.27$

$\pm 7.36 \mu \mathrm{g} / \mathrm{dL} ;$ mean $\pm \mathrm{SD}$, range $<\mathrm{LOD}-35.57 \mu \mathrm{g} / \mathrm{dL})$ and 197 nestlings $(\bar{x}=1.70 \pm 2.63$

$\mu \mathrm{g} / \mathrm{dL}$, range $<\mathrm{LOD}-22.85 \mu \mathrm{g} / \mathrm{dL})$ from 125 nests. A total of $38 \%(n=92)$ of the osprey blood samples fell below LODs (Table 1), 3\% $(\mathrm{n}=7)$ of the osprey blood samples were above the threshold for background blood lead concentrations $(10 \mu \mathrm{g} / \mathrm{dL})$, and none of the osprey had blood lead concentrations above the threshold for clinical poisoning (40 $\mu \mathrm{g} / \mathrm{dL})$ (Fallon et al. 
2017, Pokras and Kneeland 2008). There was no statistical difference in the detection frequency $\left(p=0.84, \chi^{2}=0.04, d . f .=1\right)$ or lead concentrations $\left(p=0.92, \chi^{2}=0.01, d . f .=1\right.$; note that both the chi-square test for detection frequency and the modified Wilcoxon test for concentrations produce a $\chi^{2}$ statistic) between adult and nestling osprey. Likewise, there were no significant differences in the detection frequency and lead concentrations of adult $\left(p=0.55, \chi^{2}=0.35\right.$, d.f. $=$ $\left.1 ; p=0.27, \chi^{2}=<0.01, d . f .=1\right)$ or nestling $\left(p=0.93, \chi^{2}=0.01, d . f .=1 ; p=0.44, \chi^{2}=0.60, d . f\right.$. $=1$ ) osprey from different salinity levels. There was no difference in the detection frequency $(p=$ $>0.7, \chi^{2}=>6, d . f .=4$ ) of lead exposure of nestling osprey by region. However, nestling osprey in the four rivers of the Coastal Plain had higher lead concentrations $\left(p=<0.02, \chi^{2}=>5, d . f .=4\right)$ than did those on the Eastern Shore.

We tested blood lead concentrations of 68 bald eagles including 36 nestlings $(\bar{x}=1.64 \pm$ $1.33 \mu \mathrm{g} / \mathrm{dL}$, range $<\mathrm{LOD}-6.88 \mu \mathrm{g} / \mathrm{dL})$ from 25 nests, as well as 12 pre-adults $(\bar{x}=5.94 \pm 9.10$ $\mu \mathrm{g} / \mathrm{dL}$, range $<\mathrm{LOD}-32.4 \mu \mathrm{g} / \mathrm{dL})$, and 20 adults $(\bar{x}=15.37 \pm 15.12 \mu \mathrm{g} / \mathrm{dL}$, range $<\mathrm{LOD}-50.4$ $\mathrm{ug} / \mathrm{dL})$. A total of $44 \%(n=31)$ of sample concentrations were below LODs (Table 1), 15\% ( $\mathrm{n}=$ 10) of the bald eagle blood samples were above the threshold for background blood lead concentrations $(10 \mu \mathrm{g} / \mathrm{dL})$, and two of the bald eagles had blood lead concentrations above the threshold for clinical poisoning (40 $\mu \mathrm{g} / \mathrm{dL})$ (Fallon et al. 2017, Pokras and Kneeland 2008). There was a difference in the detection frequency $\left(p=0.02, \chi^{2}=5.74, d . f .=1\right)$ but not lead concentrations $\left(p=0.3, \chi^{2}=1.3, d . f .=1\right)$ of free flying bald eagles and those admitted at WCV. Because lead levels of admitted eagles were not higher than those of free-flying birds, we felt that it was reasonable to include them in subsequent statistical tests (although we discuss the implications of this decision later in the manuscript). 
There was a statistical difference in the detection frequency $\left(p=<0.01, \chi^{2}=22.42\right.$, d.f. $=$ 2) and lead concentrations $\left(p=<0.02, \chi^{2}=<1, d . f .=2\right)$ among bald eagle age groups. Adults had the highest blood lead concentrations, pre-adults had intermediate lead concentrations, and juveniles lowest (Table 1). Blood lead concentrations were similar for bald eagles captured in low and high salinity locations (Table 2). We did not statistically compare locations of bald eagles by salinity because we were unsure if capture locations accurately represented recent foraging locations.

We compared blood lead concentrations of adult osprey and adult bald eagles and found a difference between the detection frequency $\left(p=<0.01, \chi^{2}=24.51, d . f .=1\right)$ and lead concentrations $\left(p=0.01, \chi^{2}=<1, d . f .=1\right)$ between species. Adult bald eagles had higher blood lead concentrations than did adult osprey. The detection frequency of blood lead concentrations in nestling osprey was greater than that of nestling bald eagles $\left(p=0.003, \chi^{2}=8.78, d . f .=1\right)$, but there was no difference in lead concentrations between species $\left(p=0.1, \chi^{2}=2.80, d . f .=1\right)$. Environmental lead piscivorous raptors encounter in the Chesapeake Bay watershed Many of the environmental samples contained detectable quantities of lead. The radiographs of blue catfish prior to tissue harvest never detected metallic material or other fishing equipment. We tested 42 blue catfish livers; $95 \%$ of these samples were above LODs ( $\bar{x}$ $=0.54 \pm 0.54 \mathrm{ppm}$; mean $\pm \mathrm{SD}$, range $<\mathrm{LOD}-8.32 \mathrm{ppm}$ ). Of the 39 gizzard shad livers we tested, only $1 \%$ had lead concentrations above the LOD. Therefore, we did not calculate summary statistics for this dataset. We tested 29 paint samples from the five regions. All paint samples were above the $\operatorname{LOD}(\bar{x}=21,637 \pm 55,012 \mathrm{ppm}$, range $2-181,642 \mathrm{ppm})$. We tested 20 sediment samples from the five regions; all sediment samples were above the LOD $(\bar{x}=12.53 \pm$ $12.44 \mathrm{ppm}$, range $0.96-52.44 \mathrm{ppm})$. 


\section{Correspondence of lead exposure of parent-offspring dyads}

We compared blood lead concentrations of 16 breeding osprey and their offspring. There was no significant correlation of blood lead concentrations between the two age groups $(\mathrm{p}=$ 0.197$, slope $=0.299$, intercept $=0.005$, tau $=0.233)$. We also tested for a difference between each of the 16 sets of parent-offspring pairs and found no difference in blood lead concentrations $(\mathrm{p}=0.19, \mathrm{Z}=-1.33)$.

\section{DISCUSSION}

Our work shows that low lead concentrations are common both in piscivorous raptors and in the environments they use in the Chesapeake Bay region of Maryland and Virginia. The lead we documented occurred in individuals from all age classes of both species of birds, as well as in the sediment, food, and structures the birds interacted with. The trends we observed in lead exposure were specific to species, age, and regions, but not salinity. Most of the mean blood lead concentrations we measured fell within reported levels for background exposure. If this subset of birds is experiencing negative consequences from this lead exposure, it is almost certainly sublethal and may not have demographic relevance (Franson and Pain 2011, Pattee and Pain 2003). However, these patterns of exposure can still provide important insight that can guide our understanding of lead availability for piscivorous raptors in the Chesapeake region.

\section{Spatial and demographic patterns of lead exposure}

Spatial patterns in lead concentrations and detection frequency tell different stories that inform about the implications of lead exposure of these birds. For example, although similar proportions of osprey were exposed among regions, lead concentrations were higher amongst osprey on the Coastal Plain than those on the Eastern Shore (Table 3). The majority of the nestling osprey we tested in the rivers of the Coastal Plain nested on fresh water. In contrast, the majority of the nestling osprey we tested on the Eastern Shore nested in high salinity 
environments. Earlier work has shown that the lead in nestling osprey in the Chesapeake region is ingested, not inhaled (Katzner et al. 2018). Likewise, there is a demonstrated dietary response by osprey in relation to salinity in the Chesapeake Bay region (Glass and Watts 2009). This response is such that in lower salinity waters, osprey eat catfish, a predator high on the aquatic food chain (Schloesser et al. 2011). Due to their feeding behavior and trophic position, catfish are known to accumulate lead (Crafford and Avenant-Oldewage 2010). In fact, the blue catfish we sampled, which are a primary osprey prey item in low salinity waters, generally had lead concentrations above the LOD of our sampling instrument. In higher salinity waters osprey eat almost no catfish but instead forage on a greater proportion of filter-feeding anadromous and saltwater fish. Gizzard shad are detritivores, lower on the food chain than catfish and therefore less likely to accumulate trace metals (Latour et al. 2017). It is therefore not surprising that only one of the gizzard shad we sampled had lead concentrations above the LOD. The selection of predatory fish as primary prey of Coastal Plain osprey likely illustrates a source for exposure to low levels of lead by these piscivorous birds.

Within the population of nestling osprey on the Coastal Plain, the lack of spatial variation in detection frequencies and lead concentrations of birds hatched on the different rivers (Table 3) is informative. This exposure pattern to lead is dissimilar from that expected from other toxicants that emanate from point sources of pollution. For example, birds of many species tend to have higher contaminant loads when they nest in close proximity to point sources (Lewis et al. 2001, Millow et al. 2015, Rattner et al. 2004). We conclude that the sources of low lead exposure for nestling osprey is not via a single point source but instead is most likely via either many pollution events in each of the waterways, or from a few pollution events from which lead dissipates widely. 
We saw age-patterns in lead concentrations of bald eagles, but not of osprey. As noted previously, there is immense behavioral and demographic complexity within the pre-adult and adult bald eagle populations in the Chesapeake Bay. It is therefore impossible to know the origin or recent movements of the eagles we sampled. Thus, it is difficult to draw inference about where these birds encountered environmental lead. That said, age and region-related patterns can still be informative about sources of exposure.

Among those bald eagles exposed to lead, adult and pre-adults had higher blood lead concentrations than did nestlings. These findings suggest that lead exposure of eagles is ongoing as the birds age. This is because if an animal's exposure to lead is regular, its body lead burden will build up over time (Franson and Pain 2011). Lead stored in bone from past exposure events can be mobilized and re-introduced to blood and tissue regularly, thus causing increased blood lead concentrations during eggshell production or during other times of physiological stress (Franson and Pain 2011, Langner et al. 2015). The implication of our observations is that, over the course of their lives, bald eagles are regularly exposed to lead and that a combination of recent and past exposure events combine to produce age-related differences of lead exposure.

Unlike bald eagles, osprey exhibited no age-related variation in lead concentrations. The lack of age-related differences of lead exposure suggest that osprey are exposed to low levels of lead over their lifetime. As a consequence, total lead body burden does not likely accumulate in an osprey as quickly as it does in a bald eagle. This difference highlights how lead moves through the food chain from fish to piscivore in the Chesapeake region. These age-related patterns also suggest that there is an additional source of lead that causes free-flying (postfledging) bald eagles to have higher lead concentrations than do similarly aged osprey. We discuss these potential sources below. 


\section{Potential sources of exposure}

Our findings illustrate that lead exposure of piscivorous raptors in the Chesapeake region may occur at relatively low levels during the breeding season. They do however provide information that can help understand the sources from which these environmental sentinels are exposed to toxicants. In the case of terrestrial raptors, there is extensive evidence documenting their routes of exposure (Fisher et al. 2006, Hunt et al. 2006, Langner et al. 2015). However, literature documenting routes of exposure for piscivorous raptors is less prevalent (Langner et al. 2012, Rattner et al. 2004). That said, it is well documented that a variety of raptors that occupy aquatic and terrestrial environments are exposed to lead.

Piscivorous birds are known to ingest lead in the form of fishing equipment, shotgun ammunition, paint, and sediment (Beyer et al. 2000, Blus et al. 1999, Finkelstein et al. 2003, Haig et al. 2014). For example, there is good evidence from seasonality of exposure and from necropsies that common loons (Gavia immer) receive most of their lead from fishing tackle (Burger et al. 1994, Grade et al. 2018, Pokras and Chafel 1992, Scheuhammer and Norris 1996). In contrast, swans and osprey can obtain lead from mining-related sediment that bio-accumulates into preferred food sources (Beyer et al. 1998, Blus et al. 1991, Langner et al. 2012). Bald eagles are known to focus on waterfowl as prey during times of the year when waterfowl populations are abundant in the Chesapeake region (Beyer et al. 2000). Although lead shot is no longer legal for use in duck hunting, legacy lead shot is still present in the sediment and may be ingested by waterfowl who mistake them for stones that can serve as gastroliths. Thus, there are many potential dietary sources by which osprey and bald eagles in this region may become exposed to lead via ingestion.

In general, some bald eagles and osprey in every age class in the Chesapeake region were exposed to detectable concentrations of lead. Osprey likely ingest lead from only a few sources - 
the lead in fish noted above, as well as lead paint and lead fishing tackle. Some nestling birds do eat lead paint (Finkelstein et al. 2003); however, the data presented in this paper provide no evidence as to whether or not osprey in the Chesapeake experience lead exposure through the ingestion of lead paint. Regardless of this finding, flaking lead-based paint and discarded lead fishing equipment found on channel markers and bridges are a source by which osprey nestlings and other wildlife may be accidentally exposed to lead.

Our data on blood lead concentrations of nestlings suggest that during the nesting season, bald eagles and osprey experience similar exposure to lead. It seems reasonable to conclude, therefore, that the differences in blood lead levels of free-flying birds of the two species must be due to behaviors during the non-breeding season. In fact, unlike osprey, bald eagles show strong seasonal variation in diet and during winter they scavenge frequently, often on remains of hunter-killed deer (Bedrosian et al. 2012, Wilmers et al. 2003). The process of scavenging is well known to result in lead poisoning (Haig et al. 2014, Pain et al. 2010, Stauber et al. 2010). These behavioral differences therefore explain both the differences in blood lead concentrations of the two species and, almost certainly, the age-related differences in exposure we observed within the eagle population.

\section{Birds sampled at rehabilitation facilities}

Including bald eagles sampled at a rehabilitation facility introduces potential bias into our study and our results should be interpreted with this in mind. A previous study by WCV (the rehabilitation center from which we obtained these samples) reported that $10 \%$ of bald eagles were admitted due to toxicosis from lead and pesticides (Harris and Sleeman 2007). The 28 bald eagles admitted at WCV during the breeding season from 2014 - 2017 and included in this study were admitted for a variety of reasons including trauma, aspergillosis, emaciation, and blindness. 
Of those admitted birds, 18 died or were euthanized due to poor condition and 10 were released after treatment. At the time of admission, only $1(4 \%)$ of the bald eagles included in our data set had blood lead concentrations indicative of clinical lead poisoning (Franson and Pain 2011, Pattee and Pain 2003) and blood lead concentrations were generally similar between free-flying and admitted eagles. That said, some authors have suggested that birds with subclinical lead poisoning are more susceptible to other injury or disease (Ecke et al. 2017, Kelly and Kelly 2005, Finkelstein et al 2012). However, because lead concentrations were similar among freeflying and rehabilitation birds, and because this analysis explicitly was focused on patterns and sources of lead exposure rather than its demographic impacts, we feel it is reasonable to include these data in our analyses.

\section{CONCLUSIONS}

Our study demonstrates that piscivorous raptors in the Chesapeake Bay region of Maryland and Virginia are exposed to low levels of lead during the breeding season. The patterns in our data suggest that during the breeding season, lead exposure of osprey and bald eagles are similar and occurs via the fish they ingest. However, as a result of seasonal changes in foraging behavior, bald eagles can be more frequently exposed to lead during the non-breeding season. By evaluating trends within the data we collected, we are able to better understand how lead moves through trophic levels and about how regional top predators are exposed to this toxicant. These conclusions therefore help understand the sources for lead exposure and toxicosis for these birds and provides a starting point for developing potential mitigation actions.

\section{ACKNOWLEDGMENTS}

L. Rhea, L. Montague, and D. Schmidt assisted with laboratory work. B. Watts and C. Koppie provided a small number of blood samples. Field work was covered under WVU's 
IACUC protocol \#1603001797, The College of William and Mary's IACUC protocol IACUC2017-04-18-12065, federal banding permits \#23715, \#06560, and \#21567. We thank B. Rattner and three anonymous reviewers who assisted with the improvement of this manuscript. This publication was completed with funds provided by VDGIF through a Federal Aid in Wildlife Restoration grant from the USFWS, contract \#2013-14308. JA was supported by the NSF (OIA1458952) and the USDA National Institute of Food and Agriculture, McIntire Stennis project WVA00117 during manuscript preparation. Any use of trade, product or firm names is for descriptive purposes only and does not imply endorsement by the U.S. Government. This is scientific article number XXXX of the West Virginia University Agricultural and Forestry Experiment Station, Morgantown, West Virginia. 


\section{REFERENCES}

Agilent Technologies. 2008. Agilent 7500 Series ICP-MS hardware manual. Agilent Technologies, Inc.

Ator SW. 1998. Water quality in the Potomac River basin, Maryland, Pennsylvania, Virginia, West Virginia, and the District of Columbia, 1992-96. Final/Technical Report. U.S. Geological Survey, Reston, VA.

Bedrosian B, Craighead D, Crandall R. 2012. Lead exposure in bald eagles from big game hunting, the continental implications and successful mitigation efforts. In Johnson, CJ, ed., PLoS ONE 12:e51978.

Behmke S, Fallon J, Duerr AE, Lehner A, Buchweitz J, Katzner T. 2015. Chronic lead exposure is epidemic in obligate scavenger populations in eastern North America. Environ Int 79:51-55.

Berman, M. 2014. Chesapeake Bay and Maryland/Virginia oceanside salinity - spring thru fall 2001 - 2011. Virginia Institute of Marine Sciences. Available at http://cmap.vims.edu/Aquaculture/metadata/SalinitySpringThruFall_2001_2011_metadat a.pdf

Beyer WN, Audet DJ, Heinz GH, Hoffman DJ, Day D. 2000. Relation of waterfowl poisoning to sediment lead concentrations in the Coeur d'Alene River basin. Ecotoxicology 9:207218.

Beyer WN, Day D, Morton A, Pachepsky Y. 1998. Relation of lead exposure to sediment ingestion in mute swans on the Chesapeake Bay, USA. Environ Toxicol and Chem 17:2298-2301.

Bloom PH, Clark WS, Kidd JW. 2008. Raptor Research and Management Techniques. Chapter 12, Capture Techniques. 1st ed. Bildstein K, editor. Surrey, B.C. ; Blaine, WI: Hancock House Publishers Ltd, Canada.

Blus LJ, Henny CJ, Hoffman DJ. 1999. Persistence of high lead concentrations and associated effects in tundra swans captured near a mining and smelting complex in northern Idaho. Ecotoxicology 8:125-132.

Blus LJ, Henny CJ, Hoffman DJ, Grove RA. 1991. Lead toxicosis in tundra swans near a mining and smelting complex in northern Idaho. Arch Environ Con Tox 21:549-555.

Bowerman WW, Roe AS, Gilbertson MJ, Best DA, Sikarskie JG, Mitchell RS, Summer CL. 2002. Using bald eagles to indicate the health of the Great Lakes' environment. Lake Reserv Manage 7:183-187.

Buehler DA, Fraser JD, Seegar JKD, Therres GD. 1991. Survival rates and population dynamics of bald eagles on Chesapeake Bay. J Wild Manage 55:608-613.

Burger J, Pokras M, Chafel R, Gochfeld M. 1994. Heavy metal concentrations in feathers of common loons (Gavia immer) in the Northeastern United States and age differences in mercury levels. Environ Monit Assess 30:1-7.

Clark W. 1982. Turtles as a food source of nesting bald eagles in the Chesapeake Bay region. J Field Ornithol 53:49-51.

Cooper SR. 1995. Chesapeake Bay watershed historical land use: impact on water quality and diatom communities Ecol Appl 5:703-723.

Cox DR. 1972. Regression models and life tables (with discussion). J R Statist Soc B 34:187-220

Crafford D, Avenant-Oldewage A. 2010. Bioaccumulation of non-essential trace metals in tissues and organs of Clarias gariepinus (sharptooth catfish) from the Vaal River system strontium, aluminum, lead and nickel. Water Sa 36:621-640. 
Ecke F, Navinder JS, Arnemo JM, Bignert A, Helander B, Berglund AMM, Borg H, BröjerC, Holm K, Lanzone M, Miller T, Nordstrom Ake, Räikkönen J, Rodushkin I, Ågren E, Hörnfeldt, B. 2017. Sublethal lead exposure alters movement behavior in free-ranging golden eagles. Environ Sci Technol 51:5729-5736.

Fallon JA, Redig P, Miller TA, Lanzone M, Katzner T. 2017. Guidelines for evaluation and treatment of lead poisoning of wild raptors. Wildl Soc Bull 41:205-211.

Fife D. 2014. fifer: A collection of miscellaneous functions. R package version 1.0. https://CRAN.R-project.org/package=fifer

Finkelstein ME, Doak DF, George D, Burnett J, Brandt J, Church M, Grantham J, Smith DR. 2012. Lead poisoning and the deceptive recovery of the critically endangered California condor P Natl Acad Sci USA 109:11449-11454.

Finkelstein ME, Gwiazda RH, Smith DR. 2003. Lead poisoning of seabirds: environmental risks from leaded paint at a decommissioned military base. Environ Sci Technol 37:32563260.

Fisher IJ, Pain DJ, Thomas VG. 2006. A review of lead poisoning from ammunition sources in terrestrial birds. Biol Conserv 131:421-432.

Franson JC, Pain DJ. 2011. Environmental Contaminants in Biota: Interpreting Tissue Concentrations. Chapter 16, Lead in Birds. 2nd ed. Beyer WN, Meador JP, editors. CRC Press, Boca Raton, FL, USA. pp 563-594

Franzen-Klein D, McRuer D, Slabe VA, Katzner T. 2018. The use of lead isotope analysis to identify potential sources of lead toxicosis in a juvenile bald eagle (Haliaeetus leucocephalus) with ventricular foreign bodies. J Avian Med Surg 32:34-39.

Glass KA, Watts BD. 2009. Osprey diet composition and quality in high- and low- salinity areas of lower Chesapeake Bay. J Raptor Res 43:27-36.

Grade TJ, Pokras MA, Laflamme EM, Vogel HS. 2018. Population-level effects of lead fishing tackle on common loons: Population effects of lead tackle. J Wildlife Manage 82:155164.

Grove RA, Henny CJ, Kaiser JL. 2009. Osprey: Worldwide sentinel species for assessing and monitoring environmental contamination in rivers, Lakes, reservoirs, and estuaries. J Toxicol Environ Heal B 12:25-44.

Haig SM, D’Elia J, Eagles-Smith C, Fair JM, Gervais J, Herring G, Rivers JW, Schulz JH. 2014. The persistent problem of lead poisoning in birds from ammunition and fishing tackle. Condor 116:408-428.

Harris MC, Sleeman JM. 2007. Morbidity and mortality of bald eagles (Haliaeetus leucocephalus) and peregrine falcons (Falco peregrinus) admitted to the wildlife center of Virginia, 1993-2003. J Zoo Wildl Med 38:62-66.

Helsel, D. 2009. Much ado about next to nothing: incorporating nondetects in science. The Ann Occup Hyg 54:257-262.

Helsel, D. 2012. Statistics for censored environmental data using minitab and R. 2nd ed, Wiley, Hoboken, NJ, USA.

Henny CJ, Blus LJ, Hoffman DJ, Grove RA, Hatfield JS. 1991. Lead accumulation and osprey production near a mining site on the coeur d'Alene River, Idaho. Arch Environ Con Tox 21:415-424.

Henny CJ, Smith MM, Stotts VD. 1974. The 1973 Distribution and abundance of breeding ospreys in the Chesapeake Bay. Chesapeake Sci 15:125-133.

Hopkins WA, Hopkins LB, Unrine JM, Snodgrass J, Elliot JD. 2007. Mercury concentrations in 
tissues of osprey from the Carolinas, USA. J Wildlife Manage 71:1819-1829.

Hunt WG, Burnham W, Parish CN, Burnham KK, Mutch B, Oaks JL. 2006. Bullet fragments in deer remains: Implications for lead exposure in avian scavengers. Wildlife Soc B 34:167170.

Iqbal S, Blumenthal W, Kennedy C, Yip FY, Pickard S, Flanders WD, Loringer K, Kruger K, Caldwell KL, Jean Brown M. 2009. Hunting with lead: Association between blood lead levels and wild game consumption. Environ Res 109:952-959.

Katzner TE, Stuber MJ, Slabe VA, Anderson JT, Cooper JL, Rhea LL, Millsap BA. 2018. Origins of lead in populations of raptors. Anim Conserv 21:232-240.

Kelly A, Kelly S. 2005. Are mute swans with elevated blood lead levels more likely to collide with overhead power lines. Waterbirds 28:331-335.

Komárek M, Ettler V, Chrastný V, Mihaljevič M. 2008. Lead isotopes in environmental sciences: A review. Environ Int 34:562-577.

Langner HW, Domenech R, Slabe VA, Sullivan SP. 2015. Lead and mercury in fall migrant golden eagles from western North America. Arch Environ Con Tox 69:54-61.

Langner HW, Greene E, Domenech R, Staats MF. 2012. Mercury and other mining-related contaminants in ospreys along the upper Clark Fork River, Montana, USA. Arch Environ Con Tox 62:681-695.

Latour RJ, Gartland J, Bonzek CF. 2017. Spatiotemporal trends and drivers of fish condition in Chesapeake Bay. Mar Ecol Prog Ser. 579:1-17.

Lazarus RS, Rattner BA, Brooks BW, Du B, McGowan PC, Blazer VS, Ottinger MA. 2015. Exposure and food web transfer of pharmaceuticals in ospreys (Pandion haliaetus): predictive model and empirical data. Environ Assess Manag. 11:118-129.

Lee L. 2017. NADA: Nondetects and data analysis for environmental data. R package version 1.6-1. https://CRAN.R-project.org/package=NADA

Lewis A, Poppenga RJ, Dav WR. 2001. Lead toxicosis and trace element levels in wild birds and mammals at a firearms training facility. Arch Environ Con Tox 41:208-214.

Lorenz DL, 2017. smwrQW--An R Package for Managing and Analyzing Water-Quality Data, Version 0.7.9:

Mersmann TJ. 1989. Foraging ecology of bald eagles on the northern Chesapeake Bay with an examination of techniques used in the study of bald eagle food habits. (Doctoral dissertation, Virginia Tech).

Millow, CJ, Mackintosh, SA, Lewison, RL, Dodder, NG and Hoh, E, 2015. Identifying bioaccumulative halogenated organic compounds using a nontargeted analytical approach: Seabirds as sentinels. PloS ONE. 10:p.e0127205.

Millsap B, Bjerre E, Otto M, Zimmerman G, Zimpfer N. 2016. Bald and golden eagles: Population demographics and estimation of sustainable take in the United States, 2016 update. Final/Technical Report. U.S. Department of Interior Fish and Wildlife Service, Washington, DC.

Pain DJ, Cromie RL, Newth J, Brown MJ, Crutcher E, Hardman P, Hurst L, Mateo R, Meharg AA, Moran AC. 2010. Potential hazard to human health from exposure to fragments of lead bullets and shot in the tissues of game animals. Iwaniuk A, editor. PLoS ONE 5:e10315.

Pattee OH, Pain DJ. 2003. Handbook of Ecotoxicology. Chapter 15, Lead in the Environment. 2nd ed. Hoffman DJ, Rattner BA, Burton GA, Cairns J, editors. CRC Press, Boca Raton, FL, USA, pp 376-391. 
Pokras MA, Chafel R. 1992. Lead toxicosis from ingested fishing sinkers in adult common loons (Gavia immer) in New England. J Zoo Wildlife Med 23:92-97.

Pokras MA, Kneeland MR. 2008. Lead poisoning using transdisciplinary approaches to solve an ancient problem. EcoHealth 5:379-385.

R Core Team 2017. R: A language and environment for statistical computing. R Foundation for Statistical Computing, Vienna, Austria. URL https://www.R-project.org/.

Rattner BA, Golden NH, Toschik PC, McGowan PC, Custer TW. 2008. Concentrations of metals in blood and feathers of nestling ospreys (Pandion haliaetus) in Chesapeake and Delaware Bays. Arch Environ Con Tox 54:114-122.

Rattner BA, McGowan PC. 2007. Potential hazards of environmental contaminants to avifauna residing in the Chesapeake Bay estuary. Waterbirds 30:63-81.

Rattner BA, McGowan PC, Golden NH., Hatfield, JS, Toschik, PC, Lukei RF, Hale RC, Schmitz-Afonso I, Rice CP. 2004. Contaminant exposure and reproductive success of ospreys (Pandion haliaetus) nesting in Chesapeake Bay regions of concern. Arch Environ Con Tox 47:126-140.

Scheuhammer AM, Norris SL. 1996. The ecotoxicology of lead shot and lead fishing weights. Ecotoxicology 5:279-295.

Schloesser RW, Fabrizio MC, Latour RJ, Garman GC, Greenlee B, Groves MA, Gartland, JA. 2011. Ecological role of blue catfish in Chesapeake Bay communities and implications for management. In conservation, ecology, and management of catfish: the second international symposium. American Fisheries Society. 77:369-382.

Stauber E, Finch N, Talcott PA, Gay JM. 2010. Lead poisoning of bald (Haliaeetus leucocephalus) and golden (Aquila chrysaetos) eagles in the US inland Pacific Northwest Region-An 18-year retrospective study: 1991-2008. J Avian Med Surg 24:279-287.

Therneau T. 2015. A Package for Survival Analysis in S_. version 2.38, <URL: https://CRAN.Rproject.org/package=survival $>$.

US Fish and Wildlife Service. 1986. Final Supplemental environmental impact statement. Use of lead shot for hunting migratory birds in the United States. U.S. Department of Interior Fish and Wildlife Service Washington, DC.

US Fish and Wildlife Service. 2007. National Bald Eagle Management Guidelines. May 2007. U.S. Department of Interior Fish and Wildlife Service Washington, DC.

US Geological Survey. 2012.Technical Report on Toxic Contaminants in the Chesapeake Bay and its Watershed: Extent and Severity of Occurrence and Potential Biological Effects. [accessed 2018d Jul 12]. https://www.chesapeakebay.net/channel_files/18750/attachment_vi.a.__tech_report_on_tox_contaminants_in_ches_bay_and_watershed_12_19_12_final_exec_ summary.pdf

Venables WN, Ripley BD. 2002. Modern applied statistics with S. 4th ed. Springer, New York, NY, USA, pp 183-206.

Wadanambi L, Dubey B, Townsend T. 2008. The leaching of lead from lead-based paint in landfill environments. J Hazard Mater 157:194-200.

Watts BD. 2005. Virginia bald eagle conservation plan. Center for Conservation Biology technical report series, CCBTR-05-06, Final/Technical Report. College of William and Mary, Williamsburg, VA.

Watts BD, Markham CA, Byrd MA. 2006. Salinity and population parameters of bald eagles (Haliaeetus leucocephalus) in the lower Chesapeake Bay. The Auk 123:393-404. 
Watts BD, Paxton BJ. 2007. Ospreys of the Chesapeake Bay: Population recovery, ecological requirements, and current threats. Waterbirds 30:39-49.

Watts BD, Therres GD, Byrd MA. 2008. Recovery of the Chesapeake Bay bald eagle nesting population. J Wildlife Manage 72:152-158.

Wickham H, Francois R, Henry L, Müller K. 2017. dplyr: A Grammar of Data Manipulation. R package version 0.7.4. https://CRAN.R-project.org/package $=$ dplyr

Wierda MR, Leith KF, Grubb TG, Sikarskie JG, Best DA, Bowerman W. 2016. Retracted :

Using bald eagles to track spatial (1999-2008) and temporal (1987-1992, 1999-2003, and 2004-2008) trends of contaminants in Michigan's aquatic ecosystems: Aquatic ecosystems contaminant trends, Michigan 1987 to 2008. Environ Toxicol Chem 35:2134-2134.

Wilmers CC, Stahler DR, Crabtree RL, Smith DW, Getz WM. 2003. Resource dispersion and consumer dominance: scavenging at wolf- and hunter-killed carcasses in Greater Yellowstone, USA: Resource dispersion and consumer dominance. Ecol Lett 6:9961003. 
Table 1. Age-specific statistics describing central tendencies and distributions of blood lead concentrations (WW, ug/dL) of (a) bald eagle and (b) osprey from the Chesapeake Bay region. Birds were sampled from 2014 - 2017.

\begin{tabular}{clllllll}
\hline (a) Bald Eagle & $\mathrm{n}$ & $95 \%$ LCL & $95 \%$ UCL & $<$ LOD & Median & Mean & SD \\
\hline Adult & 20 & 8.75 & 21.99 & 1 & 7.18 & 15.37 & 15.11 \\
Pre-Adult & 12 & 0.79 & 11.09 & 6 & NA & 5.94 & 9.10 \\
Nestling & 36 & 1.20 & 2.07 & 23 & NA & 1.64 & 1.33 \\
\hline (b) Osprey & $\mathrm{n}$ & $95 \%$ LCL & $95 \%$ UCL & $<$ LOD & Median & Mean & SD \\
\hline Adult & 47 & 1.17 & 5.37 & 21 & 3.27 & 1.16 & 7.36 \\
Nestling & 197 & 1.34 & 2.07 & 71 & 1.70 & 0.87 & 2.63 \\
\hline
\end{tabular}


Table 2. Salinity-specific statistics describing central tendencies and distributions of blood lead concentrations (WW, ug/dL) for (a) bald eagle and (b) osprey, by salinity, from the Chesapeake Bay region. Birds were sampled from 2012 - 2017, see text for details.

\begin{tabular}{|c|c|c|c|c|c|c|c|}
\hline (a) Bald Eagles & $\mathrm{n}$ & $95 \%$ LCL & $95 \%$ UCL & $<\mathrm{LOD}$ & Median & Mean & SD \\
\hline \multicolumn{8}{|l|}{ HIGH SALINITY } \\
\hline Adult & 10 & 3.79 & 24.66 & 0 & 5.45 & 14.23 & 16.84 \\
\hline Pre-Adult & 6 & -0.12 & 18.97 & 1 & 3.55 & 9.43 & 11.93 \\
\hline Nestling & 3 & 1.49 & 2.42 & 1 & 1.75 & 1.96 & 0.41 \\
\hline \multicolumn{8}{|l|}{ LOW SALINITY } \\
\hline Adult & 10 & 8.39 & 25.33 & 1 & 9.71 & 16.86 & 13.66 \\
\hline Pre-Adult & 6 & NA & NA & 5 & NA & 2.52 & NA \\
\hline Nestling & 33 & 1.15 & 2.10 & 22 & NA & 1.62 & 1.39 \\
\hline (b) Osprey & $\mathrm{n}$ & $95 \%$ LCL & $95 \%$ UCL & $<\mathrm{LOD}$ & Median & Mean & SD \\
\hline \multicolumn{8}{|l|}{ HIGH SALINITY } \\
\hline Adult & 22 & 0.47 & 8.76 & 8 & 1.16 & 4.62 & 9.93 \\
\hline Nestling & 93 & 1.19 & 2.52 & 35 & 0.80 & 1.86 & 3.28 \\
\hline \multicolumn{8}{|l|}{ LOW SALINITY } \\
\hline Adult & 25 & 0.67 & 3.74 & 13 & 1.06 & 2.20 & 3.92 \\
\hline Nestling & 104 & 1.20 & 1.93 & 36 & 0.88 & 1.57 & 1.90 \\
\hline
\end{tabular}


Table 3. Region-specific statistics describing central tendencies and distributions of blood lead concentrations (WW, ug/dL) for nestling osprey from the Coastal Plain and Eastern Shore of the Chesapeake Bay region. Birds were sampled from 2015 - 2017.

\begin{tabular}{llllllll}
\hline REGION & $\mathrm{n}$ & $95 \%$ LCL & $95 \%$ UCL & $<$ LOD & Median & Mean & SD \\
\hline Eastern Shore & 18 & NA & NA & 17 & NA & 1.07 & NA \\
James River & 65 & 1.13 & 2.67 & 21 & 0.94 & 1.90 & 3.16 \\
Potomac River & 43 & 1.26 & 2.75 & 16 & 0.93 & 2.00 & 2.49 \\
Rappahannock River & 36 & 0.77 & 3.00 & 8 & 0.63 & 1.89 & 3.42 \\
York River & 35 & 1.09 & 1.65 & 9 & 1.13 & 1.37 & 0.84 \\
\hline
\end{tabular}


Table 4. Statistics describing central tendencies and distributions of lead concentrations (DW, ppm) of blue catfish livers, gizzard shad livers, sediment and paint from the Chesapeake Bay region of Maryland and Virginia. Samples were collected from $2015-2017$.

\begin{tabular}{llllll}
\hline POTENTIAL LEAD SOURCE & $\mathrm{n}$ & $<$ LOD & Median & Mean & SD \\
\hline Blue catfish liver & 42 & 2 & 0.26 & 0.54 & 1.25 \\
Gizzard shad liver & 39 & 38 & - & - & - \\
Paint & 29 & 0 & 5.99 & 21636.93 & 55011.95 \\
Sediment & 20 & 0 & 8.56 & 12.53 & 12.44 \\
\hline
\end{tabular}





\title{
CHAPTER 3
}

Lead exposure of red-shouldered hawks during the breeding season in the central Appalachians

\author{
Vincent A. Slabe \\ vaslabe@mix.wvu.edu \\ West Virginia University \\ School of Natural Resources \\ PO Box 6125 \\ Morgantown, WV 26506-6125
}




\section{CHAPTER 3}

\section{Lead exposure of red-shouldered hawks during the breeding season in the central}

Appalachians, USA ${ }^{1}$

Vincent A. Slabe ${ }^{\mathrm{a},{ }^{*}}$, James T. Anderson ${ }^{\mathrm{a}}$,Jeff Cooper ${ }^{\mathrm{b}}$, , Patricia Ortiz ${ }^{\mathrm{c}}$, Anna Wrona ${ }^{\mathrm{a}}$, Meghan K. Jensen ${ }^{\mathrm{a}}$, John Buchweitz ${ }^{\mathrm{c}}$, and Todd Katzner ${ }^{\mathrm{d}}$

a Division of Forestry and Natural Resources, West Virginia University, Morgantown, WV, USA

b Virginia Department of Game and Inland Fisheries, Richmond, VA, USA

${ }^{\mathrm{c}}$ Department of Pathobiology and Diagnostic Investigation, Michigan State University, East Lansing, MI, USA

${ }^{\mathrm{d}}$ US Geological Survey, Forest and Rangeland Ecosystem Science Center, Boise, ID, USA

*Correspondence: vaslabe@mix.wvu.edu, (847) 220-3760 


\section{ABSTRACT}

Lead is toxic to humans and wildlife. Most studies of lead exposure of raptors focus on the winter, non-breeding season when they scavenge heavily. We evaluated blood lead concentrations (BLCs) of red-shouldered hawks (Buteo lineatus) during the non-scavenging season in the eastern US. BLCs of 53 of 70 hawks were above the limit of detection $(\bar{x}=9.25$ $\mu \mathrm{g} / \mathrm{dL} \pm 19.81 ; \pm \mathrm{SD})$. Adult hawks had higher BLCs $(\bar{x}=12.86 \mathrm{ug} / \mathrm{dL} \pm 24.72)$ than did nestlings $\left(\bar{x}=3.25 \mu \mathrm{g} / \mathrm{dL} \pm 2.62 ; \mathrm{p}=<0.001, \chi^{2}=13.2\right)$. There was no difference in BLCs of adult hawks among physiographic provinces but there were differences between urban and nonurban settings $\left(\mathrm{p}=0.04, \chi^{2}=4.2\right)$. Soils and invertebrate hawk prey also had quantifiable lead concentrations. Our work shows that red-shouldered hawks are exposed to lead when not scavenging, and suggests pathways by which these birds may be exposed.

\section{INTRODUCTION}

Lead is an anthropogenic poison that negatively affects all major systems of the body. A variety of wildlife species are affected by lead, including neotropical migrant songbirds (Lewis et al. 2001), carnivores (Rogers et al. 2012), and the critically endangered California condor (Gymnogyps californianus) (Cade 2007). One of the most common pathways of lead exposure in birds is ingestion of contaminated food sources (Pokras and Kneeland 2008). Sources of lead that penetrate the food chain include ammunition, fishing tackle, industrial by-products, power plant emissions, pesticides and paint.

Lead exposure is common for some scavenging raptor species (Langner et al. 2015). Many species of hawks, eagles, and owls scavenge during the winter months (Jachowski et al. 2015) and ingest lead in the form of fragmented rifle and shotgun ammunition (Cruz-Martinez et al. 2012). However, less is known about lead exposure of these species during the breeding 
season when their diets consist almost exclusively of live prey.

The red-shouldered hawk (Buteo lineatus) is a common raptor species in the eastern US that scavenges in winter (Henny et al. 1973; Jachowski et al. 2015; Martin 2004; Pranty 2002). During the breeding season, red-shouldered hawks eat a variety of live prey including small mammals, amphibians, crayfish and earthworms (Dykstra et al. 2003; Strobel and Boal 2010; Townsend 2006). In some cases, invertebrates closely associated with soil such as earthworms, insects, and crayfish composed up to $41 \%$ of the diets of breeding red-shouldered hawks (Strobel and Boal 2010; Townsend 2006). This makes them unusual among North American raptors, few of which eat so many invertebrates.

We studied the potential for lead exposure of non-scavenging red-shouldered hawks. We collected blood samples from hawks during the breeding season when these birds do not scavenge and eat live prey. Specifically, we (a) documented and compared blood lead concentrations of nestlings and adult red-shouldered hawks among the major physiographic regions of central Appalachia; (b) compared blood lead concentrations of territorial adult redshouldered hawks in urban and non-urban settings; (c) tested for lead in red-shouldered hawk prey (earthworms) and in the local environment they encounter (soil); and (d) evaluated relationships of lead concentrations in the earthworms and in the soils.

\section{METHODS}

Red-shouldered hawks in the central Appalachians nest in suburban neighborhoods, urban parks, mixed riparian forests and flooded deciduous wetlands (Dykstra et al. 2000; Dykstra et al. 2008). We focused on hawks within three physiographic regions, the Coastal Plain, the Piedmont, and the mountains (a grouping of physiographic regions including the Appalachian Plateau, Valley and Ridge and Blue Ridge provinces) (Fenneman 1938) (Fig. 1). In the densely 
populated Coastal Plain red-shouldered hawks nest in suburban and rural deciduous forests and pine plantations (Hanchette 2008). The Piedmont falls between the mountains and the Coastal Plain and red-shouldered hawks in this region nest in upland hardwood forests and pine plantations (Weakley et al. 2012). The mountainous physiographic provinces west of the Piedmont are composed of a series of ridges covered by diverse vegetation on landscapes ranging from publicly owned forest lands to urban centers. Lead contamination of air, water and soil in these three regions can come from industry, agriculture, coal mining, emissions from coal burning power plants, legacy pesticide applications at apple and poultry farms, hunting and fishing, and aviation gas (Martin and Black 1998; Schooley et al. 2009). In all three regions, earthworms, an important potential prey of these hawks (Dykstra et al. 2003), also are a potential source of lead exposure due to their close association with topsoil (Scheuhammer et al. 2003).

\section{Field Data Collection}

We collected blood samples from red-shouldered hawks in urban and non-urban habitats in each of the three physiographic provinces during the breeding season (February - August) from 2012 - 2017. We sampled adult hawks either after capture at breeding territories or after they were admitted to rehabilitation facilities. We captured free flying birds using a mechanical owl and mistnets (Jensen et al. 2019). Finally, a climber captured nestling hawks 4-7 weeks in age by hand and lowered them to the ground.

We used 27-gauge needles and $1 \mathrm{ml}$ syringes to collect up to $1 \mathrm{ml}$ of blood from the brachial vein of adult and nestling hawks. We stored blood in BD low lead vacutainers (BD Vacutainer®). In the field, we kept blood samples in a cooler on ice and we transferred them to a refrigerator as soon as possible. We determined the age of free-flying birds with a standard plumage assessment (Pyle 1997). 
To understand the characteristics of lead in the environment these birds experienced, we sampled lead from earthworms (Subclass Oligochaeta) and soil. All soil and earthworm samples were collected from at or near the soil surface in areas in the direct vicinity of used redshouldered hawk nests. We collected earthworms by using a trowel to turn over downed woody debris and retrieving the Annelids with our hands. One soil sample and up to three earthworms were collected in each red-shouldered hawk territory and within 100 meters of known nests. In some cases, we were unable to find earthworms. We know of no information suggesting redshouldered hawks prefer certain species of earthworm and so we did not identify earthworms to species. We placed earthworms and soil samples in plastic bags and stored them in a freezer when we returned from the field.

\section{Sample Processing and Laboratory Analysis}

We measured lead concentrations of all biological and environmental samples that we collected. We prepared blood for laboratory analyses by drawing aliquots of 100-400 $\mu \mathrm{L}$ from whole blood samples and pipetting them into microcentrifuge tubes. In cases when blood was clotted, we dried and homogenized samples prior to analysis. We converted dry weight results to wet weight by multiplying the dry weight concentrations by the dry:wet weight ratios or moisture content $(14-43 \%)$. In some cases, we did not have wet weights of samples prior to drying and so converted sample concentrations $(\mathrm{n}=23)$ to wet weight using the mean of the known dry:wet weight ratios or moisture content (22\%). We report blood lead concentrations on a wet weight basis in micrograms per deciliter $(\mu \mathrm{g} / \mathrm{dL})$.

We dried whole earthworms and $0.02 \mathrm{~g}$ of soil overnight in a Thermo Scientific Heratherm oven at $95{ }^{\circ} \mathrm{C}$. After drying we ground earthworms to a powder with a mortar and pestle and weighed them. Soil and earthworm lead concentrations are reported on a dry weight 
basis in parts per million (ppm).

Once samples were prepared, we sent them to the Michigan State University Veterinary Diagnostic Laboratory (MSU-VDL) for lead concentration analyses. Dried earthworm and blood samples were digested in nitric acid prior to analysis and soil was leached with fresh aqua regia consisting of $80 \%$ hydrochloric acid and $20 \%$ nitric acid. Earthworm, soil, and blood samples were then diluted with Millipore water. In all cases, MSU-VDL determined lead concentrations with inductively coupled plasma mass spectrometry (ICP-MS) with an Agilent 7900 ICP-MS (Agilent Technologies, Santa Clara, CA) as described elsewhere (Slabe et al. 2019).

\section{Data Preparation and Statistical Analysis}

We organized blood lead data from red-shouldered hawks into one of three age groups, nestlings, "second-year" adults (SY; age $~ 10-14$ months) that likely did not hold territories and “after second-year" territorial adults (ASY; age > 20 months). Our data from red-shouldered hawks included many blood lead concentrations below the limit of detection (LOD). To account for these non-detects, we first checked that our blood lead data fit a lognormal distribution. After confirming this, we used the semi-parametric robust regression on order statistics (ROS) method to calculate descriptive statistics (package 'NADA' in program R; Lee 2017; R Core Team 2017). We used the Peto and Peto modification of the Gehan-Wilcoxon test for censored datasets with multiple groups to test for differences in red-shouldered hawk adult blood lead concentrations between the physiographic regions (Coastal Plain, Piedmont, mountains) using package 'NADA' in program R (Lee 2017). In all cases where we evaluated nestlings, we used package 'survival' in program R to run censored tobit regression models using function 'survreg' to assess the effects of region on log transformed blood lead concentrations while introducing a random effect for territory to account for non-independence among brood mates (Therneau 
2015).

To compare blood lead concentrations of nestling and territorial adult red-shouldered hawks by land use, we grouped samples with known origin as urban or non-urban. We defined territories in urban settings as those where a 100-ha buffer (Dykstra et al. 2008) around the nest had > 50\% impervious surface (MacGregor-Fors 2011). Non-urban settings were those where the 100-h territory had $<50 \%$ impervious surface. We used the national landcover database to estimate impervious surface coverage using ESRI ArcMap 10.4. We again used the Peto and Peto modification of the Gehan-Wilcoxon test to test for differences in blood lead concentrations between adults and a censored regression model with a random territory effect to test for differences between nestling urban and suburban red-shouldered hawks.

To test for a correlation between earthworms and soil collected in territories of redshouldered hawks, we used a Kendall rank correlation test ('stats' package; R Core Team 2017). Finally, we used a Wilcoxon paired signed rank test to evaluate differences in earthworms and soil (R Core Team 2017).

\section{RESULTS}

We tested blood lead concentrations of 70 red-shouldered hawks (Table 1). This included 42 ASY adults, $5 \mathrm{SY}$ adults, and 23 nestlings. Ten of these birds were sampled upon admission to rehabilitation facilities. The 47 adults included 28 from the mountains, 11 from the Piedmont, and 8 from the Coastal Plain. The 23 nestlings sampled included 8 from the Coastal Plain, 5 from the mountains, and 10 from the Piedmont. We evaluated blood lead data from 41 known territorial ASY adult and 19 nestling red-shouldered hawks for the comparison between nonurban ( $\mathrm{n}=20$ and 14, respectively) and urban ( $\mathrm{n}=21$ and 5) settings. 
Lead exposure of red-shouldered hawks by region and age class

Of the red-shouldered hawk blood samples we tested, $25 \%$ ( $\mathrm{n}=18 ; 5$ adults, 12 nestlings) fell below the LOD (Table 1), 23\% ( $\mathrm{n}=16 ; 16$ adults) had blood lead concentrations consistent with subclinical lead poisoning ( $>10 \mu \mathrm{g} / \mathrm{dL}$ ), and $8 \%$ (n=3, 3 adults) had blood lead concentrations consistent with clinical lead poisoning (>40 $\mu \mathrm{g} / \mathrm{dL}$; Fallon et al. 2017; Pokras and Kneeland 2008). Only one of the birds admitted to a rehabilitation facility had blood lead concentrations above reported background concentrations and none had blood lead concentrations above the reported threshold for clinical poisoning

Adult red-shouldered hawks ( $\mathrm{n}=47,11 \%<\mathrm{LOD})$ had significantly higher blood lead concentrations than did nestlings $(\mathrm{p}=<0.001, \mathrm{z}=-4.70 ; \mathrm{n}=23,52 \%<\mathrm{LOD} ;$ Fig. 2a). We did not compute descriptive statistics for mountain nestlings due to the large proportion of concentrations below the LOD. There were no statistical differences in blood lead concentrations of red-shouldered hawk adults among the different regions $\left(p=0.4, \chi^{2}=2\right)$. A censored tobit regression model did not detect a difference in blood lead concentrations of nestlings among regions $(\mathrm{p}=>0.38, \mathrm{z}=>-0.9)$, although sample sizes were small and thus our ability to detect a difference likely was low.

Comparison of urban and non-urban blood lead concentrations of red-shouldered hawks

There was a statistical difference in blood lead concentrations between urban and nonurban adult hawks ( $\left.\mathrm{p}=0.04, \chi^{2}=4.2\right)($ Fig. $2 b)$. Although sample sizes were on the small side for statistical inference, nestlings from urban locations appeared to have higher blood lead concentrations than non-urban nestlings $(\mathrm{p}=0.03, \mathrm{z}=2.16)$.

\section{Environmental lead in red-shouldered hawk habitat}

We tested soil samples and earthworms from known red-shouldered hawk territories. All 
these had measurable lead concentrations above the LOD (Table 2). Soil $(n=20)$ and earthworm $(n=15)$ lead concentrations were consistent with concentrations reported in the literature (Scheuhammer et al. 2003; Smith et al. 2013).

Relationship between earthworms and soil in red-shouldered hawk habitat

Soil lead concentrations from 14 red-shouldered hawk territories were significantly higher than were lead concentrations from earthworms at those same sites $(p=0.013, V=14)$. There was no correlation between lead concentrations of earthworms and soil from the same territories.

\section{DISCUSSION}

These data show that red-shouldered hawks are most likely exposed to lead by routes of exposure other than scavenging. The non-random, age- and land-use related patterns in blood lead concentrations suggest potential routes of exposure via the environments the hawks occupy in the central Appalachians. These data are especially important and unusual in that they show evidence of lead exposure for a scavenging raptor during the breeding season and, they show a pathway of lead exposure via live prey.

Spatial and age-related patterns in lead exposure

Blood lead concentrations represent the accumulation and circulation of lead from both recent exposure events and the release of lead from the skeletal system from past exposure events (Redig and Arent 2008). Therefore, older birds are likely to have higher blood lead concentrations as a consequence of repeated exposure to the toxicant. Furthermore, lead exposure of adult birds during the breeding season can have negative demographic and reproductive consequences, such as a decrease in egg production and the maternal transfer of lead to embryo during egg production (Edens and Garlich 1983). The documentation of blood 
lead concentrations in nestlings that we provide is important in that it suggests that lead is ingested soon after hatching. Low levels of lead are known to negatively affect growth and development of nestling birds (Burger and Gochfield 2000). Since nestling hawks do not scavenge and their parents bring them almost exclusively live prey, their lead exposure can only be from maternal transfer or the ingestion of live prey provisioned by parents.

The lack of variation in lead exposure between regions suggests that, from the perspective of a red-shouldered hawk, no one region has higher environmental lead than other regions. That said, it was still the case that territorial adult red shouldered hawks and their nestlings had higher blood lead concentrations in urban areas. The sources of lead noted earlier can all deposit lead that can subsequently move through the food chain. Our data suggest that, from the perspective of a red-shouldered hawk, urban lead sources are penetrating the food chain at a greater rate than are non-urban lead sources.

\section{Routes of exposure}

The most likely route of lead exposure for a raptor is via diet (Katzner et al. 2018). Lead poisoning of birds occurs as the result of the inadvertent ingestion of metallic lead or the ingestion of lead poisoned biological tissue (Friend et al. 1987). Red-shouldered hawks commonly scavenge during the winter and it is thought that the frequency with which they scavenge decreases as the birds begin nesting activities (Jachowski et al. 2015). Thus, because the red-shouldered hawks we studied were lead exposed, and because their biology precludes exposure through scavenging, studying this species presents further opportunity to more thoroughly understand routes of lead penetrating through trophic levels.

The six highest blood lead concentrations of red-shouldered hawks we measured were captured at the onset of the breeding season. During this time period, prior to egg-laying, the 
birds may be scavenging in the vicinity of their territories prior to the emergence of seasonally available prey or they may be bearing a lead burden from late winter scavenging.

Piscivorous birds closely associated with benthic substrates often have elevated lead concentrations (Grade et al. 2018; Henny et al. 1991). Likewise, gallinaceous birds that consume soil invertebrates such as earthworms can have bone lead concentrations consistent with chronic lead exposure (Scheuhammer et al. 2003). All soil and earthworm samples we tested in the immediate vicinity of red-shouldered hawk nests contained measurable lead. Although we were unable to make explicit links between prey and predator, this finding is important in that it highlights the potential trophic movement of a non-bioaccumulating toxicant from soil invertebrates to predatory birds.

\section{CONCLUSION}

This study illustrates that raptors may be exposed to lead via live prey they consume. This finding is important in that it highlights a pathway of lead exposure at a time of year when scavenging occurs irregularly or not at all. This conclusion assists in the understanding of the pathways of lead toxicosis in raptors and furthermore, provides land managers with an increased understanding of the wide-reaching impacts of lead as a contaminant.

\section{ACKNOWLEDGMENTS}

L. Rhea, D. Schmidt and B. Brown assisted data collection. The Avian Conservation Center of Appalachia and Wildlife Center of Virginia provided blood samples. TK and JC raised funds. VS, AW, and MJ collected blood samples. PO and VS prepared blood samples. PO and TK obtained permits for field work. VS led writing and data analysis, all authors assisted with revisions. All field work was covered under WVU's IACUC protocol \#1603001797 and federal banding permit \#23715. This publication was completed with funds provided by the Virginia 
Department of Game and Inland Fisheries through a Federal Aid in Wildlife Restoration grant from the United States Fish and Wildlife Service, contract \#2013-14308. V. Slabe was supported by the West Virginia University Outstanding Merit Fellowship for Continuing Doctoral Students. JA was supported by the NSF (OIA-1458952) and the USDA National Institute of Food and Agriculture, McIntire Stennis project WVA00117. Any use of trade, product or firm names is for descriptive purposes only and does not imply endorsement by the U.S. Government. 


\section{REFERENCES}

Agilent Technologies. 2008. Agilent 7500 Series ICP-MS hardware manual. Agilent Technologies, Inc.

Burger J, Gochfield M (2000) Effects of lead on birds (Laridae): a review of laboratory and field studies. J Toxicol Environ Heal B. 3:59-78.

Cade TJ (2007) Exposure of California condors to lead from spent ammunition. J Wild Manage. $71: 2125$.

Cruz-Martinez L, Redig PT, Deen J (2012) Lead from spent ammunition: a source of exposure and poisoning in bald eagles. Hum-Wildl Interact. 6:94-104.

Dykstra CR, Hays JL, Simon MM, Daniel FB (2003) Behavior and prey of nesting redshouldered Hawks in southwestern Ohio. J Raptor Res. 37:177-187.

Dykstra CR, Hays JL, Crocoll ST (2008) Red-shouldered gawk (Buteo lineatus), version 2.0. in The Birds of North America (A. F. Poole, Editor). Cornell Lab of Ornithology, Ithaca, NY, USA. https://doi.org/10.2173/bna.107

Dykstra CR, Hays JL, Daniel FB, Simon MM (2000) Nest site selection and productivity of suburban red-shouldered hawks in southern Ohio. Condor. 102:401-408.

Edens FW, Garlich JD (1983) Lead-induced egg production decrease in leghorn and Japanese quail hens. Poultry Sci. 62:1757-1763.

Fallon JA, Redig P, Miller TA, Lanzone M, Katzner T (2017) Guidelines for evaluation and treatment of lead poisoning of wild raptors: Guidelines for lead poisoned raptors. Wildlife Soc B. 41:205-211.

Fenneman NM (1938) Physiography of eastern United States. New York and London: McGrawHill Book Co. (GBl24 F335).

Friend M, Laitman CJ, Kampen RS (1987) Field Guide to Wildlife Diseases: Volume 1. General Field Procedures and Diseases of Migratory Birds. US Fish and Wildlife Service.

Grade TJ, Pokras MA, Laflamme EM, Vogel HS (2018) Population-level effects of lead fishing tackle on common loons: Population Effects of Lead Tackle. J Wild Manage. 82:155164.

Hanchette CL (2008) The political ecology of lead poisoning in eastern North Carolina. Health Place. 14:209-216.

Henny CJ, Blus LJ, Hoffman DJ, Grove RA, Hatfield JS (1991) Lead accumulation and osprey production near a mining site on the Coeur d'Alene River, Idaho. Arch Environ Con Tox 21:415-424.

Henny CJ, Schmid FC, Martin EM, Hood LL (1973) Territorial behavior, pesticides, and the population ecology of red-shouldered hawks in central Maryland, 1943-1971. Ecology 54:546-554.

Jachowski DS, Katzner T, Rodrigue JL, Ford WM (2015) Monitoring landscape-level distribution and migration Phenology of Raptors using a volunteer camera-trap network: Raptor camera-trapping. Wildlife Soc B. 39:553-563.

Jensen MK, Hamburg SD, Rota CT, Brinker DF, Coles DL, Manske MA, Slabe VA, Stuber MJ, Welsh AB and Katzner TE (2019) An Improved Mechanical Owl for Efficient Capture of Nesting Raptors. J Raptor Res 53:14-25.

Katzner TE, Stuber MJ, Slabe VA, Anderson JT, Cooper JL, Rhea LL, Millsap BA (2018) Origins of lead in populations of raptors. Anim Conserv 21:232-240.

Langner HW, Domenech R, Slabe VA, Sullivan SP (2015) Lead and mercury in fall migrant golden eagles from western North America. Arch Environ Con Tox. 69:54-61. 
Lee L (2017) NADA: Nondetects and data analysis for environmental data. R package version 1.6-1. https://CRAN.R-project.org/package=NADA

Lewis LA, Poppenga RJ, Davidson WR, Fischer JR, Morgan KA (2001) Lead toxicosis and trace element levels in wild birds and mammals at a firearms training facility. Arch Environ Con Tox. 41:208-214.

MacGregor-Fors I (2011) Misconceptions or misunderstandings? On the standardization of basic terms and definitions in urban ecology. Landscape Urban Plan. 100:347-349.

Martin EM (2004) Decreases in a population of red shouldered hawks nesting in central Maryland. J Raptor Res. 38:312-319.

Martin LK, Black MC (1998) Biomarker assessment of the effects of coal strip-mine contamination on channel catfish. Ecotox Environ Safe. 41:307-320.

Pokras MA, Kneeland MR (2008) Lead poisoning: Using transdisciplinary approaches to solve an ancient problem. EcoHealth. 5:379-385.

Pranty B (2002) Red-shouldered hawk feeds on carrion. J Raptor Res. 36:152-153.

Pyle P. (1997) Molt limits in North American passerines. North American Bird Bander. 22:4989.

R Core Team (2017) R: A language and environment for statistical computing. R Foundation for Statistical Computing, Vienna, Austria. URL https://www.R-project.org/.

Redig, P.T. and Arent, L.R., 2008. Raptor toxicology. Veterinary Clinics of North America: Exoti Anim Pract, 11:261-282.

Rogers TA, Bedrosian B, Graham J, Foresman KR (2012) Lead exposure in large carnivores in the greater Yellowstone ecosystem. J Wild Manage. 76:575-582.

Scheuhammer AM, Bond DE, Burgess NM, Rodrigue J (2003) Lead and stable lead isotope ratios in soil, earthworms, and bones of American woodcock (Scolopax minor) from eastern Canada. Environ Toxicol and Chem. 22:2585-2591.

Schooley T, Weaver M, Mullins D, Eick M (2009) The history of lead arsenate use in apple production: Comparison of its impact in Virginia with other states. Journal of Pesticide Safety Education. 10:22-53.

Slabe VA, Anderson JT, Cooper J, Brown B, Ortiz P, Buchweitz J, McRuer D and Katzner T (2019) Lead in piscivorous raptors during breeding season in the Chesapeake Bay region of Maryland and Virginia, USA. Environ Toxicol and Chem. 38:862-871. (DOI) - 10.1002/etc.4376

Smith DB, Cannon WF, Woodruff LG, Solano F, Kilburn JE, and Fey DL (2013) Geochemical and mineralogical data for soils of the conterminous United States: U.S. Geological Survey Data Series 801, 19 p., https://pubs.usgs.gov/ds/801/.

Strobel BN, Boal CW (2010) Regional variation in diets of breeding red-shouldered hawks. Wilson J Ornithol 122:68-74.

Townsend, KAL (2006) Nesting ecology and sibling behavior of Red-shouldered Hawks at the St. Francis sunken lands wildlife management area in northeastern Arkansas. Ph.D. dissertation, Arkansas State University, Jonesboro.

Therneau T (2015) A Package for Survival Analysis in R. version 2.38, <URL: https://CRAN.Rproject.org/package=survival > .

Weakley, AS, Ludwig JC, Townsend JF, Crowder B (2012) Flora of Virginia. Botanic Research Institute of Texas Press. 
Table 1. Blood lead concentrations (WW, ug/dL) for red-shouldered hawks from the central Appalachians. Data are organized by age class, physiographic region, and land use. Birds were sampled from $2012-2018$. See text for details on age classification; ASY = "after second year", always adult territory holders.

\begin{tabular}{|c|c|c|c|c|c|c|c|c|}
\hline & $\mathrm{n}$ & $\begin{array}{l}95 \% \\
\text { LCL }\end{array}$ & $\begin{array}{l}95 \% \\
\text { UCL }\end{array}$ & $<\mathrm{LOD}$ & Median & Mean & SD & $\mathrm{SE}$ \\
\hline \multicolumn{9}{|c|}{ RSHA Age Group } \\
\hline Adult & 47 & 1.02 & 37.86 & 5 & 6.82 & 12.86 & 24.72 & 2.58 \\
\hline Nestling & 23 & 0.79 & 9.04 & 12 & 2.32 & 3.25 & 2.62 & 0.27 \\
\hline \multicolumn{9}{|l|}{ Region - Adult } \\
\hline Mountains & 27 & 2.51 & 20.36 & 1 & 7.49 & 8.47 & 5.95 & 0.62 \\
\hline Piedmont & 11 & 0.29 & 37.43 & 4 & 3.29 & 10.20 & 15.42 & 1.63 \\
\hline Coastal Plain & 8 & 2.43 & 121.86 & 0 & 8.83 & 31.73 & 55.20 & 5.82 \\
\hline \multicolumn{9}{|c|}{ Region - Nestlings } \\
\hline Mountains & 5 & - & - & 4 & - & - & - & - \\
\hline Piedmont & 10 & 0.82 & 6.99 & 6 & 1.86 & 2.7 & 2.51 & 0.26 \\
\hline Coastal Plain & 8 & 1.46 & 8.84 & 2 & 3.64 & 4.42 & 2.87 & 0.30 \\
\hline \multicolumn{9}{|c|}{ Land Use - ASY } \\
\hline Urban & 21 & 2.72 & 20.51 & 0 & 8.84 & 9.72 & 6.15 & 0.54 \\
\hline Non-urban & 20 & 0.64 & 25.40 & 5 & 3.50 & 7.54 & 10.54 & 1.09 \\
\hline \multicolumn{9}{|c|}{ Land Use - Nestlings } \\
\hline Urban & 5 & 1.81 & 8.64 & 1 & 4.45 & 4.91 & 2.99 & 0.26 \\
\hline Non-urban & 14 & 0.84 & 5.95 & 8 & 1.94 & 2.64 & 2.16 & 0.23 \\
\hline
\end{tabular}

Table 2. Lead concentrations (DW, ppm) for earthworms and soil from the central Appalachians. Samples were collected from 2016 2018 within known red-shouldered hawk territories and always near nests that were being used. Because all lead concentrations were above the LOD, we present minimum and maximum rather than confidence intervals.

\begin{tabular}{lcccccccc}
\hline & $\mathrm{n}$ & $\min$ & $\max$ & $<$ LOD & Median & Mean & SD & SE \\
\hline Soil & 20 & 9.08 & 139.16 & 0 & 22.87 & 36.00 & 19.64 & 4.09 \\
Earthworm & 15 & 1.83 & 88.5 & 0 & 9.40 & 14.89 & 40.69 & 10.51 \\
\hline
\end{tabular}


Figure 1. Physiographic provinces in Virginia and West Virginia including the Coastal Plain, Piedmont, Blue Ridge, Valley and Ridge, and Appalachian Plateau. In this study, we compared samples collected in the Coastal Plain, the Piedmont, and the mountains (Blue Ridge, Valley and Ridge, and Appalachian Plateau)

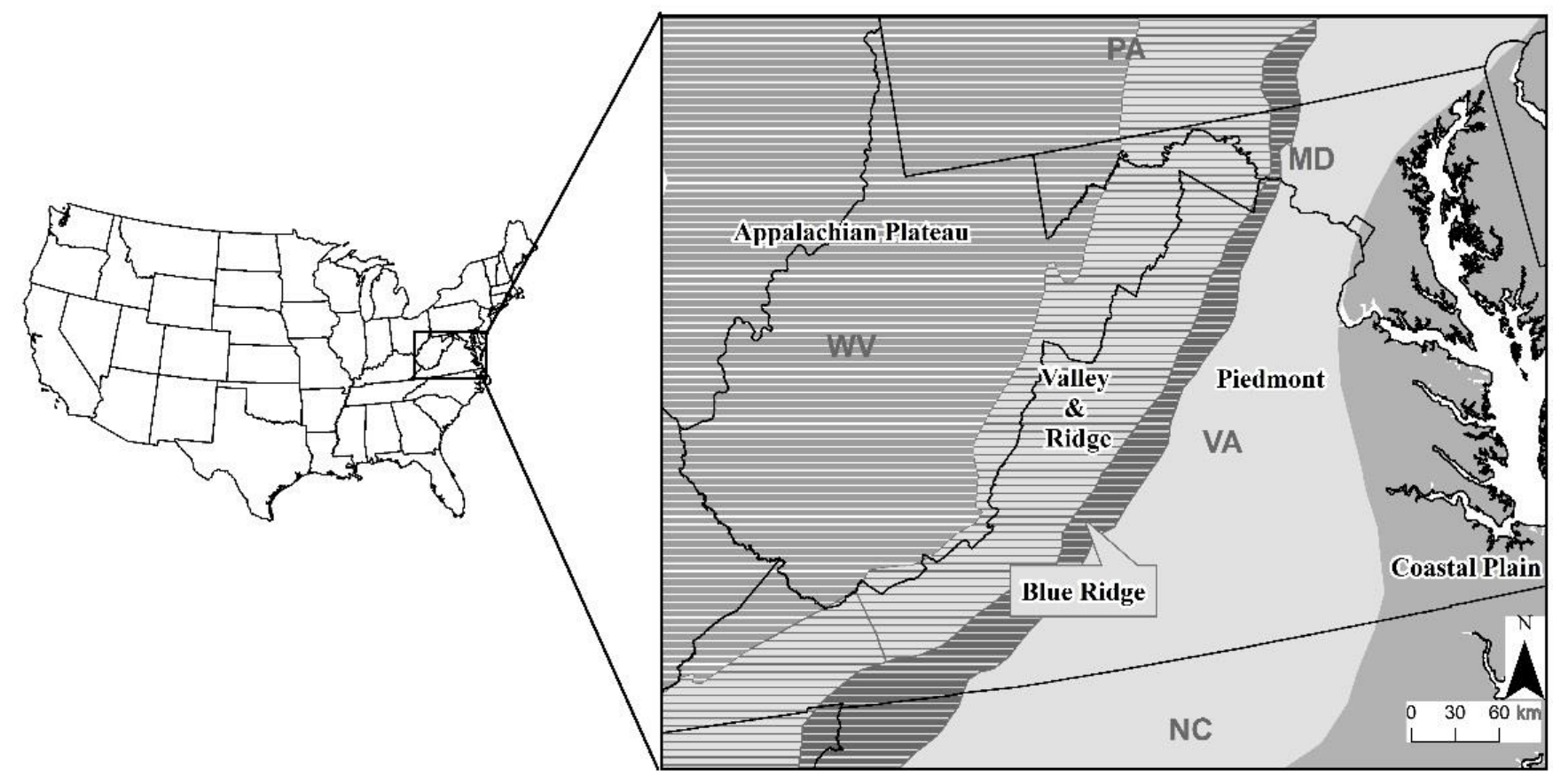


Figure 2. Censored boxplots of blood lead concentrations of red-shouldered hawks from the central Appalachians, USA; (a) adults and nestlings (b) urban and non-urban settings. Boxplots are presented on a log scale to limit the $y$ axis for graphical representation of the data. The line running perpendicular to the y axis represents the censoring threshold for the dataset. Whiskers are extended to include extreme data points.

(a)

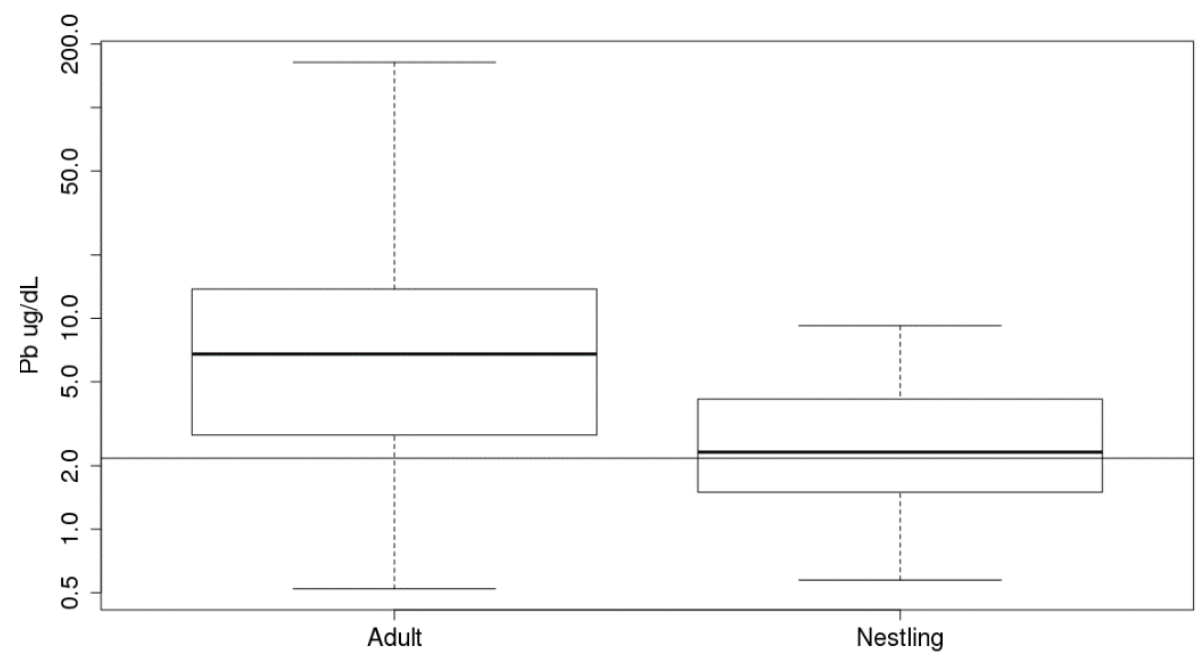

(b)

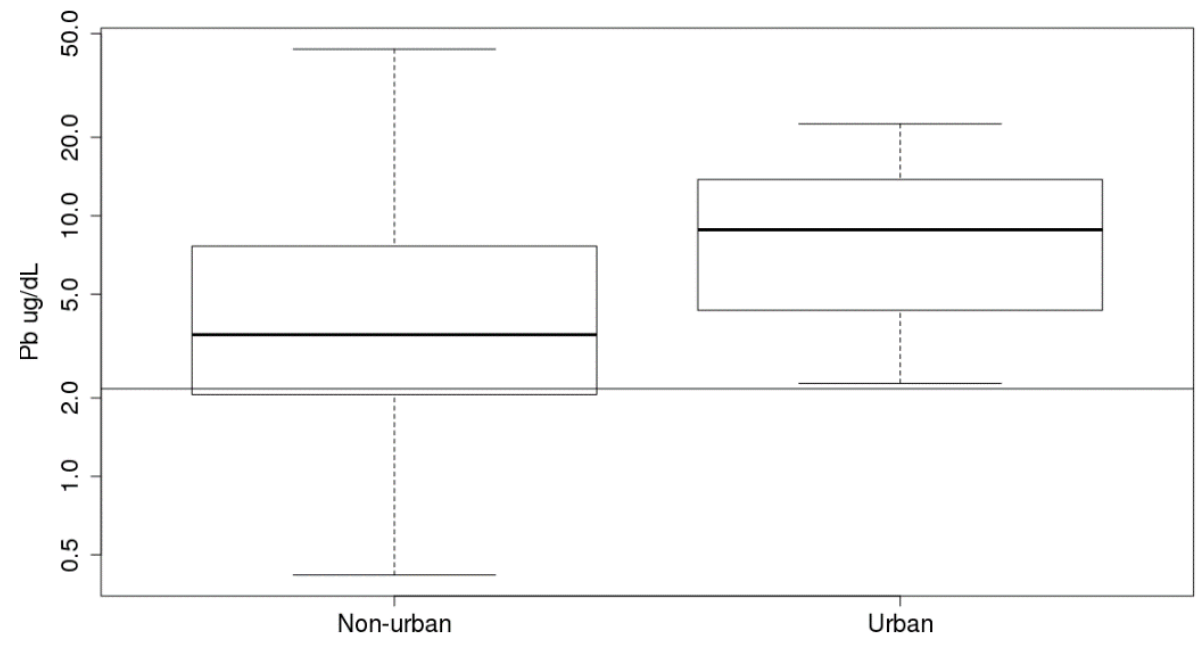




\title{
CHAPTER 4
}

Foraging ecology drives lead exposure of facultative and obligate avian scavengers in eastern North America

\author{
Vincent A. Slabe \\ vaslabe@mix.wvu.edu \\ West Virginia University \\ School of Natural Resources \\ PO Box 6125 \\ Morgantown, WV 26506-6125
}




\section{CHAPTER 4}

\section{Foraging ecology drives lead exposure of facultative and obligate avian scavengers in eastern North America ${ }^{1}$}

Vincent A. Slabe ${ }^{\mathrm{a},{ }^{*}, \text { James T} \text {. Anderson }}{ }^{\mathrm{a}}$, Jeff Cooper ${ }^{\mathrm{b}}$, Tricia A. Miller ${ }^{\mathrm{c}}$, Bracken Brown ${ }^{\mathrm{a}}$, Anna Wrona $^{\mathrm{a}}$, Patricia Ortiz ${ }^{\mathrm{d}}$, John Buchweitz ${ }^{\mathrm{e}}$, Dave McRuer ${ }^{\mathrm{f}}$, Ernesto Dominguez-Villegas $^{\mathrm{f}}$, Shannon Behmke ${ }^{a}$ and Todd Katzner ${ }^{d}$

${ }^{a}$ Division of Forestry and Natural Resources, West Virginia University, Morgantown, WV, USA

${ }^{\mathrm{b}}$ Virginia Department of Game and Inland Fisheries, Richmond, VA, USA

${ }^{\mathrm{c}}$ Conservation Science Global, Cape May, NJ, USA

${ }^{\mathrm{d}}$ US Geological Survey, Forest and Rangeland Ecosystem Science Center, Boise, ID, USA

${ }^{\mathrm{e}}$ Department of Pathobiology and Diagnostic Investigation, Michigan State University, East

Lansing, MI, USA

${ }^{\mathrm{f}}$ Wildlife Center of Virginia, Waynesboro, VA, USA

*Author correspondence to: vaslabe@mix.wvu.edu 


\section{ABSTRACT}

Lead poisoning of scavenging birds is a global issue. However, the drivers of lead exposure of avian scavengers have been understood from the perspective of individual species, not cross-taxa assemblages. We analyzed blood $(n=285)$ and liver $(n=226)$ lead concentrations from a community of 6 facultative and 2 obligate avian scavenger species in eastern North America to identify ecological correlates of lead exposure that might provide insight into assemblage-wide patterns of exposure. Species and age were significant $(\alpha<0.05)$ predictors of blood lead exposure of facultative scavengers, and species, but not age, was a significant predictor of their liver lead exposure. During the spring and summer months when they scavenge less, these species exhibited lower blood and liver lead concentrations than during the fall and winter months when they scavenge more (blood: median $=12.93 \mu \mathrm{g} / \mathrm{dL}$ vs $4.40 \mu \mathrm{g} / \mathrm{dL} ; \mathrm{p}=<0.001$; liver: median $=4.25$ ppm vs $0.32 \mathrm{ppm} ; \mathrm{p}=<0.001)$. We detected between season differences in blood lead concentrations of bald eagles (Haliaeetus leucocephalus) $(\mathrm{p}=0.01)$ and redshouldered hawks (Buteo lineatus) $(\mathrm{p}=0.001)$, and within season differences between red-tailed hawks (Buteo jamaicensis) and bald eagles during the summer months $(\mathrm{p}=0.002)$. Finally, during summer months, obligate scavengers had substantially higher liver lead concentrations than did facultative scavengers (median $=1.76 \mathrm{ppm}$ vs $0.22 \mathrm{ppm} ; \mathrm{p}=<0.001)$. These data suggest that feeding ecology of avian scavengers is tightly tied to the degree to which they are lead exposed and they highlight the importance of ecological and behavioral variation in determining lead exposure. When species- and season-specific variation in foraging behavior is well understood, it may be possible to predict broad-scale and assemblage-wide patterns in relative lead exposure of avian scavengers. 


\section{INTRODUCTION}

Predators and scavengers are high on the food chain and therefore good indicators of environmental health and of the overall effects of contaminants on ecological communities (Helander et al. 2008). For example, dichlorodiphenyltrichloroethane (DDT) was widely used throughout North America and it contributed to population declines of at least 3 species of predatory birds (Ratcliffe 1967, Wiemeyer et al. 1984). These declines were also indicative of the system-wide effects of this toxin, resulting in demographic consequences for multiple other species (Hoffman et al. 2002). Similarly, in some regions, mercury bio-magnifies through aquatic food chains, with increasing system effects at higher trophic levels (Lawson and Mason 1998). This toxin can ultimately lead to negative effects on multiple species in piscivorous raptor communities (Scheuhammer et al. 2007). Furthermore, in Africa and India, poisoning has resulted in the decline of Old World vulture communities (Ogada et al. 2012). The decline of this scavenging community results in the spread of disease to wildlife and humans from carcasses that would be otherwise consumed (Markandya et al. 2008). In each of these three cases, the study of raptors at the top of the food chain was instrumental in identifying the mechanisms by which these contaminants travel through environmental systems.

Of the toxicants that move through ecosystems, lead is one of the most frequently documented (Franson and Pain 2011). The pathway by which most birds are exposed to anthropogenic lead is by incidental ingestion (Katzner et al. 2018). The unintentional ingestion of lead particles in the form of paint, fishing equipment, and used hunting projectiles also is documented for multiple bird species (Sileo and Fefer 1987, Finkelstein et al. 2012, CruzMartinez et al. 2012). The pathways of lead exposure by birds are varied such that waterfowl 
consume fishing tackle and spent ammunition (Franson et al. 2003), waterbirds ingest contaminated sediment (Blus et al. 1999), and avian scavengers feed on gut piles and unretrieved game harvested with lead ammunition (Haig et al. 2014).

Of the species affected by lead, avian predators and scavengers may be the most susceptible due to their diet (Krone 2018, Nadjafzadeh et al. 2013). Scavenging birds have evolved a low $\mathrm{pH}$ in their digestive tract that protects them from food-borne pathogens. In fact, the degree to which a vertebrate scavenges can dictate the amount of acidity in the digestive tract (Beasley et al. 2015). However, this acidic environment exposes the birds to non-bacterial dangers, as metals such as lead break down easily at low $\mathrm{pH}$ and therefore can be quickly assimilated in the bloodstream. As a result, scavenging birds such as New World vultures (e.g., California condors (Gymnogyps californianus) and Andean Condors (Vultur gryphus) are highly susceptible to lead poisoning (Finkelstein et al. 2012, Lambertucci et al. 2011).

Despite the many studies of lead exposure that focus on a single species at a time, there are few broader studies documenting the extent to which lead exposure may be spatially and temporally synchronized across multiple species. Comparing toxicant exposure among multiple species can be informative about sources of exposure. In the case of lead, studying species with similar, but not identical, feeding behaviors can provide insights into how an animal's ecology determines its lead exposure. For example, a study in Sweden illustrated how ecological factors such as habitat preference and foraging behavior can drive differing levels of lead exposure of multiple scavenging bird species (Ganz et al. 2018).

As top predators who respond strongly to lead poisoning, it should therefore be informative to characterize lead exposure of multiple avian predators and scavengers within a single community assemblage. This is in part because, although most members of this group 
scavenge, there are substantial ecological and behavioral differences in how and when they do so. In fact, these birds may use carrion as their only source of food ("obligate scavengers") or they may take either live or dead prey ("facultative scavengers"). Furthermore, the class of facultative scavengers includes those that may scavenge all year long as well as others that scavenge only during a specific season of the year. These behavioral differences could result in species-specific patterns of lead exposure. Study of those patterns therefore should provide insight into routes of exposure and the significance of different sources of lead in the ecosystem.

We investigated how lead moved through the ecosystem by documenting lead concentrations in a suite of ecologically and behaviorally different scavenging birds. The data we evaluated include blood and liver lead concentrations from members of an assemblage of facultative and obligate avian predators and scavengers. Because we collected data across the full annual cycle, we were able to evaluate how lead concentrations varied by season, species and whether a bird was sampled in a rehabilitation facility or in the wild. Furthermore, the work was also relevant because data were collected in eastern North America, an area in which there have been only a few studies of lead exposure of free flying raptors and corvids (Behmke et al. 2015, 2017, Slabe et al. 2019) other studies have focused on nestlings (Rattner et al. 2008) or birds admitted at rehabilitation facilities (Harris and Sleeman 2007). To understand how speciesspecific variation in foraging behavior influences lead exposure, we evaluated how lead concentrations varied (a) among facultative scavengers within and between seasons; and (b) between facultative and obligate scavengers within a single season. In all cases, we hypothesized that lead exposure would correlate with variation in the degree to which a species scavenged. Thus, we predicted the following: 1) facultative scavengers would experience inter-seasonal variations in lead concentrations; 2) facultative scavengers with greater dependence on 
scavenging would have higher lead levels; and 3) by necessity, obligate scavengers would have higher levels of exposure than facultative scavengers.

\section{METHODS}

Study area and focal species

We studied lead exposure in facultative and obligate avian scavengers in the eastern US states of Alabama, Georgia, Maryland, New Jersey, New York, North Carolina, Pennsylvania, Tennessee, Virginia, and West Virginia. This region of eastern North America hosts a community of facultative and obligate avian scavengers including members of the Families Accipitridae, Corvidae, and Cathartidae. These birds forage in a variety of habitats ranging from coastal wetlands to the high elevation ridges and valleys of the Appalachian Mountains. These foraging areas occur near urban centers and in remote and forested tracts of wilderness. The time of year, latitude, and altitude determine the specific assemblages of avian scavengers present at any one time. Furthermore, regardless of which species are present, this community utilizes a wide range of carrion including that from domestic livestock, roadkill, nuisance wildlife, and hunter-harvested animals.

We evaluated lead exposure of 5 species of facultative scavengers in eastern North America. These were American crows (Corvus brachyrhynchos), bald eagles (Haliaeetus leucocephalus), golden eagles (Aquila chrysaetos), red-shouldered hawks (Buteo lineatus) and red-tailed hawks (Buteo jamaicensis). The American crow is a human commensal, widespread throughout North American, and its year-round diet includes a variety of food sources including carrion (Marzluff et al. 2001). Bald eagles are found throughout the year in eastern North America and the local population at our study site can include individuals that migrated from the north, others that migrated from the south, and others that are year-round residents (Watts et al. 2008). Golden eagles do not breed in the eastern US but those that nest in the eastern Canadian 
provinces are long-distant migrants that winter from Maine south to Alabama (Katzner et al. 2012). Both eagle species are known to scavenge year-round but do so more frequently in the winter months when live prey is less abundant. Red-shouldered hawks and red-tailed hawks are year-round residents or short distance migrants throughout most of their range in eastern North America. These birds are known to opportunistically scavenge during the winter months when live prey is less abundant (Jachowski et al. 2015).

We also collected data from two species of obligate scavengers, black vultures (Coragyps atratus) and turkey vultures (Cathartes aura). Both vulture species are year-round residents in eastern North America, from Pennsylvania south to Florida (Buckley 1999, Kirk and Mossman 1998). Turkey vultures with breeding territories in the northeastern states usually spend the winters in the southern US states and southward to South America. Black vultures make seasonal movements that are less well known. Black vultures and turkey vultures scavenge year-round on nearly any carrion they encounter.

\section{Data collection}

We collected liver samples from all seven species we considered and blood samples from the five facultative scavengers only. Blood samples were collected throughout the region during the period 2010 to 2018 , from wild birds upon capture or within 48 hours of being admitted to a rehabilitation facility. Liver samples were collected from 2012 to 2018 in the state of Virginia. These were taken from bird mortalities recovered by both state and federal agencies, birds euthanized within 72 hours of admittance to licensed raptor rehabilitation facilities, birds donated by falconers and hunters (American crows), or birds culled by the United States Department of Agriculture. In the case of rehabilitation facilities, only blood collected within the first 48 hours after admission, or liver within the first 72 hours, post-mortem, were used in this study, a 
protocol based on communications with pathologists at the National Wildlife Health Center (NWHC) (NWHC unpublished data).

We captured live birds with mist nets, mini-net launchers, rocket nets and bow nets. Once in hand, we banded the birds and used $20-27$-gauge needles and $3 \mathrm{~mL}$ syringe to draw $1-3 \mathrm{~mL}$ of blood from the brachial vein. We immediately transferred the blood to a low lead BD Vacutainer (BD Vacutainer@) and placed it in a cooler for the remainder of the field day before being stored in a refrigerator. When possible, we aged the birds as adult or pre-adult based on published methods for aging raptors (McCollough 1989, Pyle 1997).

Sample processing and laboratory analysis

We prepared whole blood samples by drawing aliquots of $100-400 \mu \mathrm{L}$ from vacutainers and pipetting them in to $1 \mathrm{~mL}$ microcentrifuge tubes. When blood was clotted, we recorded wet weights, dried the samples in a $95^{\circ} \mathrm{C}$ oven, and we recorded the dry weights prior to digestion. All blood data are reported as wet weight by converting the dry weight results with the dry:wet weight ratio as previously described (Slabe et al. 2019).

We collected a single liver lobe from birds during post-mortem tissue harvest. To ensure no cross-contamination between individuals, we used separate disposable scalpel blades for each bird. Other instruments were cleaned with a bleach solution after tissue harvesting events. Liver samples were immediately placed in a plastic bag and stored in a freezer. For preparation, liver samples were thawed to room temperature and a $1 \mathrm{~g}( \pm 0.05 \mathrm{~g})$ section of liver was weighed wet, dried, and weighed again. All samples were sent to the Michigan State Veterinary Diagnostic Laboratory (MSU-VDL) for lead concentration analyses.

At MSU-VDL, liver and blood samples were digested in nitric acid, diluted with Millipore water and analyzed with an Agilent 7900 inductively coupled mass spectrometer (ICP- 
MS) (Agilent Technologies, Santa Clara, CA) fitted with a Cetac Auto Sampler (Cetac, Omaha, NE) and Micro Mist Nebulizer (Agilent) at MSU-VDL. For accuracy, the machine was calibrated for lead concentration determinations with $1000 \mathrm{ug} / \mathrm{mL}$ stock solutions (Alfa Aesar, Ward Hill, MA) in accordance with standard operation procedures published by the manufacturer (Agilent Technologies 2008). Standard reference materials (SRM) were used for matrix matched quality control of lead concentrations and initial instrument calibrations (Slabe et al. 2019). Data on liver lead concentrations are reported on a dry weight basis (DW) in parts per million (ppm) and blood lead concentrations are reported on a wet weight basis (WW) in migrograms per deciliter $(\mu \mathrm{g} / \mathrm{dL})$.

\section{Organizing data}

We described blood and liver sample collection as occurring in one of two time periods: post-hatching and scavenging. We defined the post-hatching season as the time period that started when eggs hatched and that ended when the scavenging season began. We defined the scavenging season as the period that started when field data suggested that facultative scavengers had switched to a greater proportion of dead prey in their diet and that ended when the posthatching season began. We considered lead concentrations of $>40 \mu \mathrm{g} / \mathrm{dL} \mathrm{WW}$ in blood and $>20$ ppm DW in liver to be indicative of clinical lead poisoning, or the threshold by which the physiological effects of lead are existent (Fallon et al. 2017, Franson and Pain 2011). We considered lead concentrations > LOD to be indicative of anthropogenic exposure, or the threshold by which anthropogenic lead is present in biological tissue but below a concentration by which the bird is thought to experience adverse health effects (Franson and Pain 2011).

Hatching dates are species specific. As such, the beginning of the post-hatching season was unique to each species and defined based on breeding records specific to eastern North 
America (Rodewald 2015). The longest post-hatching season was for bald eagles (March 15 October 31), followed by red-shouldered hawks and American crows (April 15 - October 31). The shortest post-hatching season was for red-tailed hawks (May 1 - October 31). There were no post-hatching samples from golden eagles.

The scavenging season started on 01 November. We chose this date because game cameras in the Appalachian Mountains documented scavenging of all study species as early as the month of November (Slabe unpublished data). It is unlikely that all facultative scavengers reduce foraging on live prey in concert with each other. In the absence of species-specific knowledge, selection of this date seemed a reasonable way to evaluate seasonal differences in lead exposure. The scavenging season ended the day before the post-hatching season began. We chose this date because some raptors are known to scavenge early in the breeding season during the courtship, egg-laying and incubation periods.

\section{Statistical analyses}

Many of the liver and blood lead concentrations recorded were below the analytical limits of detection (LODs) and the data were not normally distributed. As such, we used the KaplanMeier method to calculate summary statistics based on a cumulative probability distribution using package 'NADA' in program R. (Helsel 2012, Lee 2017, R Core Team 2017). LODs were dependent on sample volume and ranged from $0.083-3.52$ ppm DW in livers and from $1-2.17$ $\mu \mathrm{g} / \mathrm{dL} \mathrm{WW}$ in blood samples.

We evaluated how lead concentrations varied among facultative scavengers (our first research objective) using tobit regression models with a stepwise variable selection process using package 'survival' in the R program (Therneau 2015). Tobit regression models are specifically designed to estimate linear relationships between variables when the dependent variable is 
censored (Tobin 1958). We tested for the influence of multiple variables to explain variation of log-transformed liver and blood lead concentrations of facultative scavengers, in the aggregate, between seasons. The variables we tested included season and species, which were the two variables in our research question. We also tested age and the disposition, i.e., whether the bird was free-flying or in a rehabilitation facility when sampled. If age was present in the final model, we included this variable as a random effect since it was outside the scope of our research objectives. If we detected a disposition-induced difference, we excluded rehabilitation birds from subsequent analyses. When the season and species variables were present as significant effects in the final model, we ran the Peto and Peto modification of the Gehan-Wilcoxon multiple comparisons test, with the data grouped by season and species, using package 'survminer' in R (Kassambara and Kosinski 2018). We organized the data so that these tests specifically compared each species between seasons and each species to others within a single season. We used the Peto and Peto Gehan-Wilcoxon test because it accommodates censored data and does not require substitution methods. Unfortunately, because our data had unequal censoring between groups, this test can have limited power (Helsel 2012). Despite this, we felt this test was the most appropriate comparative statistical method available for our data.

To compare lead levels of facultative scavengers to obligate scavengers within a single season (our second research objective), we fit a tobit regression model with covariates for scavenger type (obligate or facultative), species and disposition. We applied the same rule as above for disposition. If we determined that season and species were significant effects in the final model, we grouped the data by season and species and again ran a multiple comparison test.

For all of the above tobit models, lead concentration was the dependent variable and the dataset included a separate column identifying specific left-censored concentrations below the 
LOD. We removed individual predictor variables from each model iteration in a stepwise manner based on p-values using the standard threshold of $p<0.05$ (Aldridge and Boyce 2007). We stopped removing variables when all $p$-values were below the significance threshold.

\section{RESULTS}

We tested blood lead concentrations for 285 wild facultative scavengers from eastern North America (Table 1a, Figure 1a). Of these, 156 were sampled within 24 hours of admission to rehabilitation facilities (Table 2b). The other 129 were sampled in the field. Of the blood samples analyzed, $13 \%(\mathrm{n}=37 ; 22$ bald eagles, 10 golden eagles, 4 red-shouldered hawks, and 1 red-tailed hawk) were above the threshold for clinical poisoning and 10\% ( $\mathrm{n}=26 ; 1$ American crow, 12 bald eagles, 1 golden eagle, 9 red-shouldered hawks, and 3 red-tailed hawks) fell below the instrument's LOD.

Of 285 total blood samples, 129 were collected during the post-hatching season (6 American crows, 64 bald eagles, 33 red-shouldered hawks and 26 red-tailed hawks) and 156 during the scavenging season (5 American crows, 48 bald eagles, 57 golden eagles, 24 redshouldered hawks and 22 red-tailed hawks) (Table 2a). Of the samples collected during the posthatching season, $4 \%(\mathrm{n}=5$ bald eagles) were above the threshold for clinical poisoning (40 $\mu \mathrm{g} / \mathrm{dL})$ and $18 \%(\mathrm{n}=23 ; 1$ American crow, 11 bald eagles, 9 red-shouldered hawks, and 2 redtailed hawks) were below the LOD (Fallon et al. 2017, Pokras and Kneeland 2008). During the scavenging season, $21 \%(\mathrm{n}=32 ; 17$ bald eagles, 10 golden eagles, 4 red-shouldered hawks, and 1 red-tailed hawk) of samples were above the threshold for clinical poisoning and $3 \%(\mathrm{n}=3 ; 1$ bald eagle, 1 golden eagle and 1 red-tailed hawk) were below the LOD.

We also tested the liver lead concentrations for 122 wild facultative scavengers from eastern North America (Table 1b, Fig 1b). Of these, 38 birds were sampled after being 
euthanized or after having died on their own within 72 hours of admission to a rehabilitation facility (the Wildlife Center of Virginia; WCV and the Avian Conservation Center of Appalachia; ACCA) (Table 2b). Of the facultative avian scavenger liver samples tested, considering all time periods, 25\% $(\mathrm{n}=30 ; 20$ American crows, 8 bald eagles, and 2 red-tailed hawks) of samples were above the threshold for clinical poisoning and $22 \%(n=27 ; 10$ American crows, 4 bald eagles, 2 red-shouldered hawks, and 11 red-tailed hawks) fell below the LOD (Table 2b).

Sixty-four of the livers included in this study were collected from facultative scavengers in the post-hatching season (13 American crows, 25 bald eagles, 8 red-shouldered hawks and 18 red-tailed hawks) (Table 2a). Of these, 9\% $(\mathrm{n}=6 ; 1$ American crows, 3 bald eagles, and 2 redtailed hawks) had lead concentrations above the reported threshold for clinical poisoning and $34 \%(\mathrm{n}=22 ; 5$ American crows, 4 bald eagles, 2 red-shouldered hawks, and 11 red-tailed hawks) were below the LOD. The other 58 livers we considered were collected during the scavenging season (43 American crows, 12 bald eagles, and 3 red-tailed hawks). Of these, $41 \%$ ( $\mathrm{n}=24 ; 19$ American crows and 5 bald eagles) had liver lead concentrations above the threshold for clinical poisoning and 9\% $(\mathrm{n}=5 ; 5$ American crows $)$ were below the LOD.

\section{Season and species-specific differences of lead exposure of facultative avian scavengers}

We detected between-season differences in blood lead concentrations of facultative avian scavengers (Table 2a, 3a). When considered as a single group, aggregated across species, blood lead concentrations of facultative scavengers were higher during the scavenging season than during the post-hatching season $(\mathrm{p}=<0.001)$. Similarly, liver lead concentrations of aggregate facultative avian scavengers also were statistically higher during the scavenging season than during the post-hatching season $(\mathrm{p}=<0.001)$. Disposition was not a significant predictor of 
blood or liver lead exposure and therefore not included in the final blood or liver models (Table 2b, 3a). Age was a significant predictor of blood lead concentrations but not of liver lead concentrations of facultative scavengers. Therefore, we included age as a random effect in the final blood model.

For blood lead concentrations, we detected seasonal differences for some, but not all, of the individual species of avian scavengers we tested (Table 2a, Figure 1a). Bald eagles $(\mathrm{p}=0.01)$ and red-shouldered hawks $(\mathrm{p}=0.001)$ had higher blood lead concentrations during the scavenging season than during the post-hatching season. In contrast, we did not detect a seasonal difference in blood lead concentrations of American crows $(\mathrm{p}=0.4)$ or red-tailed hawks $(\mathrm{p}=$ $0.2)$.

For liver lead concentrations, we again detected seasonal differences for some, but not all, of the individual species of avian scavengers we tested (Table 2a, Figure 1b). The only species that had similar patterns in liver lead concentrations as in blood lead concentrations were red-tailed hawks (no difference between scavenging and post-hatching seasons; $p=0.1$ ). In contrast, the other two species for which we had sufficient numbers of samples, bald eagles and American crows showed opposite patterns (no difference for the eagle $(p=0.2)$, higher in scavenging season for the crow $(\mathrm{p}=0.004)$.

Finally, aggregated across seasons, we did not detect differences in blood lead concentrations among species (Table 2a, Figure 1a). In contrast, during the post-hatching season, bald eagles had higher liver lead concentrations than did red-tailed hawks $(\mathrm{p}=0.002)$ (Figure 1b). There were no other within-season differences in liver lead levels within either season. 


\section{Within season comparison of lead exposure of obligate and facultative avian scavengers}

We tested liver lead concentrations from 104 obligate avian scavengers and 50 facultative avian scavengers that were collected during the months of April, May, June and July (see Fig 2 for species-specific sample sizes; the 72 other liver samples from facultative avian scavengers were collected outside these months and thus, we considered them to be less useful for direct comparison to the obligate scavenger samples). Of the facultative avian scavengers tested during this period, 35\% ( $\mathrm{n}=17$; 1 American crow, 3 bald eagles, 2 red-shouldered hawks, and 11 redtailed hawks) fell below the LOD. All lead concentrations from livers of obligate avian scavengers were above the LOD. Less than $1 \%$ of lead concentrations from livers of obligate avian scavengers were above the threshold reported for clinical lead poisoning $(\mathrm{n}=1$ black vulture), and $4 \%$ of the lead concentrations from livers of facultative obligate scavengers were above that threshold ( $\mathrm{n}=2 ; 1$ American crow and 1 red-tailed hawk).

Scavenger type and species were significant predictors of within-season lead concentrations of the birds we considered (Table 3b). However, disposition was not a significant predictor of within-season lead exposure. When considered as a group and aggregated across species, livers of obligate avian scavengers had higher lead concentrations than did livers of facultative avian scavengers $(\mathrm{p}=<0.001)$. In contrast to the within-season comparisons done exclusively for facultative avian scavengers (above), here we did detect substantial pairwise differences among species (Fig 2). Liver lead concentrations of black vultures were higher than those of American crows $(\mathrm{p}=0.001)$, bald eagles $(\mathrm{p}=<0.001)$, red-shouldered hawks $(\mathrm{p}=<$ 0.001), and red-tailed hawks $(\mathrm{p}=<0.001)$. Likewise, liver lead concentrations of red-tailed hawks were lower than those of bald eagles $(\mathrm{p}=0.006)$ and turkey vultures $(\mathrm{p}=0.02)$. 


\section{DISCUSSION}

These data suggest that our hypothesis accurately predicted a link between feeding ecology and subsequent lead exposure of scavenging birds. In fact, the degree to which these species scavenge is a primary determinant of their liver and blood lead concentrations. This was true when we compared facultative avian scavengers across their annual cycle and when we compared facultative vs obligate scavengers within a single season. These findings highlight the importance of ecological and behavioral variation in determining the overall lead exposure of avian scavengers. Furthermore, this study suggests that it may be possible to predict broad, assemblage-wide patterns in relative levels of lead exposure of avian scavengers based on an understanding of species- and season-specific variation in foraging behavior.

\section{Lead exposure response of facultative scavengers to seasonal and ecological variation}

The differences observed in blood and liver lead concentrations between seasons should be interpreted in the context of how acute exposure events affect these two tissue types. In particular, lead persists in the liver for a longer time after exposure events than it does in the blood. As such, a point in time comparison is more likely to detect among-group differences in blood lead concentrations than in liver lead concentrations. This likely explains why we detected a seasonal difference in bald eagle blood lead concentrations but not in liver lead concentrations. We attribute the lack of seasonal differences in American crow blood to the small sample size that was available for this species.

Despite these challenges in cross-tissue comparison, the seasonal variation in lead exposure generally suggested that facultative avian scavengers are more commonly exposed to lead during the scavenging season. Since elevated lead concentrations in predatory and scavenging birds are known to be caused by incidental ingestion of metallic lead (Manning et al. 2019), our data highlight the importance of two seasonal processes that drive lead poisoning in 
this community. The first process is the variation in foraging ecology between seasons exhibited by these species. The second is the correlation of this seasonal change in feeding behavior to the availability of fragmented lead projectiles in carrion (Cruz-Martinez et al. 2012, Hunt et al. 2006). Our data, therefore, can be used to infer that the correspondence in timing of these ecological and anthropogenic processes is driving the lead exposure of these birds.

There were unexpected patterns in lead exposure for different tissues of individual species between seasons. We observed seasonal differences in American crow but not in bald eagle liver lead concentrations. However, we detected no inter-seasonal differences in our small data set of blood lead concentrations from American crows. This runs contrary to previous work suggesting elevated blood lead concentrations during big game hunting seasons in the closely related common raven (Corvus corax) (Craighead and Bedrosian 2008). We observed the opposite pattern for bald eagles between seasons - a significant difference in blood lead concentrations, but not in liver. Free flying bald eagles and American crows are known to feed opportunistically during all times of the year and the variation in our data suggest that these birds may consume lead-contaminated food sources year-round. In particular, the tendency for both of these species to feed on human refuse could easily lead to lead exposure from other anthropogenic sources such as paint, plastics and common trash items (Elliott et al. 2006, Franzen-Klein et al. 2018). This finding suggests that there may be sources of lead exposure in addition to lead contaminated offal for facultative scavengers that are also human commensals.

We observed one difference in lead exposure among species within the post-hatching season. This was between liver lead concentrations of red-tailed hawks and of bald eagles. Presumably both these species are focused on live prey during the post-hatching season. However, bald eagles initiate the nesting season earlier than red-tailed hawks, during a time of 
year when few live prey items are available. As a result, bald eagles are more likely to scavenge during the courtship and egg laying periods, a behavior that could result in elevated liver lead concentrations during the post-hatching season. This finding suggests that facultative scavengers with earlier breeding seasons may be more susceptible to the potential negative effects of lead during the breeding period.

Of the 32 blood samples in the range of clinical lead poisoning during the scavenging season, $84 \%$ were from bald and golden eagles and $16 \%$ were from the Buteo hawks. While there is limited information on lead exposure for red-tailed hawks and red-shouldered hawks (Martin et al. 2008), there is some evidence to suggest Buteo species scavenge less frequently than eagles and corvids in eastern North America (Jachowski et al. 2015). Furthermore, there is an established correlation between the feeding ecology of North American eagles and elevated lead concentrations (Bedrosian et al. 2012, Cruz-Martinez et al. 2012, Kramer and Redig 1997, Langner et al. 2015). The extent to which eagle species scavenge in comparison to Buteo species likely explains the higher incidence of clinical lead poisoning in these birds.

\section{Response of lead exposure to behavioral variation among types of scavengers}

Obligate avian scavengers were exposed to lead to a greater degree in the post-hatching season than were facultative avian scavengers. The differences in the foraging ecology of these two scavenger groups appears to drive these patterns. The facultative scavengers we studied consumed substantially less carrion when they had nestlings. In contrast, obligate scavengers exhibit a year-round feeding behavior that leaves them more vulnerable to toxicants incidentally ingested through scavenging. In California, turkey vultures exhibited a decrease in blood lead concentrations after lead ammunition was banned in the range of the California condor (Kelly et al. 2011). In addition to ammunition in carcasses and gut piles, vultures can be exposed to lead in 
other ways. For example, the vultures tested for this study were culled because they engaged in nuisance behaviors resulting in the destruction of buildings and vehicles. The materials used for building construction and car parts can contain lead. Additionally, vultures are known to forage at garbage dumps and they may ingest lead when they do so (Plaza and Lambertucci 2019). Lead exposure of free flying birds vs. birds sampled at rehabilitation facilities

The lack of differences in lead concentrations between free flying birds and birds admitted at rehabilitation facilities within our dataset is an important finding. It is widely reported that birds experiencing toxicological stress have increased susceptibility to injury, disease and death, and thus are more likely to be admitted at rehabilitation facilities (Ecke et al. 2017, Finkelstein et al. 2012, Kelly and Kelly 2005). As a result, many researchers dismiss lead concentration data collected from birds admitted at rehabilitation facilities because they assume that these data poorly represent lead exposure of the wider free-flying population. Since disposition was not a significant predictor of lead concentrations in any of our models, our data suggests that lead concentrations of admitted birds were similar to that of free flying birds, regardless of the underlying reasons for admission or eventual cause of death. This finding validates the use of data collected from admitted birds to address certain research objectives such as those targeted at understanding toxicant concentrations in wild populations.

\section{Conclusions - ecological and behavioral drivers of lead exposure}

Our work identifies the significance of animal behavior and ecology in determining lead exposure. In this case, seasonal and species-specific behavioral and ecological differences determined the extent each species is exposed to lead. Thus, these differences appear to be a primary driver of lead exposure in scavenging birds. 
We draw 2 additional conclusions from this work. First, our study illustrates that lead exposure is a potential indicator of the ecological health of the scavenging community in eastern North America. Prior North American studies of lead exposure in predatory and scavenging birds have mostly been conducted in the western states. Thus, as the first study to focus on these species in eastern North America, this paper fills an important spatial gap in our knowledge.

Secondly, this work highlights the importance to simultaneously evaluating lead exposure in a community of avian scavengers. More specifically, many of the inferences drawn about the ecological differences in this community were stronger because we looked at multiple species simultaneously. The logical conclusion of our work is that it is reasonable to make projections about lead exposure based on foraging behavior of a given species. These conclusions from our multi-species dataset strengthen and expand the geographic extent of evidence in the scientific literature that lead poisoning is a significant driver of the ecological health of both facultative and obligate avian scavengers.

\section{ACKNOWLEDGMENTS}

L. Rhea, L. Montague, J. Borkholder, M. Kirchgessner, J. Slabe, J. Fallon and D. Schmidt assisted with laboratory work. E. Frank, M. Lanzone and D. Haines assisted with field work. The Avian Conservation Center of Appalachia provided a small number of blood samples. Field work was covered under WVU's IACUC protocol \#1603001797, federal banding permits \#23715 and \#06560. We thank who assisted with the improvement of this manuscript. This

publication was completed with funds provided by VDGIF through a Federal Aid in Wildlife Restoration grant from the USFWS, contract \#2013-14308. JA was supported by the NSF (OIA1458952) and the USDA National Institute of Food and Agriculture, McIntire Stennis project WVA00117 during manuscript preparation. Any use of trade, product or firm names is for 
descriptive purposes only and does not imply endorsement by the U.S. Government. This is scientific article number XXXX of the West Virginia University Agricultural and Forestry Experiment Station, Morgantown, West Virginia. 


\section{REFERENCES}

Agilent Technologies. 2008. Agilent 7500 Series ICP-MS hardware manual. Agilent Technologies, Inc.

Aldridge, C.L., Boyce, M.S., 2007. Linking occurrence and fitness to occurrence: Habitat-based approach for endangered greater sage-grouse. Ecological Applications 17, 508-526. https://doi.org/10.1890/05-1871

Beasley, D.E., Koltz, A.M., Lambert, J.E., Fierer, N., Dunn, R.R., 2015. The evolution of stomach acidity and its relevance to the human microbiome. PLOS ONE 10, e0134116. https://doi.org/10.1371/journal.pone.0134116

Bedrosian, B., Craighead, D., Crandall, R., 2012. Lead exposure in bald eagles from big game hunting, the continental implications and Successful Mitigation Efforts. PLoS ONE 7, e51978. https://doi.org/10.1371/journal.pone.0051978

Behmke, S., Fallon, J., Duerr, A.E., Lehner, A., Buchweitz, J., Katzner, T., 2015. Chronic lead exposure is epidemic in obligate scavenger populations in eastern North America. Environment International 79, 51-55. https://doi.org/10.1016/j.envint.2015.03.010

Blus, L.J., Henny, C.J., Hoffman, D.J., 1999. Persistence of high lead concentrations and associated effects in tundra swans captured near a mining and smelting complex in northern Idaho. Ecotoxiology 8, 125-132

Buckley, N. J. (1999). Black Vulture (Coragyps atratus), version 2.0. In The Birds of North America (A. F. Poole and F. B. Gill, Editors). Cornell Lab of Ornithology, Ithaca, NY, USA. https://doi.org/10.2173/bna.411

Craighead, D., Bedrosian, B., 2008. Blood lead levels of common ravens with access to biggame offal. Journal of Wildlife Management 72, 240-245. https://doi.org/10.2193/2007120

Cruz-Martinez, L., Redig, P.T., Deen, J., 2012. Lead from spent ammunition: a source of exposure and poisoning in bald eagles. Human-Wildlife Interactions 6, 94-104.

Ecke, F., Singh, N.J., Arnemo, J.M., Bignert, A., Helander, B., Berglund, Å.M.M., Borg, H., Bröjer, C., Holm, K., Lanzone, M., Miller, T., Nordström, À., Räikkönen, J., Rodushkin, I., Ågren, E., Hörnfeldt, B., 2017. Sublethal lead exposure alters movement behavior in free-ranging golden eagles. Environmental Science \& Technology 51, 5729-5736. https://doi.org/10.1021/acs.est.6b06024

Elliott, K.H., Duffe, J., Lee, S.L., Mineau, P., Elliott, J.E., 2006. Foraging ecology of bald eagles at an urban landfill. The Wilson Journal of Ornithology 118, 380-390. https://doi.org/10.1676/04-126.1

Fallon, J.A., Redig, P., Miller, T.A., Lanzone, M., Katzner, T., 2017. Guidelines for evaluation and treatment of lead poisoning of wild raptors: Guidelines for lead poisoned raptors. Wildlife Society Bulletin 41, 205-211. https://doi.org/10.1002/wsb.762

Finkelstein, M.E., Doak, D.F., George, D., Burnett, J., Brandt, J., Church, M., Grantham, J., Smith, D.R., 2012. Lead poisoning and the deceptive recovery of the critically endangered California condor. Proceedings of the National Academy of Sciences 109, 11449-11454. https://doi.org/10.1073/pnas.1203141109

Franson, J.C., Hansen, S.P., Creekmore, T.E., Brand, C.J., Evers, D.C., Duerr, A.E., DeStefano, S., 2003. Lead fishing weights and other fishing tackle in selected waterbirds. Waterbirds 26, 345-352. https://doi.org/10.1675/1524-4695(2003)026[0345:LFWAOF]2.0.CO;2

Franson JC, Pain DJ. 2011. Environmental Contaminants in Biota: Interpreting Tissue Concentrations. Chapter 16, Lead in Birds. 2nd ed. Beyer WN, Meador JP, editors. CRC 
Press, Boca Raton, FL, USA. pp 563-594.

Franzen-Klein D, McRuer D, Slabe VA, Katzner T. 2018. The use of lead isotope analysis to identify potential sources of lead toxicosis in a juvenile bald eagle (Haliaeetus leucocephalus) with ventricular foreign bodies. Journal of Avian Medicine and Surgery 32:34-39.

Ganz, K., Jenni, L., Madry, M.M., Kraemer, T., Jenny, H., Jenny, D., 2018. Acute and chronic lead exposure in four avian scavenger species in Switzerland. Archives of Environmental Contamination and Toxicology 75, 566-575. https://doi.org/10.1007/s00244-018-0561-7

Haig, S.M., D’Elia, J., Eagles-Smith, C., Fair, J.M., Gervais, J., Herring, G., Rivers, J.W., Schulz, J.H., 2014. The persistent problem of lead poisoning in birds from ammunition and fishing tackle. The Condor 116, 408-428. https://doi.org/10.1650/CONDOR-14-36.1

Harris, M.C., Sleeman, J.M., 2007. Morbidity and mortality of bald eagles (Haliaeetus leucocephalus) and peregrine falcons (Falco peregrinus) admitted to the wildlife center of virginia, 1993-2003. Journal of Zoo and Wildlife Medicine 38, 62-66. https://doi.org/10.1638/05-099.1

Helander, B., Bignert, A., Asplund, L., 2008. Using raptors as environmental sentinels: monitoring the white-tailed sea eagle (Haliaeetus albicilla) in Sweden. AMBIO: A Journal of the Human Environment 37, 425-431. https://doi.org/10.1579/00447447(2008)37[425:URAESM]2.0.CO;2

Helsel, D. 2012. Statistics for censored environmental data using minitab and R. 2nd ed, Wiley, Hoboken, NJ, USA.

Hoffman, D.J., Rattner, B.A., Burton Jr, G.A. and Cairns Jr, J. eds., 2002. Handbook of ecotoxicology. $2^{\text {nd }}$ Ed., CRC press, Boca Raton, FL, USA.

Hunt, W.G., Burnham, W., Parish, C.N., Burnham, K.K., Mutch, B., Oaks, J.L., 2006. Bullet fragments in deer remains: Implications for lead exposure in avian scavengers. Wildlife Society Bulletin 34, 167-170. https://doi.org/10.2193/00917648(2006)34[167:BFIDRI]2.0.CO;2

Jachowski, D.S., Katzner, T., Rodrigue, J.L., Ford, W.M., 2015. Monitoring landscape-level distribution and migration Phenology of raptors using a volunteer camera-trap network: Raptor camera-trapping. Wildlife Society Bulletin 39, 553-563. https://doi.org/10.1002/wsb.571

Kassambara A, Kosinski M. 2018. survminer: Drawing survival curves using 'ggplot2'. R package version 0.4.3. https://CRAN.R-project.org/package=survminer

Katzner, T., Smith, B.W., Miller, T.A., Brandes, D., Cooper, J., Lanzone, M., Brauning, D., Farmer, C., Harding, S., Kramar, D.E. and Koppie, C., 2012. Status, biology, and conservation priorities for North America's eastern golden eagle (Aquila chrysaetos) population, 2012. The Auk 129, 168-176. https://doi.org/10.1525/auk.2011.11078

Katzner T.E., Stuber M.J., Slabe V.A., Anderson J.T., Cooper J.L., Rhea L.L., Millsap B.A., 2018. Origins of lead in populations of raptors. Animal Conservation 21, 232-240.

Kelly, T.R., Bloom, P.H., Torres, S.G., Hernandez, Y.Z., Poppenga, R.H., Boyce, W.M., Johnson, C.K., 2011. Impact of the california lead ammunition ban on reducing lead exposure in golden eagles and turkey vultures. PLoS ONE 6, e17656. https://doi.org/10.1371/journal.pone.0017656

Kelly, A., Kelly, S. 2005. Are mute swans with elevated blood lead levels more likely to collide with overhead power lines? Waterbirds: The International Journal of Waterbird Biology 28, 331-334. 
Kirk, D. A. and M. J. Mossman. 1998. Turkey vulture (Cathartes aura), version 2.0. In The Birds of North America (A. F. Poole and F. B. Gill, Editors). Cornell Lab of Ornithology, Ithaca, NY, USA. https://doi.org/10.2173/bna.339

Kramer, J.L., Redig, P.T., 1997. Sixteen years of lead poisoning in eagles, 1980-95: an epizootiologic view. Journal of Raptor Research 31, 327-332.

Krone, O., 2018. Lead poisoning in birds of prey, in: Sarasola, J.H., Grande, J.M., Negro, J.J. (Eds.), Birds of prey. Springer International Publishing, Cham, pp. 251-272. https://doi.org/10.1007/978-3-319-73745-4_11

Lambertucci, S.A., Donázar, J.A., Huertas, A.D., Jiménez, B., Sáez, M., Sanchez-Zapata, J.A., Hiraldo, F., 2011. Widening the problem of lead poisoning to a South-American top scavenger: Lead concentrations in feathers of wild Andean condors. Biological Conservation 144, 1464-1471. https://doi.org/10.1016/j.biocon.2011.01.015

Langner, H.W., Domenech, R., Slabe, V.A., Sullivan, S.P., 2015. Lead and mercury in fall migrant golden eagles from western North America. Arch Environ Contam Toxicol 1-8. https://doi.org/10.1007/s00244-015-0139-6

Lawson, N.M. and Mason, R.P., 1998. Accumulation of mercury in estuarine food chains. Biogeochemistry, 40(2-3), pp.235-247.Lee L (2017) NADA: Nondetects and data analysis for environmental data. R package version 1.6-1. https://CRAN.Rproject.org/package $=$ NADA

Lee L. 2017. NADA: Nondetects and data analysis for environmental data. $R$ package version 1.6-1. https://CRAN.R-project.org/package=NADA

Manning, L.K., Wünschmann, A., Armién, A.G., Willette, M., MacAulay, K., Bender, J.B., Buchweitz, J.P., Redig, P., 2019. Lead intoxication in free-ranging bald eagles (Haliaeetus leucocephalus). Veterinary Pathology 56, 289-299. https://doi.org/10.1177/0300985818813099

Markandya, A., Taylor, T., Longo, A., Murty, M.N., Murty, S., Dhavala, K., 2008. Counting the cost of vulture decline-An appraisal of the human health and other benefits of vultures in India. Ecological Economics 67, 194-204. https://doi.org/10.1016/j.ecolecon.2008.04.020

Martin, P.A., Campbell, D., Hughes, K., McDaniel, T., 2008. Lead in the tissues of terrestrial raptors in southern Ontario, Canada, 1995-2001. Science of The Total Environment 391, 96-103. https://doi.org/10.1016/j.scitotenv.2007.11.012

Marzluff, J.M., McGowan, K.J., Donnelly, R., Knight, R.L., 2001. Causes and consequences of expanding American crow populations, in: Marzluff, J.M., Bowman, R., Donnelly, R. (Eds.), Avian Ecology and Conservation in an Urbanizing World. Springer US, Boston, MA, pp. 331-363. https://doi.org/10.1007/978-1-4615-1531-9_16

McCollough, M.A., 1989. Molting sequence and aging of bald eagles. Wilson Bulletin 101, 1-10.

Nadjafzadeh, M., Hofer, H., Krone, O., 2013. The link between feeding ecology and lead poisoning in white-tailed eagles. The Journal of Wildlife Management 77, 48-57. https://doi.org/10.1002/jwmg.440

Ogada, D.L., Keesing, F., Virani, M.Z., 2012. Dropping dead: causes and consequences of vulture population declines worldwide: Worldwide decline of vultures. Annals of the New York Academy of Sciences 1249, 57-71. https://doi.org/10.1111/j.17496632.2011.06293.x

Plaza, P.I., Lambertucci, S.A., 2019. What do we know about lead contamination in wild vultures and condors? A review of decades of research. Science of The Total 
Environment 654, 409-417. https://doi.org/10.1016/j.scitotenv.2018.11.099

Pokras, M.A., Kneeland, M.R., 2008. Lead poisoning: Using transdisciplinary approaches to solve an ancient problem. EcoHealth 5, 379-385. https://doi.org/10.1007/s10393-0080177-x

Pyle, P., 1997. Molt limits in North American passerines. North American Bird Bander 22, 4989.

R Core Team 2017. R: A language and environment for statistical computing. R Foundation for Statistical Computing, Vienna, Austria. URL https://www.R-project.org/.

Ratcliffe, D.A., 1967. Decrease in eggshell weight in certain birds of prey. Nature, 215(5097), p.208.

Rattner, B.A., Golden, N.H., Toschik, P.C., McGowan, P.C., Custer, T.W., 2008. Concentrations of metals in blood and feathers of nestling ospreys (Pandion haliaetus) in Chesapeake and Delaware Bays. Archives of Environmental Contamination and Toxicology 54, 114122. https://doi.org/10.1007/s00244-007-9004-6

Rodewald, P. (Editor). 2015. The Birds of North America: https://birdsna.org. Cornell Laboratory of Ornithology, Ithaca, NY.

Scheuhammer, A.M., Meyer, M.W., Sandheinrich, M.B., Murray, M.W., 2007. Effects of environmental methylmercury on the health of wild birds, mammals, and fish. AMBIO: A Journal of the Human Environment 36, 12-19. https://doi.org/10.1579/00447447(2007)36[12:EOEMOT]2.0.CO;2

Sileo, L., Fefer, S.I., 1987. Paint chip poisoning of Layson albatross at Midway Atoll. Journal of Wildlife Diseases 23, 432-437. https://doi.org/10.7589/0090-3558-23.3.432

Slabe, V.A., Anderson, J.T., Cooper, J., Brown, B., Ortiz, P., Buchweitz, J., McRuer, D., Katzner, T., 2019. Lead in piscivorous raptors during breeding season in the Chesapeake Bay region of Maryland and Virginia, USA. Environmental Toxicology and Chemistry 38, 862-871. https://doi.org/10.1002/etc.4376

Therneau T., 2015. A Package for Survival Analysis in R. version 2.38, <URL: https://CRAN.Rproject.org/package $=$ survival $>$.

Tobin, J., 1958. Estimation of relationships for limited dependent variables. Econometrica. 26, 24-36. doi:10.2307/1907382.

Watts, B.D., Therres, G.D., Byrd, M.A., 2008. Recovery of the Chesapeake Bay bald eagle nesting population. Journal of Wildlife Management 72, 152-158. https://doi.org/10.2193/2005-616

Wiemeyer, S.N., Lamont, T.G., Bunck, C.M., Sindelar, C.R., Gramlich, F.J., Fraser, J.D. and Byrd, M.A., 1984. Organochlorine pesticide, polychlorobiphenyl, and mercury residues in bald eagle eggs - 1969-79 - and their relationships to shell thinning and reproduction. Archives of Environmental Contamination and Toxicology, 13, 529-549. 
Table 1. Statistics describing central tendencies of lead concentrations of scavenger blood (a) ( $\mu \mathrm{g} / \mathrm{dL})$ from eastern North America and liver (b) (ppm) from Virginia. Samples were collected from 2010-2018

\begin{tabular}{|c|c|c|c|c|c|c|}
\hline (a) BLOOD & & $\mathrm{n}$ & $<$ LOD & Median & Mean & SD \\
\hline American Crow & Unknown Age & 11 & $1(9 \%)$ & 6.07 & 7.99 & 4.97 \\
\hline \multirow[t]{2}{*}{ Bald Eagle } & Adult & 76 & $2(3 \%)$ & 13.15 & 113.05 & 321.22 \\
\hline & Pre-adult & 36 & $10(27 \%)$ & 5.29 & 40.97 & 175.08 \\
\hline \multirow[t]{2}{*}{ Golden Eagle } & Adult & 21 & $1(5 \%)$ & 19.99 & 40.34 & 70.31 \\
\hline & Pre-adult & 36 & 0 & 13.73 & 22.06 & 18.17 \\
\hline \multirow[t]{2}{*}{ Red-shouldered Hawk } & Adult & 45 & $5(11 \%)$ & 6.73 & 9.10 & 8.58 \\
\hline & Pre-adult & 12 & $4(33 \%)$ & 8.33 & 29.47 & 49.59 \\
\hline \multirow[t]{2}{*}{ Red-tailed Hawk } & Adult & 24 & $2(8 \%)$ & 2.01 & 2.96 & 2.08 \\
\hline & Pre-adult & 24 & $1(4 \%)$ & 1.31 & 5.79 & 12.01 \\
\hline (b) LIVER & & $\mathrm{n}$ & $<$ LOD & Median & Mean & SD \\
\hline American Crow & Unknown Age & 56 & $10(18 \%)$ & 2.85 & 43.12 & 79.36 \\
\hline \multirow[t]{2}{*}{ Bald Eagle } & Adult & 24 & $1(4 \%)$ & 1.63 & 19.93 & 42.87 \\
\hline & Pre-adult & 13 & $3(23 \%)$ & 2.85 & 43.12 & 79.36 \\
\hline Black Vulture & Unknown Age & 95 & 0 & 1.79 & 2.46 & 2.91 \\
\hline \multirow[t]{2}{*}{ Red-shouldered Hawk } & Adult & 3 & $1(33 \%)$ & 0.11 & 0.12 & 0.03 \\
\hline & Pre-adult & 5 & $1(20 \%)$ & 0.28 & 0.40 & 0.25 \\
\hline \multirow[t]{2}{*}{ Red-tailed Hawk } & Adult & 9 & $3(33 \%)$ & 0.12 & 23.43 & 69.43 \\
\hline & Pre-adult & 12 & $8(67 \%)$ & NA & 18.35 & 68.65 \\
\hline Turkey Vulture & Unknown Age & 9 & 0 & 1.50 & 1.73 & 1.05 \\
\hline
\end{tabular}


Table 2. Statistics describing central tendencies of lead concentrations of avian scavengers from eastern North America by (a) season, (b) disposition, and (c) scavenging behavior. Samples were collected from 2010-2018.

\begin{tabular}{|c|c|c|c|c|c|c|}
\hline (a) Season & & $\mathrm{n}$ & $<$ LOD & Median & Mean & SD \\
\hline \multirow[t]{2}{*}{ Blood $(\mu \mathrm{g} / \mathrm{dL})$} & Post-hatching & 131 & $25(19 \%)$ & 4.40 & 26.79 & 193.72 \\
\hline & Scavenging & 158 & $5(3 \%)$ & 12.93 & 58.45 & 169.99 \\
\hline \multirow[t]{2}{*}{ Liver (ppm) } & Post-hatching & 64 & $22(34 \%)$ & 0.32 & 13.92 & 43.14 \\
\hline & Scavenging & 58 & $5(9 \%)$ & 4.25 & 47.51 & 79.42 \\
\hline \multicolumn{7}{|l|}{ (b) Disposition } \\
\hline \multirow[t]{2}{*}{ Blood $(\mu \mathrm{g} / \mathrm{dL})$} & Free-flying & 130 & $15(12 \%)$ & 9.56 & 18.76 & 34.54 \\
\hline & Rehabilitation & 159 & $15(9 \%)$ & 6.67 & 64.91 & 240.99 \\
\hline \multirow[t]{2}{*}{ Liver (ppm) } & Free-flying & 84 & $22(26 \%)$ & 1.10 & 35.82 & 73.30 \\
\hline & Rehabilitation & 38 & $5(13 \%)$ & 1.55 & 16.80 & 38.97 \\
\hline \multicolumn{7}{|c|}{ (c) Scavenging behavior } \\
\hline \multirow[t]{2}{*}{ Liver (ppm) } & Facultative & 50 & $17(34 \%)$ & 0.22 & 7.11 & 32.10 \\
\hline & Obligate & 104 & 0 & 1.76 & 2.40 & 2.81 \\
\hline
\end{tabular}


Table 3. Beta coefficients, standard errors, z-scores and p values for the final tobit models including (a) blood and liver lead concentrations of facultative obligate scavengers and (b) liver lead concentrations of obligate and facultative scavengers during the summer months.

\begin{tabular}{|c|c|c|c|c|c|}
\hline (a) & & $\beta$ & SE & $\mathrm{Z}$ & $\mathrm{P}$ \\
\hline \multirow[t]{6}{*}{ Blood } & Intercept & 1.25 & 0.41 & 3.08 & 0.00 \\
\hline & Season - Scavenge & 1.06 & 0.18 & 5.98 & 0.00 \\
\hline & Species - Bald Eagle & 0.98 & 0.42 & 2.34 & 0.02 \\
\hline & Species - Golden Eagle & 0.80 & 0.46 & 1.75 & 0.08 \\
\hline & Species - Red-shouldered Hawk & 0.18 & 0.44 & 0.42 & 0.67 \\
\hline & Species - Red-tailed Hawk & -0.77 & 0.45 & -1.72 & 0.09 \\
\hline \multirow[t]{5}{*}{ Liver } & Intercept & -0.15 & 0.56 & -0.27 & 0.79 \\
\hline & Season - Scavenge & 2.10 & 0.56 & 3.75 & 0.00 \\
\hline & Species - Bald Eagle & 0.36 & 0.59 & 0.61 & 0.54 \\
\hline & Species - Red-shouldered Hawk & -1.86 & 1.06 & -1.77 & 0.08 \\
\hline & Species - Red-tailed Hawk & -1.72 & 0.78 & -2.21 & 0.03 \\
\hline (b) & & $\beta$ & SE & $\mathrm{Z}$ & $\mathrm{P}$ \\
\hline \multirow[t]{7}{*}{ Liver } & Intercept & -0.43 & 0.41 & -1.05 & 0.29 \\
\hline & Scavenger - Obligate & 0.84 & 0.58 & 1.44 & 0.15 \\
\hline & Season - Bald Eagle & 0.47 & 0.51 & 0.92 & 0.36 \\
\hline & Species - Black Vulture & 0.16 & 0.43 & 0.38 & 0.70 \\
\hline & Species - Red-shouldered Hawk & -1.30 & 0.63 & -2.05 & 0.04 \\
\hline & Species - Red-tailed Hawk & -1.24 & 0.56 & -2.23 & 0.03 \\
\hline & Species - Turkey Vulture & 0.00 & 0.00 & NA & NA \\
\hline
\end{tabular}


Figure 1. Boxplots of (a) blood (eastern North America) and (b) liver (Virginia) lead concentrations of American crows (AMCR), bald eagles (BAEA), golden eagles (GOEA), red-shouldered hawks (RSHA), and red-tailed hawks (RTHA). Seasons (post-hatching (PH) and scavenge (SC) are based on mean hatching dates and earliest scavenging dates from game camera images. Boxplots are presented on a $\log$ scale to limit the $y$ axis for graphical representation of the data. 
Fig. 1a

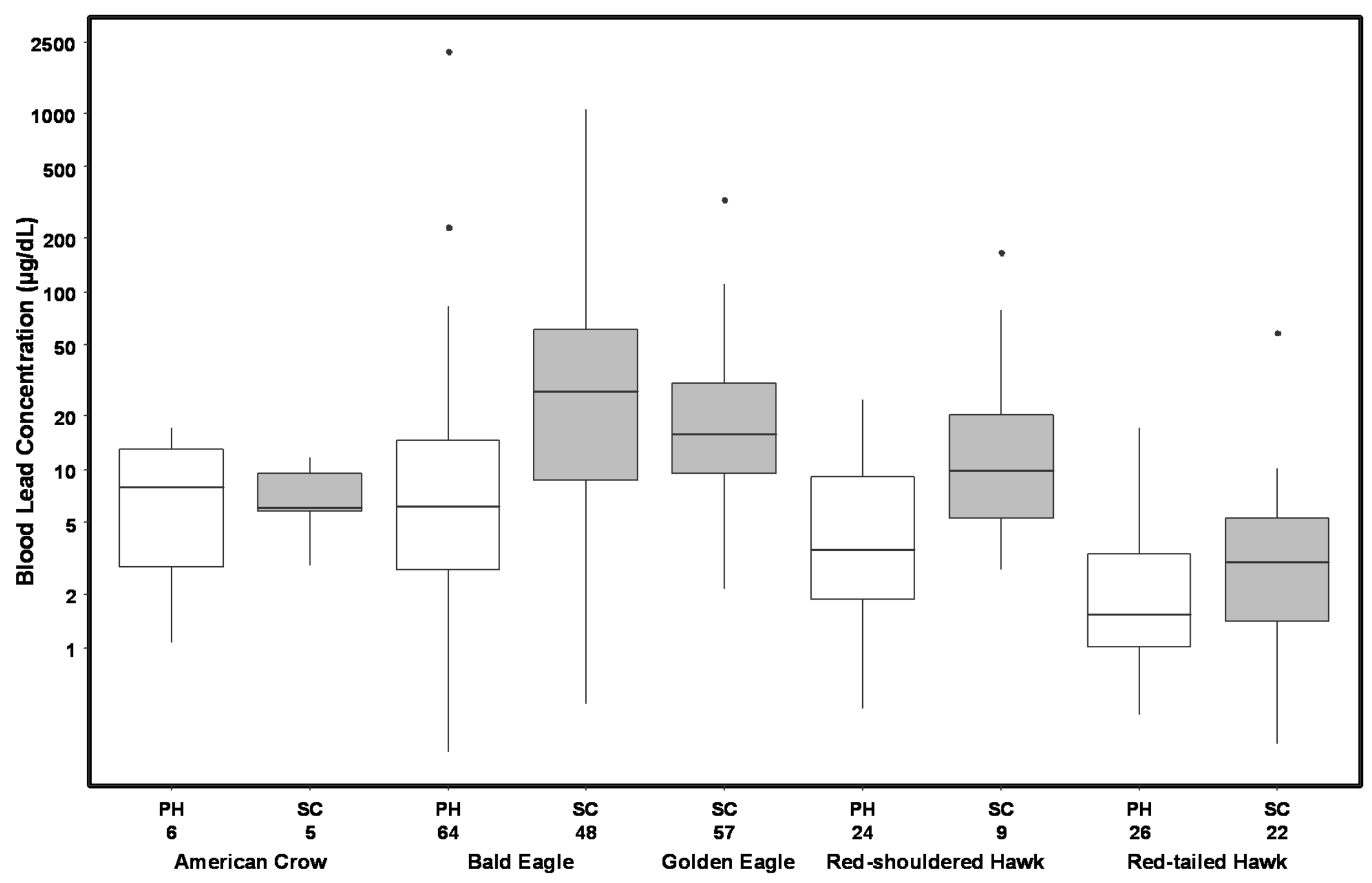


Fig. 1b

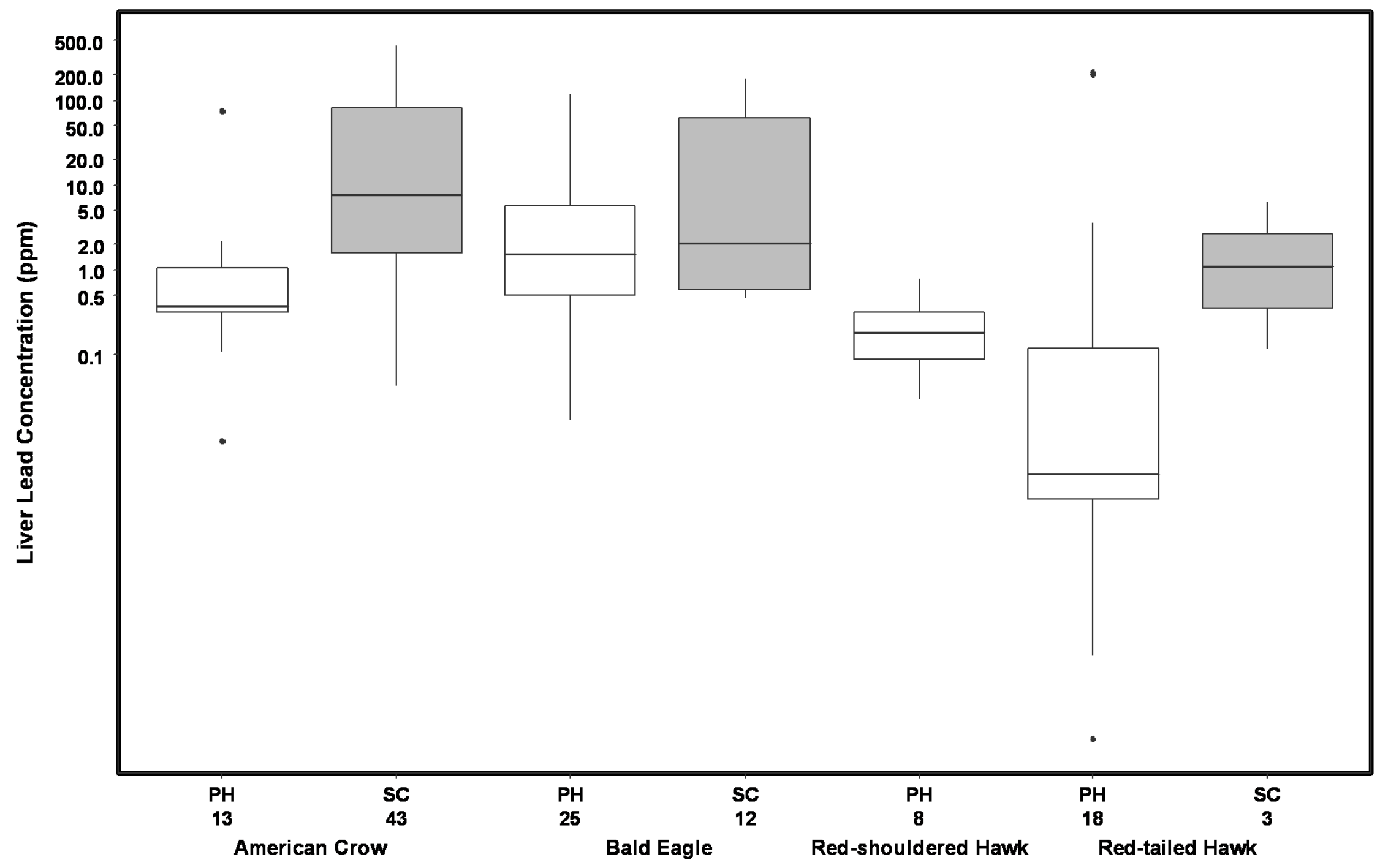


Figure 2. Boxplots of liver lead concentrations of facultative (American crows (AMCR), bald eagles (BAEA), golden eagles (GOEA), red-shouldered hawks (RSHA), and red-tailed hawks (RTHA) and obligate (black vultures (BLVU) and turkey vultures (TUVU) avian scavengers that were culled or euthanized between the months of April and July in Virginia, USA. Boxplots are presented on a log scale to limit the y axis for graphical representation of the data. 
Fig. 2

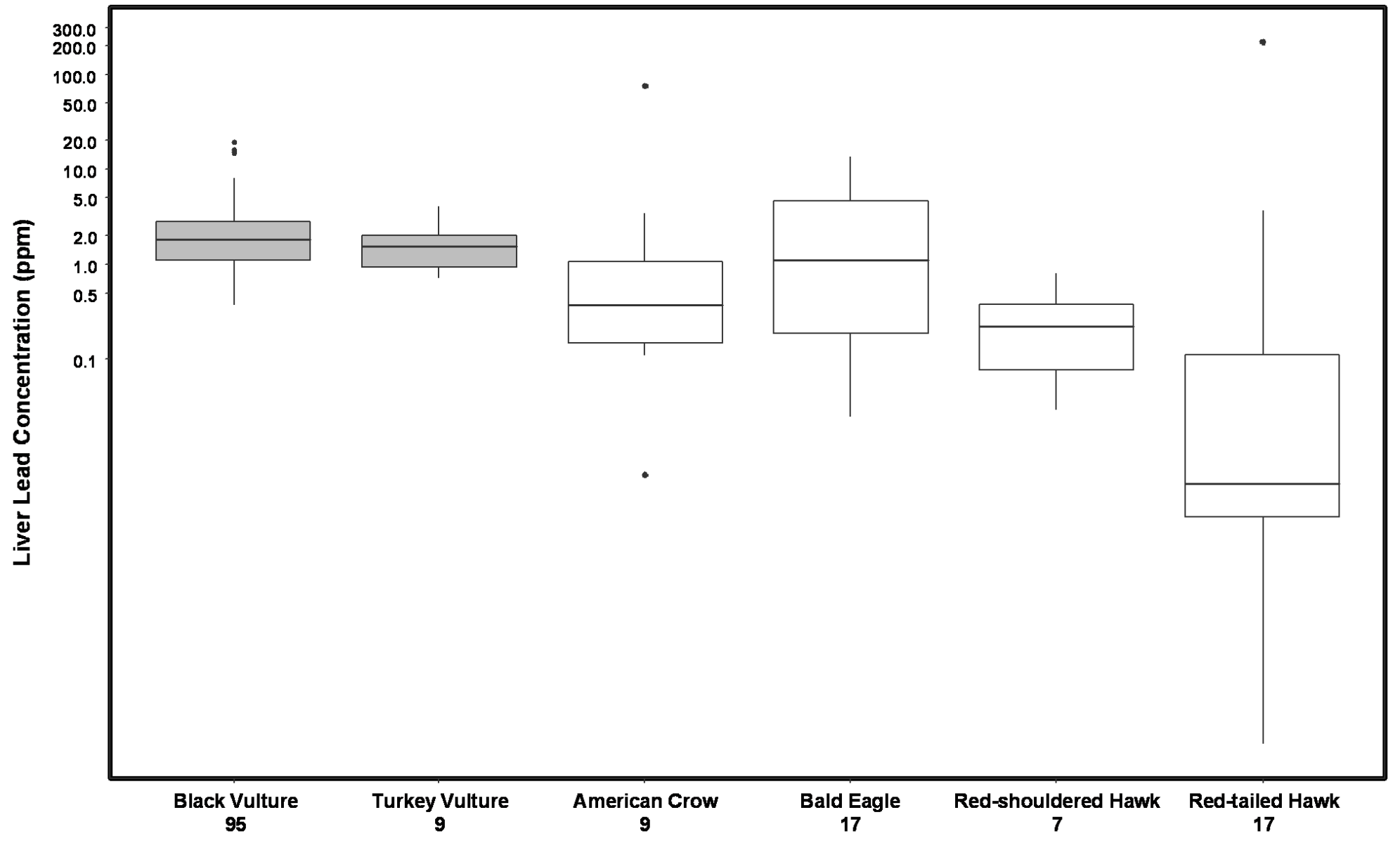




\title{
CHAPTER 5
}

Eagles are frequently exposed to lead in the USA

\author{
Vincent A. Slabe \\ vaslabe@mix.wvu.edu \\ West Virginia University \\ School of Natural Resources \\ PO Box 6125 \\ Morgantown, WV 26506-6125
}




\section{CHAPTER 5}

\section{Eagles are frequently exposed to lead in the USA}

Vincent A. Slabe ${ }^{\mathrm{a}, *}$, James T. Anderson ${ }^{\mathrm{a}}$, Brian Millsap ${ }^{\mathrm{b}}$, and Todd Katzner ${ }^{\mathrm{c}}$

*Additional co-authors will be added for publication

${ }^{a}$ Division of Forestry and Natural Resources, West Virginia University, Morgantown, WV, USA

${ }^{\mathrm{b}}$ US Fish and Wildlife Service, Albuquerque, NM, USA

${ }^{c}$ US Geological Survey, Forest and Rangeland Ecosystem Science Center, Boise, ID, USA

*Author correspondence to: vaslabe@mix.wvu.edu 


\section{ABSTRACT}

Lead poisoning is documented worldwide in a variety of predatory bird populations. However, the degree to which these conservation-reliant apex predators are exposed to lead is only known from regional hotspots of poisoning. To assess the extent, degree and drivers of lead exposure of North American eagles, we analyzed samples of blood, liver and femur collected from bald eagles (Haliaeetus leucocephalus) and golden eagles (Aquila chrysaetos) sampled across the continent. Median blood and liver lead concentrations for bald eagles $(17.37 \mu \mathrm{g} / \mathrm{dL} ; \mathrm{n}=237$; 1.27 ppm dry weight (DW); $n=271$, respectively) were significantly higher than for golden eagles $(9.51 \mu \mathrm{g} / \mathrm{dL} ; \mathrm{n}=384 ; 0.52 \mathrm{ppm} \mathrm{DW} ; \mathrm{n}=171 ; \mathrm{p}<0.001$ in both cases $)$. In contrast, there was no difference between median femur lead concentrations of bald eagles $(8.95$ ppm DW; $\mathrm{n}=$ 226) and golden eagles (8.81 ppm DW; $n=223 ; \mathrm{p}=0.34)$. We detected intra-annual variation in blood lead concentrations of bald eagles $(\mathrm{p}<0.01)$, but not of golden eagles, and in liver lead concentrations of both species $(\mathrm{p}<0.001, \mathrm{p}=<0.04)$. There were also regional differences in blood lead concentrations of golden eagles ( $p<0.02)$, but not of bald eagles. Golden eagles had higher blood lead concentrations in the Atlantic Flyway when compared to the Pacific and Central Flyways. We found age-related differences in liver $(\mathrm{p}<0.04)$ and femur $(\mathrm{p}<0.02)$ lead concentrations of bald eagles, but not of golden eagles, and blood lead concentrations of golden eagles ( $\mathrm{p}<0.02)$ but not of bald eagles. In all cases, adults had higher lead concentrations than at least one of the younger age groups. We found no species-specific or regional differences in femur lead concentrations. However, of the femur samples tested, $47 \%$ of bald eagle samples ( $\mathrm{n}$ $=106)$ and $46 \%$ of golden eagle samples $(n=102)$ were above the threshold for clinical

poisoning. These exposure patterns within and between North American eagle species expand on earlier, regional studies revealing lead poisoning on a continental scale in two apex predators and facultative avian scavengers of conservation concern. 


\section{INTRODUCTION}

Human activity emits toxicants through industrial, recreational, and agricultural activities (Moe et al. 2013). Since the industrial revolution, environmental toxicants have accumulated and subsequently poisoned humans and wildlife. These toxicants have reached the most remote parts of the Earth leaving no remaining pristine environments (Blais 2005, Carson 1962). Understanding patterns of toxicant movement is typically achieved by sampling water, soil, air, and in some cases plants. However, an important component of toxicological relevance is how they affect apex predators.

Lead is a common environmental toxicant released by human activity (Liang and Mao 2015). Of the non-essential heavy metals in the Earth's crust, lead is the most abundant (Collins et al. 1953). Although acute lead poisoning of humans has become less common in developed nations, it still remains a serious health issue (Tong et al. 2000). Unborn children have a high absorption rate of lead in the blood stream and consequently are particularly susceptible to the resulting neurological effects including delayed cognitive development, behavioral problems, and mental impairment (Huang et al. 2012, Sowers et al. 2002). Clinically relevant lead exposure, however, is not only important for humans but is documented in multiple wildlife taxa including mammals, amphibians, fish and birds (Pain et al. 2019). Of these groups, birds make up the overwhelming majority of the available literature on lead poisoning in wildlife.

Avian species particularly sensitive to lead include waterbirds and raptors. In the years following the North American ban on lead in shotgun ammunition used to hunt waterfowl, raptors such as bald and golden eagles continued to suffer an unchanged rate of lead poisoning (Franson and Russell 2014). Globally, multiple additional raptor species are documented with lead poisoning and overwhelming evidence suggests lead from ammunition is the primary source (Ganz et al. 2018, Krone 2018, Lambertucci et al. 2011, Pain et al. 1997). 
Golden eagles (Aquila chrysaetos) and bald eagles (Haliaeetus leucocephalus) are apex predators that are widely distributed across North America. Both species have been the subject of large-scale conservation efforts epitomized by the listing, management, and subsequent delisting, of the bald eagle under the Endangered Species Act (Doremus and Pagel 2001). Because of their position on the food chain and their susceptibility to anthropogenic lead, these species are excellent indicators of the spatial and temporal extent of the trophic penetration of lead throughout ecosystems. Bald and golden eagles are known to be subjected to lead poisoning at multiple regional locations throughout the continental US (Bedrosian et al. 2012, CruzMartinez et al. 2012, Langner et al. 2015). Furthermore, lead is documented as an important and wide-reaching source of mortality for bald and golden eagles in the US (Franson and Russell 2014, USFWS 2016a).

However, understanding of lead exposure of eagles comes from studies focused on local or regional processes at potential hotspots of exposure (Cruz-Martinez et al. 2012, Kelly et al. 2011, Riley et al. 2007, Rogers et al. 2012, Slabe et al. 2019). The research in this body of work therefore is, for the most part, constrained in its spatial extent. As such, these studies are vulnerable to the criticism that they represent local or regional trends. Understanding lead exposure of apex predators therefore requires large-scale studies that are not vulnerable to this criticism.

To address this important knowledge gap, we investigated lead exposure of eagles at a continental scale. To accomplish this objective, we studied the trophic penetration of lead by quantifying lead exposure of bald and golden eagles sampled across the annual cycle and across the continent. More specifically, we evaluated (a) the spatial and temporal extent of lead exposure, and (b) the degree to which these spatial and temporal patterns were influenced by 
demographic parameters - age and sex - of bald and golden eagles in North America.

\section{METHODS}

\section{Study area and focal species}

Bald eagles are endemic to and common throughout most of North America and populations consist of year-round residents, northern breeding birds that migrate to the south, and southern breeding birds that migrate to the north (Buehler 2000, Watts et al. 2008). Golden eagles are not as widely distributed in North America, but they have a circumpolar distribution at northern latitudes. Within the continental US, golden eagles reside year-round in the western plains, Rocky Mountains, and the western coast (Kochert et al. 2002). Breeding populations in the Alaskan interior are long-distance southerly migrants. Eastern populations nest in Quebec, Labrador and Ontario and winter in southern Canada and the Appalachians; there are no known breeding territories in the lower 48 states east of the Mississippi River (Katzner et al. 2012). Both North American eagle species are facultative scavengers and will utilize carrion as a food source, particularly during the winter months when live prey is less abundant.

\section{Data collection}

We collected blood, liver and femur samples from bald and golden eagles throughout the continental US (Figure 1). Blood samples were collected from wild birds upon capture or within 48 hours of admission to licensed rehabilitation facilities. We captured live birds with noose traps, rocket nets, net launchers and bow nets (Harmata and Restani 2013, Langner et al. 2015). Once in hand, we harvested blood samples from the brachial vein using 25 or 26 gauge needles and $3 \mathrm{~mL}$ syringes to draw $1-3 \mathrm{~mL}$ of blood. We immediately transferred the blood to low lead BD Vacutainers (BD Vacutainer®) and stored the samples in a freezer.

Liver and femur samples were collected by personnel at licensed rehabilitation facilities or sampled by the authors after being recovered dead in the field by permitted university, private, 
state, or federal field biologists. Causes of death of these birds included multiple natural or anthropogenic and known or unknown causes. Typical known causes of death included conspecific fighting, emaciation, unknown trauma, toxicant poisoning (rodenticides and lead), colliding with wind turbines, electrocutions, gunshots and vehicle collisions. In the case of gunshot birds ( $\mathrm{n}=10$ ), we did not collect liver or femur samples from tissue that was obviously damaged by bullet shrapnel. For birds admitted at rehabilitation facilities, we adopted National Wildlife Health Center (NWHC) protocols and only included liver samples from birds that died or were euthanized within 72 hours of admission (NWHC unpublished data).

Sample processing and laboratory analysis

We prepared whole blood samples by drawing aliquots of $100-400 \mu \mathrm{L}$ from vacutainers and pipetting them in to $1 \mathrm{~mL}$ microcentrifuge tubes. When blood was partially clotted, we recorded wet weights of the entire sample, dried the samples in a $95^{\circ} \mathrm{C}$ oven, and recorded the dry weights prior to digestion. Dry weight results were converted to wet weights by using the dry:wet weight ratio (Slabe et al. 2019).

We collected one liver lobe and one $2.5-\mathrm{cm}$ section of femur. To ensure no cross contamination between individuals, we used separate disposable scalpel blades to collect tissue from each bird. Other instruments were cleaned with a bleach solution after tissue harvest from each bird. Liver and femur samples were immediately placed in a plastic bag and stored in a freezer. For preparation, liver and femur samples were thawed to room temperature and a $1 \mathrm{~g}( \pm$ $0.05 \mathrm{~g}$ ) section was weighed wet, dried, and weighed again prior to being sent to the Michigan State Veterinary Diagnostic Laboratory (MSU-VDL) for lead concentration analyses. MSU-VDL digested blood, liver and femur samples in nitric acid, diluted the samples with Millipore water prior to determining lead concentrations with an Agilent 7900 inductively 
coupled mass spectrometer (ICP-MS) (Agilent Technologies, Santa Clara, CA) fitted with a Cetac Auto Sampler (Cetac, Omaha, NE) and Micro Mist Nebulizer (Agilent) at MSU-VDL. The ICP-MS was calibrated for lead concentration determinations with $1000 \mathrm{ug} / \mathrm{mL}$ stock solutions (Alfa Aesar, Ward Hill, MA) in accordance with standard operating procedures published by the manufacturer (Agilent Technologies 2008). Standard reference materials (SRM) were used for matrix matched quality control of lead concentrations and initial instrument calibrations (Slabe et al. 2019). Data on liver and femur lead concentrations are reported on a dry weight basis (DW) in parts per million (ppm) and blood lead concentrations are reported on a wet weight basis (WW) in micrograms per deciliter $(\mu \mathrm{g} / \mathrm{dL})$.

\section{Organizing data}

We assessed regional differences in tissue lead concentrations by dividing the data according to United States Fish and Wildlife Service (USFWS) designated migratory Flyways (Atlantic, Mississippi, Central and Pacific). To assess temporal differences in liver and blood lead concentrations, we grouped the data by month of the year in which the sample was collected. We assessed age-related differences in blood, liver and femur lead concentrations by grouping the birds into one of three categories (adult, subadult or juvenile) based on published methods for aging raptors (McCollough 1989, Pyle 1997). We did not consider nestlings in our analyses. To assess the impact of disposition of birds on tissue lead concentrations at the time the samples were collected, we categorized birds as either free-flying or admitted at a rehabilitation facility.

Statistical Analyses

A proportion of our blood, liver and femur lead concentrations were below limits of detection (LODs) and the data on detections thus were not normally distributed. To 
accommodate these non-parametric data, we used the Kaplan-Meier method to calculate summary statistics based on a cumulative probability distribution and implemented within package 'NADA' in program R. (Helsel 2012, Lee 2017, R Core Team 2017). The sample volumes varied and thus LODs ranged from $0.5-2 \mu \mathrm{g} / \mathrm{dL}$ WW in blood samples, $0.1-2.65$ ppm DW in liver samples and $0.1-0.5$ ppm DW in femur samples.

To evaluate spatial, age-related, temporal and disposition-related differences in bald and golden eagles, we used tobit regression models with a stepwise variable selection process using the R package 'survival' (Therneau 2015). We removed individual predictor variables based on p-values using the standard threshold of $p<0.05$ and stopped removing variables when all $p$ values were below this threshold. We tested for the effect of each of these covariates to explain variation of log-transformed blood, liver and femur lead concentrations of bald and golden eagles. When covariates were present in the final models, we ran the Peto and Peto modification of the Gehan-Wilcoxon multiple comparisons test on each of the significant predictors using package 'survminer' in R (Kassambara and Kosinski 2018). In the case of golden eagles, when covariates were present in the final femur model, we ran a traditional multiple comparisons test in $r$ using function 'pairwise.wilcox.test' in place of the Peto and Peto modification of the Gehan-Wilcoxon test. We did this because the traditional Wilcoxon test performed better than the modified test in a situation such as this when few or no lead concentrations fell below the LOD. To avoid type 2 error, we do not report statistical significance for comparisons when the sample size within one of the groups was $<10$.

To test for species-specific differences between lead concentrations of bald and golden eagle we used tobit regression models with random effects. We included random effects for month of the year, age, disposition and migratory flyway for the liver and blood models and age, 
flyway and disposition in the femur model (Therneau 2015). In each of these models, species was the predictor variable and lead concentration was the response variable.

To evaluate the degree to which bald and golden eagles were exposed to lead in the continental US, we compared proportions of individuals exposed at physiologically-, clinicallyand conservation-relevant thresholds among the migratory flyways (Franson and Pain 2011, NWHC unpublished data). These thresholds were 1) the existence of anthropogenic lead (above or below the highest ICP-MS LOD for blood, liver, and femur listed above), 2) sub-lethal lead exposure (10 $\mu \mathrm{g} / \mathrm{dL}$ for liver, $6.5 \mathrm{ppm}$ for liver, and $6.75 \mathrm{ppm}$ for femur), and 3) clinical lead poisoning (40 $\mu \mathrm{g} / \mathrm{dL}$ for blood, $20 \mathrm{ppm}$ for liver, and $10 \mathrm{ppm}$ for femur) (NHWC unpublished data, Fallon et al. 2017, Franson and Pain 2011). To do this, we used generalized linear mixed models to run logistic regressions in package 'lme4' in R (Bates et al. 2015). In each of these models, a binary variable with concentrations above and below the three thresholds was the dependent variable and the predictor variable was migratory flyway. We used random effects for age group and month of the year the sample was collected for blood and liver lead concentrations and age group for femur lead concentrations.

\section{RESULTS}

We tested blood lead concentrations of 237 wild bald eagles and 384 wild golden eagles from North America (Table 1). Of these, most were free-flying birds captured by permitted researchers, sampled, and subsequently released unharmed. However, 109 bald eagles and 29 golden eagles were sampled within 24 hours of admission to rehabilitation facilities. Of the blood samples we tested, $29 \%$ of bald eagles $(n=68)$ and $9 \%$ of golden eagles $(n=34)$ were above the threshold for clinical poisoning and $3 \%$ of bald eagles and $13 \%$ of golden eagles $(\mathrm{n}=$ 50) fell below the instrument's LOD. 
We tested liver lead concentrations from 271 bald eagles and 171 golden eagles (Table 2). Of these, the majority were collected in the field, but 53 bald eagles and 2 golden eagles were sampled after being euthanized or having died on their own within 72 hours of admission to a rehabilitation facility. Of the liver samples we tested, $27 \%$ of bald eagle samples $(n=74)$ and $7 \%$ of golden eagle samples $(n=12)$ were above the threshold for clinical poisoning. In contrast, $7 \%$ of bald eagle samples $(n=19)$ and $10 \%$ of golden eagle samples $(n=17)$ fell below the LOD.

We tested femur lead concentrations from 226 bald eagles and 223 golden eagles (Table 3). Of these, the majority were collected in the field, but 55 bald eagles and 5 golden eagles were sampled after being euthanized or dying on their own at a rehabilitation facility. Of the femur samples we tested, $47 \%$ of those from bald eagles $(n=106)$ and $46 \%$ of those from golden eagles $(\mathrm{n}=102)$ were above the threshold for clinical poisoning. In contrast, only $2 \%$ of those from bald eagles $(\mathrm{n}=5)$ and $<1 \%$ of those from golden eagles $(\mathrm{n}=1)$ fell below the LOD.

Temporal, age-related, regional, and species-specific differences of lead exposure of bald and golden eagles

We detected between-month differences in blood lead concentrations of bald eagles but not of golden eagles (Figure 2a, Table 4). Blood lead concentrations of bald eagles were higher in winter than in summer. Bald eagles had higher lead concentrations in December when compared to February $(p=0.01)$ and in November when compared to February $(p=0.01)$. For liver lead concentrations, we detected between-month differences in tissue from both bald and golden eagles. Liver lead concentrations of bald eagles were higher in the winter than in summer. Bald eagles had lower liver lead concentrations in the month of June when compared to March (p $<0.001)$, April $(\mathrm{p}=0.007)$ and November $(\mathrm{p}=0.02)$; in July when compared to January $(\mathrm{p}<$ 0.001), February $(\mathrm{p}<0.001)$, March $(\mathrm{p}=0.004)$, November $(\mathrm{p}=0.02)$, and December $(\mathrm{p}=$ 0.004); and finally, in October when compared to January ( $\mathrm{p}<0.001)$, February $(\mathrm{p}=0.007)$, 
March $(\mathrm{p}=0.004)$, and December $(\mathrm{p}=0.04)$. Golden eagles had lower liver lead concentrations in the month of May when compared to December $(p=0.038)$ and March $(p=0.031)$.

We detected age-related differences in blood lead concentrations of golden eagles, but not of bald eagles. Adult golden eagles had higher blood lead concentrations than did subadults $(p=0.01)$ and juveniles $(p=0.02)$. Also, subadult golden eagles had higher blood lead concentrations than juveniles $(\mathrm{p}<0.001)$. We detected age-related differences in liver lead concentrations of bald eagles, but not of golden eagles. Bald eagle adults had higher liver lead concentrations than did subadults ( $\mathrm{p}<0.001)$ or juveniles $(\mathrm{p}<0.001)$ (Figure 3$)$. We detected differences in femur lead concentrations of bald and golden eagles. For bald eagles, adults had higher femur lead concentrations than juveniles $(\mathrm{p}=0.02)$. For golden eagles, adults had higher femur lead concentrations than did subadults $(\mathrm{p}<0.001)$ or juveniles $(\mathrm{p}<0.001)$.

We detected region-specific differences in blood lead concentrations of golden eagles, but not of bald eagles. Golden eagles from the Atlantic Flyway had higher blood lead concentrations than birds from the Central $(p=0.009)$ and Pacific $(p=0.006)$ Flyways (Figure 2b). There were no region-specific differences in liver lead concentrations for either species. We detected region-specific differences in femur lead concentrations of bald eagles, but not of golden eagles. For bald eagles, adults had higher femur lead concentrations than juveniles $(\mathrm{p}=$ 0.02). Bald eagles had higher blood $(\mathrm{p}<0.001)$ and liver $(\mathrm{p}=0.002)$ concentrations than did golden eagles (Figure 4), but we did detect inter-specific differences in femur lead concentrations. Among region comparison of threshold-specific lead exposure of bald and golden eagles There were spatial differences in the frequency with which birds in different regions exhibited blood-lead concentrations above physiologically-, clinically- and conservation-relevant 
thresholds. Across most flyways, similar proportions of both golden and bald eagles had blood lead concentrations above the threshold for anthropogenic exposure, However, a higher proportion of golden eagles were above that threshold in the Atlantic Flyway as compared to the Central $(\mathrm{p}=0.04)$ and Pacific $(\mathrm{p}=0.03)$ Flyways. We did not detect region-specific differences anthropogenic lead exposure in the liver or femur of either species.

We detected spatial differences in the degree to which blood from bald and golden eagles indicated sub-lethal exposure to lead. A higher proportion of bald eagles had blood lead concentrations above the threshold for sublethal exposure in the Central Flyway when compared to the Atlantic $(\mathrm{p}=0.001)$ and Mississippi $(\mathrm{p}=0.04)$ Flyways. For golden eagles, a higher proportion of birds had sub-lethal lead exposure in the Atlantic Flyway when compared to the Central Flyway $(\mathrm{p}=0.02)$. We did not detect spatial differences in sub-lethal lead exposure in the livers of bald and golden eagles. For femur, we found differences in sub-lethal exposure in bald, but not golden, eagles. Bald eagles in the Central Flyway had a higher proportion of femur lead concentrations above this threshold than did birds in the Atlantic $(p=0.004)$ and Pacific $(p$ $=0.03$ ) Flyways.

Finally, there were some spatial differences in the degree to which birds in different regions were clinically exposed to lead. A higher proportion of bald eagles had blood lead concentrations above the clinical poisoning threshold in the Central Flyway when compared to the Atlantic Flyway $(\mathrm{p}<0.001)$ or to the Mississippi Flyway $(\mathrm{p}=0.04)$. We did not detect any spatial differences in the frequency in the clinical lead poisoning of liver tissue of either species. Finally, the rate at which femur data suggested clinical lead poisoning was different between regions for bald, but not golden eagles. Femurs from bald eagles in the Central Flyway had lead 
concentrations above the clinical threshold more frequently than those in the Atlantic $(\mathrm{p}<0.001)$ or Pacific ( $\mathrm{p}=0.004)$ Flyways.

\section{DISCUSSION}

Our nationwide dataset shows important spatial, temporal and age-related patterns in bald and golden eagle lead exposure in the US. These continental scale patterns highlight the widereaching effects of this toxicant and illustrate how they extend beyond previously documented local geographic scales. Furthermore, this study suggests that modern anthropogenic uses of lead continue to penetrate the ecosystem causing physiological harm and mortality of two federally protected apex predators.

\section{Temporal trends in the lead exposure of bald and golden eagles}

We saw monthly variation in lead exposure in bald and golden eagles. Blood lead concentrations in bald eagles and liver lead concentrations in bald and golden eagles were higher during winter months when these species commonly scavenge. Elevated lead concentrations in predatory and scavenging birds are widely assumed to be caused by primary lead poisoning, or the direct ingestion of lead fragments (Manning et al. 2019). Lead is widely used in modern society in many forms including paint, tire weights, car batteries, fishing equipment, and hunting projectiles (Finkelstein et al. 2012, Franson et al. 2003, Sileo and Fefer 1987). Of these common uses of lead, only one corresponds directly with the feeding ecology of facultative scavengers such as bald and golden eagles (Nadjafzadeh et al. 2013). Lead ammunition is widely used to harvest big game animals in the US during and prior to the months the birds in this study showed statistically higher lead concentrations. During these months, bald and golden eagles are known to scavenge, and carrion is a primary food source at this time of year. The coincidence of the timing of hunting seasons and the seasonal feeding behavior of eagles likely explains the 
temporal differences we observed in liver and blood lead concentrations. This temporal pattern has been previously observed at local scales throughout the US. However, our data shows a national trend in the link between lead poisoning and lead ammunition in these species (Bedrosian et al. 2012, Cruz-Martinez et al. 2012).

Spatial trends in the lead exposure of bald and golden eagles

We observed notable spatial differences in the blood lead concentrations of bald and golden eagles. These data reveal sub-continental trends within the continental-scale patterns of lead exposure of these species. For example, golden eagles in the Atlantic Flyway are more frequently lead poisoned than were birds in other North American flyways. While the reason for increased lead poisoning of golden eagles in the Atlantic Flyway is not clear, it may be related to a higher density of lead contaminated offal in a smaller geographic area causing an increased risk of lead poisoning. This finding is of particular concern due to a recent study of golden eagles in this region estimating the population at only 5,000 individuals (Dennhardt et al. 2015, 2017). Since golden eagles occur at low abundance in the Atlantic Flyway when compared to other regions, have low breeding rates and delayed sexual maturity, they are particularly susceptible to any significant cause of mortality that can reduce population growth rates (Hunt et al. 2017). Furthermore, preventable causes of anthropogenic mortality of bald and golden eagles such as lead poisoning are of particular interest in this region as mitigation practices are required by the USFWS to compensate for eagle mortality associated with renewable energy development (USFWS 2016b).

Age-related trends in the lead exposure of bald and golden eagles

The age-related trends in the blood and liver lead concentrations of bald and golden eagles we observed are similar to earlier findings in regional studies and confirms that these local 
trends are also continental patterns (Bedrosian et al. 2012, Cruz-Martinez et al. 2012, Langner et al. 2015). More specifically, we observed no age-related differences in blood lead concentrations of bald eagles or in liver lead concentrations of golden eagles. In contrast, we did find agerelated differences in liver lead concentrations of bald eagles and in blood lead concentrations of golden eagles.

The age-related patterns we found in femur lead exposure of bald and golden eagles most likely reflects the additive nature of lead in scavenging birds as they age. Metallic lead is ingested, corroded by digestive acidity, incorporated into the blood stream, absorbed by soft tissue organs such as liver, and ultimately stored in the skeletal system (Franson and Pain 2011). This finding suggests that femur lead concentrations of scavenging birds can be ascribed to the age of the bird and the relative amount of exposure events over the bird's lifetime. Species-specific patterns of lead exposure of eagles

Of the two eagle species, bald eagles had higher blood and liver lead concentrations of bald eagles suggesting a higher rate of acute lead poisoning in this species. However, femur lead concentration data show that the rate of chronic lead poisoning in bald and golden eagles is similar. This difference in acute lead poisoning between species could speak to the further extent to which bald eagles incidentally ingest lead, the further extent to which bald eagles seek opportunistic food sources such as human refuse, or it could also speak to physiological variation in the susceptibility to lead poisoning between species. Bald and golden eagles exhibit similar patterns in year-round feeding behavior, focus on live prey during the breeding season and show a tendency to scavenge during the winter. However, phylogenic, physiologic, or behavioral variation may drive the differences we found in the blood and liver lead concentrations. More research is needed to quantify species-specific scavenging rates and the physiological stress 
associated with toxicant exposure in eagles. Regardless of the drivers in the variation of lead exposure between these two species, the higher liver and blood lead concentrations of bald eagles suggest that they are more prone to the negative demographic consequences associated with lead poisoning on a continental scale.

Almost half of bald and golden eagles sampled had femur lead concentrations indicative of clinical lead poisoning. This finding specifically highlights the extent to which lead penetrates the ecosystem in the continental US and highlights a potentially underestimated source of mortality in North American eagle species.

\section{Threshold specific variation of lead exposure between eagle species}

We observed spatial differences in threshold-specific lead exposure of bald eagles. The blood and femur lead concentrations of bald eagles suggested a higher frequency of occurrence of sub-lethal lead exposure and clinical lead poisoning in the Central Flyway when compared to other regions. This finding may suggest ecological processes that are unique to the Central Flyway such as increased snowpack, lower temperatures, and a lower availability of alternate prey items during the winter months that result in a higher rate of scavenging (Lindblom et al. 2017). Our blood lead concentration data showed a higher occurrence of anthropogenic lead in golden eagles in the Atlantic Flyway. The higher occurrence of lead above the LOD in the blood of golden eagles in this region may be a reflection of higher human population density and the associated risk to toxicants in the Atlantic Flyway.

\section{CONCLUSIONS}

Our work illustrates the extent which lead exposure is relevant to bald and golden eagles, and the continent-wide temporal, spatial, age-related and species-specific patterns in this exposure. These patterns help define the extent to which eagles are acutely and chronically lead 
poisoned in the US. Most importantly, this continental dataset confirms earlier regional trends observed in the lead exposure of bald and golden eagles and highlights the importance to further understand and mitigate for lead as a source of anthropogenic mortality in North American eagle species.

\section{ACKNOWLEDGMENTS}

L. Rhea, L. Montague, D. Schmidt, M. Wheeler and D. Hartman assisted with laboratory work. Countless biologists assisted with field work. Field work was covered under WVU's IACUC protocol \#1603001797, federal banding permit \#23715 and multiple additional state, federal and IACUC protocols available upon request. We thank who assisted with the improvement of this manuscript. This publication was completed with funds provided by VDGIF through a Federal Aid in Wildlife Restoration grant from the USFWS, contract \#2013-14308, contract F13PX02485 from the USFWS, and funds from the American Eagle Foundation. JA was supported by the NSF (OIA-1458952) and the USDA National Institute of Food and Agriculture, McIntire Stennis project WVA00117 during manuscript preparation. Any use of trade, product or firm names is for descriptive purposes only and does not imply endorsement by the U.S.

Government. This is scientific article number XXXX of the West Virginia University Agricultural and Forestry Experiment Station, Morgantown, West Virginia. 


\section{REFERENCES}

Agilent Technologies. 2008. Agilent 7500 Series ICP-MS hardware manual. Agilent Technologies, Inc.

Bates, D, Martin M, Bolker, B, Walker, S. 2015. Fitting linear mixed-effects models using lme4. Journal of Statistical Software, 67, 1-48, doi:10.18637/jss.v067.i01.

Bedrosian, B., Craighead, D., Crandall, R. 2012. Lead exposure in bald eagles from big game hunting, the continental implications and successful mitigation efforts. PLoS ONE 7, e51978. https://doi.org/10.1371/journal.pone.0051978

Blais, J.M. 2005. Biogeochemistry of persistent bioaccumulative toxicants: processes affecting the transport of contaminants to remote areas. Canadian Journal of Fisheries and Aquatic Sciences, 62, 236-243.

Buehler, D. A. 2000. Bald Eagle (Haliaeetus leucocephalus), version 2.0. In The Birds of North America (A. F. Poole and F. B. Gill, Editors). Cornell Lab of Ornithology, Ithaca, NY, USA. https://doi.org/10.2173/bna.506

Carson, R., 1962. Silent spring. Houghton Mifflin Harcourt.

Collins, C.B., Russell, R.D. and Farquhar, R.M., 1953. The maximum age of the elements and the age of the earth's crust. Canadian Journal of Physics, 31, 402-418.

Cruz-Martinez, L., Redig, P.T., Deen, J., 2012. Lead from spent ammunition: a source of exposure and poisoning in bald eagles. Human-Wildlife Interactions 6, 94-104.

Dennhardt, A.J., Duerr, A.E., Brandes, D. and Katzner, T.E., 2015. Integrating citizen-science data with movement models to estimate the size of a migratory golden eagle population. Biological Conservation, 184, 68-78.

Dennhardt, A.J., Duerr, A.E., Brandes, D. and Katzner, T.E. 2017. Applying citizen-science data and mark-recapture models to estimate numbers of migrant golden eagles in an Important Bird Area in eastern North America. The Condor: Ornithological Applications, 119, 817831.

Doremus, H. and Pagel, J.E., 2001. Why listing may be forever: perspectives on delisting under the US Endangered Species Act. Conservation Biology, 15, 1258-1268.

Fallon, J.A., Redig, P., Miller, T.A., Lanzone, M., Katzner, T. 2017. Guidelines for evaluation and treatment of lead poisoning of wild raptors: Guidelines for lead poisoned raptors. Wildlife Society Bulletin 41, 205-211. https://doi.org/10.1002/wsb.762

Finkelstein, M.E., Doak, D.F., George, D., Burnett, J., Brandt, J., Church, M., Grantham, J., Smith, D.R., 2012. Lead poisoning and the deceptive recovery of the critically endangered California condor. Proceedings of the National Academy of Sciences 109, 11449-11454. https://doi.org/10.1073/pnas.1203141109

Franson, J.C., Hansen, S.P., Creekmore, T.E., Brand, C.J., Evers, D.C., Duerr, A.E., DeStefano, S., 2003. Lead fishing weights and other fishing tackle in selected waterbirds. Waterbirds 26, 345-352. https://doi.org/10.1675/1524-4695(2003)026[0345:LFWAOF]2.0.CO;2

Franson JC, Pain DJ. 2011. Environmental contaminants in biota: interpreting tissue concentrations. Chapter 16, Lead in Birds. 2nd ed. Beyer WN, Meador JP, editors. CRC Press, Boca Raton, FL, USA. pp. 563-594.

Franson, J.C. and Russell, R.E., 2014. Lead and eagles: demographic and pathological characteristics of poisoning, and exposure levels associated with other causes of mortality. Ecotoxicology, 23, 1722-1731.

Ganz, K., Jenni, L., Madry, M.M., Kraemer, T., Jenny, H., Jenny, D., 2018. Acute and chronic lead exposure in four avian scavenger species in Switzerland. Archives of Environmental 
Contamination and Toxicology 75, 566-575. https://doi.org/10.1007/s00244-018-0561-7

Harmata, A.R. and Restani, M., 2013. Lead, mercury, selenium, and other trace elements in tissues of golden eagles from southwestern Montana, USA. Journal of Wildlife Diseases, 49, 114-124.

Helsel, D. 2012. Statistics for censored environmental data using minitab and R. 2nd ed, Wiley, Hoboken, NJ, USA.

Huang, P.C., Su, P.H., Chen, H.Y., Huang, H.B., Tsai, J.L., Huang, H.I. and Wang, S.L., 2012. Childhood blood lead levels and intellectual development after ban of leaded gasoline in Taiwan: a 9-year prospective study. Environment international, 40, 88-96.

Hunt, W.G., Wiens, J.D., Law, P.R., Fuller, M.R., Hunt, T.L., Driscoll, D.E. and Jackman, R.E., 2017. Quantifying the demographic cost of human-related mortality to a raptor population. PloS one, 12, p.e0172232.

Kassambara A, Kosinski M. 2018. survminer: Drawing survival curves using 'ggplot2'. R package version 0.4.3. https://CRAN.R-project.org/package=survminer

Katzner, T., Smith, B.W., Miller, T.A., Brandes, D., Cooper, J., Lanzone, M., Brauning, D., Farmer, C., Harding, S., Kramar, D.E. and Koppie, C., 2012. Status, biology, and conservation priorities for North America's eastern golden eagle (Aquila chrysaetos) population. The Auk 129, 168-176. https://doi.org/10.1525/auk.2011.11078

Kelly, T.R., Bloom, P.H., Torres, S.G., Hernandez, Y.Z., Poppenga, R.H., Boyce, W.M., Johnson, C.K. 2011. Impact of the California Lead ammunition ban on reducing lead exposure in golden eagles and turkey vultures. PLoS ONE 6, e17656. https://doi.org/10.1371/journal.pone.0017656

Kochert, M. N., K. Steenhof, C. L. McIntyre, and E. H. Craig. 2002. Golden Eagle (Aquila chrysaetos), version 2.0. In The Birds of North America (A. F. Poole and F. B. Gill, Editors). Cornell Lab of Ornithology, Ithaca, NY, USA. https://doi.org/10.2173/bna.684

Krone, O., 2018. Lead Poisoning in Birds of Prey, in: Sarasola, J.H., Grande, J.M., Negro, J.J. (Eds.), Birds of Prey. Springer International Publishing, Cham, pp. 251-272. https://doi.org/10.1007/978-3-319-73745-4_11

Lambertucci, S.A., Donázar, J.A., Huertas, A.D., Jiménez, B., Sáez, M., Sanchez-Zapata, J.A., Hiraldo, F., 2011. Widening the problem of lead poisoning to a South-American top scavenger: Lead concentrations in feathers of wild Andean condors. Biological Conservation 144, 1464-1471. https://doi.org/10.1016/j.biocon.2011.01.015

Langner, H.W., Domenech, R., Slabe, V.A., Sullivan, S.P., 2015. Lead and mercury in fall migrant golden eagles from western North America. Archives of Environmental Contamination and Toxicology, 69, 54-61. https://doi.org/10.1007/s00244-015-0139-6

Lee L. 2017. NADA: Nondetects and data analysis for environmental data. R package version 1.6-1. https://CRAN.R-project.org/package=NADA

Liang, J. and Mao, J., 2015. Source analysis of global anthropogenic lead emissions: their quantities and species. Environmental Science and Pollution Research, 22, 7129-7138.

Lindblom, R.A., Reichart, L.M., Mandernack, B.A., Solensky, M., Schoenebeck, C.W. and Redig, P.T., 2017. Influence of snowfall on blood lead levels of free-flying bald eagles (Haliaeetus leucocephalus) in the Upper Mississippi River Valley. Journal of Wildlife Diseases, 53, 816-823.

Manning, L.K., Wünschmann, A., Armién, A.G., Willette, M., MacAulay, K., Bender, J.B., Buchweitz, J.P., Redig, P., 2019. Lead intoxication in free-ranging bald eagles (Haliaeetus leucocephalus). Veterinary Pathology 56, 289-299. 
https://doi.org/10.1177/0300985818813099

McCollough, M.A., 1989. Molting sequence and aging of bald eagles. Wilson Bulletin 101, 110.

Moe, S.J., De Schamphelaere, K., Clements, W.H., Sorensen, M.T., Van den Brink, P.J. and Liess, M., 2013. Combined and interactive effects of global climate change and toxicants on populations and communities. Environmental Toxicology and Chemistry, 32, 49-61.

Nadjafzadeh, M., Hofer, H., Krone, O., 2013. The link between feeding ecology and lead poisoning in white-tailed eagles. The Journal of Wildlife Management 77, 48-57. https://doi.org/10.1002/jwmg.440

Pain, D.J., Bavoux, C. and Burneleau, G., 1997. Seasonal blood lead concentrations in marsh harriers Circus aeruginosus from Charente-Maritime, France: Relationship with the hunting season. Biological Conservation, 81, 1-7.

Pain, D.J., Mateo, R. and Green, R.E., 2019. Effects of lead from ammunition on birds and other wildlife: A review and update. Ambio, 48, 1-19.

Pyle, P., 1997. Molt limits in North American passerines. North American Bird Bander 22, 4989.

R Core Team 2017. R: A language and environment for statistical computing. R Foundation for Statistical Computing, Vienna, Austria. URL https://www.R-project.org/.

Riley, S.P., Bromley, C., Poppenga, R.H., Uzal, F.A., Whited, L. and Sauvajot, R.M., 2007. Anticoagulant exposure and notoedric mange in bobcats and mountain lions in urban southern California. The Journal of Wildlife Management, 71, 1874-1884.

Rogers, T.A., Bedrosian, B., Graham, J. and Foresman, K.R., 2012. Lead exposure in large carnivores in the greater Yellowstone ecosystem. The Journal of Wildlife Management, 76, 575-582.

Sileo, L., Fefer, S.I., 1987. Paint chip poisoning of Layson albatross at Midway Atoll. Journal of Wildlife Diseases 23, 432-437. https://doi.org/10.7589/0090-3558-23.3.432

Slabe, V.A., Anderson, J.T., Cooper, J., Brown, B., Ortiz, P., Buchweitz, J., McRuer, D., Katzner, T., 2019. Lead in piscivorous raptors during breeding season in the Chesapeake Bay region of Maryland and Virginia, USA. Environmental Toxicology and Chemistry 38, 862-871. https://doi.org/10.1002/etc.4376

Sowers, M., Jannausch, M., Scholl, T., Li, W., Kemp, F.W. and Bogden, J.D., 2002. Blood lead concentrations and pregnancy outcomes. Archives of Environmental Health: An International Journal, 57, 489-495.

Therneau T (2015) A Package for Survival Analysis in R. version 2.38, <URL: https://CRAN.Rproject.org/package=survival $>$.

Tong, S., Schirnding, Y.E.V. and Prapamontol, T., 2000. Environmental lead exposure: a public health problem of global dimensions. Bulletin of the world health organization, 78, 10681077.

USFWS. 2016a. Bald and Golden Eagles: Population demographics and estimation of sustainable take in the United States, 2016 update. Division of Migratory Bird Management, Washington D.C., USA.

USFWS. 2016b. Eagle permits; revisions to regulations for eagle incidental take and take of eagle nests. <https://www.federalregister.gov/documents/2016/12/16/2016-29908/eaglepermits-revisions-to-regulations-for-eagle-incidental-take-and-take-of-eagle-nests $>$. Accessed 13 Mar 2019.

Watts, B.D., Therres, G.D., Byrd, M.A., 2008. Recovery of the Chesapeake Bay bald eagle 
nesting population. Journal of Wildlife Management 72, 152-158. https://doi.org/10.2193/2005-616 
Table 1. Statistics describing Central tendencies of blood lead concentrations ( $\mu \mathrm{g} / \mathrm{dL})$ of (a) golden eagles and (b) bald eagles from North America by (a) age, (b) month, (c) Flyway, and (d) disposition. Samples were collected from 2010-2018.

\begin{tabular}{llllllll}
\hline \multicolumn{6}{c}{ (a) Bald Eagle } & \multicolumn{7}{c}{ ( } \\
\hline Age & $\mathrm{n}$ & $<$ LOD & Median & Mean & SD & $95 \%$ LCL & $95 \%$ UCL \\
\hline Adult & 145 & 2 & 19.04 & 92.78 & 264.79 & 49.68 & 135.87 \\
Juvenile & 39 & 1 & 11.18 & 36.19 & 79.40 & 11.27 & 61.11 \\
Subadult & 53 & 5 & 23.04 & 62.72 & 160.01 & 19.64 & 105.80 \\
\hline Month & & & & & & & \\
\hline January & 22 & 1 & 30.20 & 119.45 & 206.37 & 33.22 & 205.68 \\
February & 26 & 4 & 8.93 & 17.22 & 18.31 & 10.18 & 24.26 \\
March & 24 & 2 & 20.36 & 37.32 & 58.01 & 14.11 & 60.53 \\
April & 8 & 1 & 5.25 & 7.04 & 4.86 & 3.67 & 10.40 \\
May & 7 & 0 & 2.44 & 4.76 & 5.40 & 0.76 & 8.76 \\
June & 18 & 0 & 7.49 & 10.16 & 7.82 & 6.55 & 13.77 \\
July & 18 & 0 & 6.40 & 8.63 & 8.27 & 4.81 & 12.45 \\
August & 12 & 0 & 14.50 & 17.45 & 14.59 & 9.20 & 25.71 \\
September & 7 & 0 & 7.76 & 328.36 & 830.14 & -286.60 & 943.32 \\
October & 14 & 0 & 14.99 & 22.38 & 22.29 & 10.70 & 34.05 \\
November & 40 & 0 & 32.90 & 121.93 & 262.26 & 40.66 & 203.21 \\
December & 41 & 0 & 58.20 & 148.67 & 261.72 & 68.56 & 228.78 \\
\hline Flyway & & & & & & & \\
\hline Atlantic & 123 & 4 & 10.31 & 82.78 & 271.46 & 34.81 & 130.75 \\
Central & 83 & 0 & 34.20 & 70.60 & 113.38 & 46.21 & 94.99 \\
Mississippi & 28 & 4 & 10.13 & 72.78 & 253.17 & -21.00 & 166.55 \\
Pacific & 3 & 0 & 43.03 & 34.73 & 24.12 & 7.43 & 62.02 \\
\hline Disposition & & & & & & & \\
\hline Free-flying & 128 & 8 & 25.20 & 52.15 & 95.43 & 35.62 & 68.68 \\
Rehabilitation & 109 & 0 & 10.88 & 105.65 & 311.07 & 47.25 & 164.04 \\
\hline & & & & & & & \\
\hline
\end{tabular}




\section{(b) Golden Eagle}

\begin{tabular}{llllllll}
\hline Age & $\mathrm{n}$ & $<$ LOD & Median & Mean & SD & $95 \%$ LCL & $95 \%$ UCL \\
\hline Adult & 116 & 18 & 11.99 & 22.78 & 40.84 & 15.35 & 30.21 \\
Juvenile & 61 & 18 & 2.03 & 6.11 & 10.02 & 3.60 & 8.63 \\
Subadult & 207 & 14 & 10.22 & 18.91 & 36.52 & 13.94 & 23.89 \\
\hline Month & & & & & & & \\
\hline January & 62 & 4 & 62 & 4 & 12.06 & 22.99 & 43.43 \\
February & 96 & 16 & 12.07 & 27.27 & 54.33 & 16.41 & 38.14 \\
March & 62 & 2 & 11.99 & 17.78 & 19.51 & 12.92 & 22.63 \\
April & 24 & 1 & 9.26 & 19.68 & 29.16 & 8.01 & 31.35 \\
May & 14 & 1 & 4.10 & 9.16 & 16.21 & 0.67 & 17.65 \\
June & 7 & 0 & 8.07 & 11.46 & 10.09 & 3.99 & 18.93 \\
July & 2 & 0 & $\mathrm{NA}$ & 0.98 & 0.60 & 0.14 & 1.81 \\
August & 1 & 0 & $\mathrm{NA}$ & 3.706 & $\mathrm{NA}$ & $\mathrm{NA}$ & $\mathrm{NA}$ \\
September & 12 & 4 & 6.72 & 6.85 & 3.41 & 4.92 & 8.78 \\
October & 68 & 17 & 3.53 & 8.63 & 13.14 & 5.51 & 11.76 \\
November & 17 & 2 & 10.39 & 12.77 & 12.50 & 6.83 & 18.72 \\
December & 19 & 3 & 4.69 & 13.75 & 18.47 & 5.45 & 22.06 \\
\hline Flyway & & & & & & & \\
\hline Atlantic & 57 & 1 & 14.94 & 26.63 & 45.08 & 14.93 & 38.33 \\
Central & 112 & 16 & 8.79 & 20.82 & 43.24 & 12.81 & 28.83 \\
Pacific & 215 & 33 & 8.30 & 14.28 & 26.91 & 10.68 & 17.88 \\
\hline Disposition & & & & & & & \\
\hline Free-flying & 355 & 48 & 9.70 & 17.11 & 30.92 & 13.90 & 20.33 \\
Rehabilitation & 29 & 2 & 8.17 & 29.24 & 71.20 & 3.33 & 55.16 \\
\hline & & & & & & & \\
\hline
\end{tabular}


Table 2. Statistics describing Central tendencies of liver lead concentrations (ppm DW) of (a) bald eagles and (b) golden eagles from North America by age, month, Flyway, and disposition. Samples were collected from 2010-2018.

\section{(a) Bald Eagle}

\begin{tabular}{llllllll}
\hline Age & $\mathrm{n}$ & $<$ LOD & Median & Mean & SD & $95 \%$ LCL & $95 \%$ UCL \\
\hline Adult & 179 & 3 & 1.73 & 44.83 & 73.67 & 34.03 & 55.62 \\
Juvenile & 47 & 11 & 0.25 & 17.73 & 51.73 & 2.94 & 32.52 \\
Subadult & 45 & 5 & 0.72 & 16.65 & 38.75 & 5.33 & 27.97 \\
\hline Month & & & & & & & \\
\hline January & 49 & 0 & 1.70 & 28.73 & 47.43 & 15.45 & 42.01 \\
February & 30 & 0 & 2.18 & 43.54 & 66.08 & 19.90 & 67.19 \\
March & 50 & 1 & 2.61 & 63.55 & 80.79 & 41.15 & 85.94 \\
April & 33 & 2 & 2.66 & 55.15 & 94.75 & 22.82 & 87.48 \\
May & 12 & 1 & 0.28 & 19.85 & 65.39 & -17.14 & 56.85 \\
June & 17 & 5 & 0.16 & 1.09 & 2.44 & -0.07 & 2.25 \\
July & 16 & 5 & 0.29 & 0.81 & 1.13 & 0.25 & 1.36 \\
August & 8 & 1 & 0.36 & 0.71 & 0.54 & 0.34 & 1.08 \\
September & 7 & 1 & 1.63 & 15.43 & 38.75 & -13.28 & 44.13 \\
October & 14 & 3 & 0.72 & 17.05 & 40.33 & -4.08 & 38.17 \\
November & 13 & 0 & 0.76 & 42.43 & 75.62 & 1.33 & 83.54 \\
December & 22 & 0 & 1.53 & 32.78 & 68.33 & 4.22 & 61.33 \\
\hline Flyway & & & & & & & \\
\hline Atlantic & 53 & 10 & 1.29 & 18.70 & 40.26 & 7.86 & 29.54 \\
Central & 131 & 7 & 1.82 & 46.05 & 77.77 & 32.73 & 59.37 \\
Mississippi & 39 & 0 & 0.74 & 39.94 & 73.46 & 16.89 & 63.00 \\
Pacific & 48 & 2 & 1.08 & 21.37 & 42.69 & 9.29 & 33.45 \\
\hline Disposition & & & & & & & \\
\hline Free flying & 218 & 12 & 1.22 & 37.98 & 69.81 & 28.71 & 47.25 \\
Rehabilitation & 53 & 7 & 1.55 & 25.03 & 51.25 & 11.23 & 38.83 \\
\hline & & & & & & & \\
\hline & 53 & & & & \\
\hline
\end{tabular}


(b) Golden Eagle

\begin{tabular}{llllllll}
\hline Age & $\mathrm{n}$ & $<$ LOD & Median & Mean & SD & $95 \%$ LCL & $95 \%$ UCL \\
\hline Adult & 70 & 5 & 1.02 & 7.20 & 18.04 & 2.97 & 11.42 \\
Juvenile & 34 & 4 & 0.47 & 1.78 & 4.60 & 0.23 & 3.32 \\
Subadult & 67 & 8 & 0.39 & 41.23 & 319.47 & -35.27 & 117.73 \\
\hline Month & & & & & & & \\
\hline January & 24 & 2 & 1.15 & 112.81 & 533.89 & -100.79 & 326.40 \\
February & 19 & 1 & 0.88 & 12.59 & 23.02 & 2.24 & 22.94 \\
March & 25 & 1 & 0.34 & 7.09 & 20.79 & -1.06 & 15.24 \\
April & 19 & 1 & 0.85 & 3.90 & 7.70 & 0.44 & 7.37 \\
May & 10 & 3 & 0.22 & 0.40 & 0.44 & 0.12 & 0.67 \\
June & 7 & 0 & 0.38 & 1.03 & 1.17 & 0.17 & 1.90 \\
July & 14 & 1 & 0.46 & 0.64 & 0.45 & 0.40 & 0.88 \\
August & 9 & 3 & 0.30 & 0.47 & 0.39 & 0.22 & 0.73 \\
September & 12 & 3 & 0.21 & 0.33 & 0.27 & 0.18 & 0.48 \\
October & 10 & 1 & 0.21 & 0.65 & 0.89 & 0.10 & 1.20 \\
November & 9 & 1 & 2.34 & 6.90 & 14.33 & -2.47 & 16.26 \\
December & 13 & 0 & 2.23 & 2.50 & 2.12 & 1.35 & 3.66 \\
\hline Flyway & & & & & & & \\
\hline Atlantic & 4 & 0 & 2.45 & 9.84 & 15.98 & -5.82 & 25.49 \\
Central & 83 & 14 & 0.75 & 5.52 & 16.10 & 2.06 & 8.98 \\
Pacific & 84 & 3 & 0.47 & 33.68 & 285.09 & -27.29 & 94.65 \\
\hline Disposition & & & & & & & \\
\hline Free flying & 169 & 17 & 0.49 & 19.47 & 201.22 & -10.87 & 49.81 \\
Rehabilitation & 2 & 0 & NA & 18.09 & 22.11 & -12.56 & 48.74 \\
\hline & & & & & & & \\
\hline
\end{tabular}


Table 3. Statistics describing Central tendencies of femur lead concentrations (ppm DW) of (a) bald eagles and (b) golden eagles by age, Flyway, and disposition. Samples were collected from 2010-2018.

\begin{tabular}{llllllll}
\hline \multicolumn{2}{c}{ (a) Bald Eagle } & \multicolumn{7}{c}{} \\
\hline Age & $\mathrm{n}$ & $<$ LOD & Median & Mean & SD & 95\% LCL & 95\% UCL \\
\hline Adult & 137 & 1 & 13.27 & 17.91 & 18.43 & 14.82 & 21.00 \\
Juvenile & 50 & 3 & 2.11 & 14.52 & 41.92 & 2.90 & 26.15 \\
Subadult & 39 & 1 & 5.54 & 13.22 & 20.35 & 6.84 & 19.61 \\
\hline Flyway & & & & & & & \\
\hline Atlantic & 89 & 2 & 6.13 & 11.88 & 21.40 & 7.43 & 16.32 \\
Central & 63 & 1 & 16.37 & 26.90 & 36.10 & 17.98 & 35.81 \\
Mississippi & 16 & 0 & 11.43 & 13.47 & 9.75 & 8.70 & 18.25 \\
Pacific & 58 & 2 & 5.95 & 12.55 & 17.07 & 8.16 & 16.94 \\
\hline Disposition & & & & & & & \\
\hline Free-flying & 171 & 4 & 9.55 & 17.98 & 28.13 & 13.77 & 22.20 \\
Rehabilitation & 55 & 1 & 6.42 & 11.27 & 15.22 & 7.24 & 15.29 \\
\hline
\end{tabular}

\begin{tabular}{llllllll}
\hline \multicolumn{2}{c}{ (b) Golden Eagle } & \multicolumn{1}{c}{} \\
\hline Age & $\mathrm{n}$ & $<$ LOD & Median & Mean & SD & $95 \%$ LCL & 95\% UCL \\
\hline Adult & 90 & 0 & 15.87 & 33.71 & 69.64 & 19.32 & 48.10 \\
Juvenile & 39 & 1 & 3.29 & 10.84 & 16.91 & 5.54 & 16.15 \\
Subadult & 94 & 0 & 4.27 & 10.99 & 15.03 & 7.95 & 14.02 \\
\hline Flyway & & & & & & & \\
\hline Atlantic & 11 & 0 & 14.88 & 20.00 & 23.89 & 5.88 & 34.11 \\
Central & 63 & 0 & 13.83 & 26.49 & 72.26 & 8.64 & 44.33 \\
Pacific & 149 & 1 & 5.67 & 17.45 & 32.70 & 12.20 & 22.70 \\
\hline Disposition & & & & & & & \\
\hline Free flying & 218 & 1 & 8.61 & 20.06 & 47.36 & 13.77 & 26.34 \\
Rehabilitation & 5 & 0 & 9.95 & 23.30 & 34.07 & -6.57 & 53.16 \\
\hline
\end{tabular}


Table 4. Beta coefficients, standard errors, $\mathrm{z}$-scores and $\mathrm{p}$ values for the significant predictor variables in the final tobit models describing blood, liver, and femur lead concentrations of (a) bald eagles and (b) golden eagles.

\begin{tabular}{|c|c|c|c|c|}
\hline \multicolumn{2}{|c|}{ (a) Bald Eagle } & $\beta$ & $\mathrm{SE}$ & $\mathrm{Z}$ \\
\hline \multirow[t]{12}{*}{ Blood } & (Intercept) & 1.52 & 0.47 & 3.21 \\
\hline & Month - August & 0.92 & 0.61 & 1.52 \\
\hline & Month - December & 2.67 & 0.51 & 5.19 \\
\hline & Month - February & 0.57 & 0.54 & 1.06 \\
\hline & Month - January & 1.98 & 0.55 & 3.60 \\
\hline & Month - July & 0.38 & 0.56 & 0.67 \\
\hline & Month - June & 0.49 & 0.56 & 0.86 \\
\hline & Month - March & 1.28 & 0.54 & 2.35 \\
\hline & Month - May & -0.34 & 0.69 & -0.50 \\
\hline & Month - November & 2.09 & 0.52 & 4.06 \\
\hline & Month - October & 1.00 & 0.59 & 1.69 \\
\hline & Month - September & 1.50 & 0.69 & 2.18 \\
\hline \multirow[t]{14}{*}{ Liver } & (Intercept) & 0.30 & 0.44 & 0.70 \\
\hline & Age - Juvenile & -0.39 & 0.38 & -1.02 \\
\hline & Age - Subadult & -0.63 & 0.32 & -2.00 \\
\hline & Month - August & -1.40 & 0.72 & -1.94 \\
\hline & Month - December & 0.35 & 0.62 & 0.56 \\
\hline & Month - February & 0.58 & 0.55 & 1.04 \\
\hline & Month - January & 0.21 & 0.53 & 0.40 \\
\hline & Month - July & -0.78 & 0.60 & -1.30 \\
\hline & Month - June & -0.55 & 0.75 & -0.73 \\
\hline & Month - March & -0.50 & 0.53 & -0.94 \\
\hline & Month - May & -1.78 & 0.69 & -2.59 \\
\hline & Month - November & 0.56 & 0.69 & 0.80 \\
\hline & Month - October & -0.99 & 0.67 & -1.47 \\
\hline & Month - September & -1.56 & 0.64 & -2.42 \\
\hline \multirow[t]{6}{*}{ Femur } & (Intercept) & 2.05 & 0.15 & 13.29 \\
\hline & Age - Juvenile & -1.24 & 0.21 & -5.83 \\
\hline & Age - Subadult & -0.64 & 0.23 & -2.76 \\
\hline & Flyway - Central & 0.71 & 0.19 & 3.79 \\
\hline & Flyway - Mississippi & 0.49 & 0.29 & 1.70 \\
\hline & Flyway - Pacific & -0.58 & 0.33 & -1.75 \\
\hline
\end{tabular}




\begin{tabular}{cllll}
\hline (b) Golden Eagle & & $\beta$ & SE & Z \\
\hline Blood & (Intercept) & 1.52 & 0.47 & 3.21 \\
& Age - Juvenile & 0.92 & 0.61 & 1.52 \\
& Age - Subadult & 2.67 & 0.51 & 5.19 \\
& Flyway - Central & 0.57 & 0.54 & 1.06 \\
& Flyway - Pacific & 1.50 & 0.69 & 2.18 \\
\hline Liver & (Intercept) & -0.08 & 0.40 & -0.19 \\
& Month - August & -1.52 & 0.72 & -2.11 \\
& Month - December & 0.49 & 0.62 & 0.79 \\
& Month - February & 0.58 & 0.56 & 1.04 \\
& Month - January & 0.40 & 0.53 & 0.76 \\
& Month - July & -0.77 & 0.61 & -1.26 \\
& Month - June & -0.53 & 0.76 & -0.70 \\
Month - March & -0.30 & 0.53 & -0.58 \\
& Month - May & -1.67 & 0.69 & -2.41 \\
& Month - November & 0.50 & 0.70 & 0.71 \\
& Month - October & -1.09 & 0.68 & -1.61 \\
& Month - September & -1.63 & 0.65 & -2.51 \\
\hline Femur & (Intercept) & 2.51 & 0.55 & 4.58 \\
& Age - Juvenile & -1.37 & 0.28 & -4.87 \\
& Age - Subadult & -0.78 & 0.25 & -3.09 \\
& Flyway - Central & 0.45 & 0.56 & 0.79 \\
& Flyway - Mississippi & -0.27 & 0.70 & -0.38 \\
& Flyway - Pacific & -0.34 & 0.56 & -0.59 \\
\hline & & & & \\
& & & &
\end{tabular}


Figure 1. Continental US with blood, liver, and femur sample locations by county and USFWS administrative Flyway.

Figure 2. Boxplots of blood lead concentrations by (a) month (bald eagle) and (b) Flyway (golden eagle). Boxplots are presented on a log scale to limit the y axis for graphical representation of the data.

Figure 3. Boxplots of liver lead concentrations of bald eagles by age group. Boxplots are presented on a log scale to limit the y axis for graphical representation of the data.

Figure 4. Boxplots comparing (a) blood and (b) liver lead concentrations of North American eagle species. Boxplots are presented on a log scale to limit the y axis for graphical representation of the data. 
Fig 1.
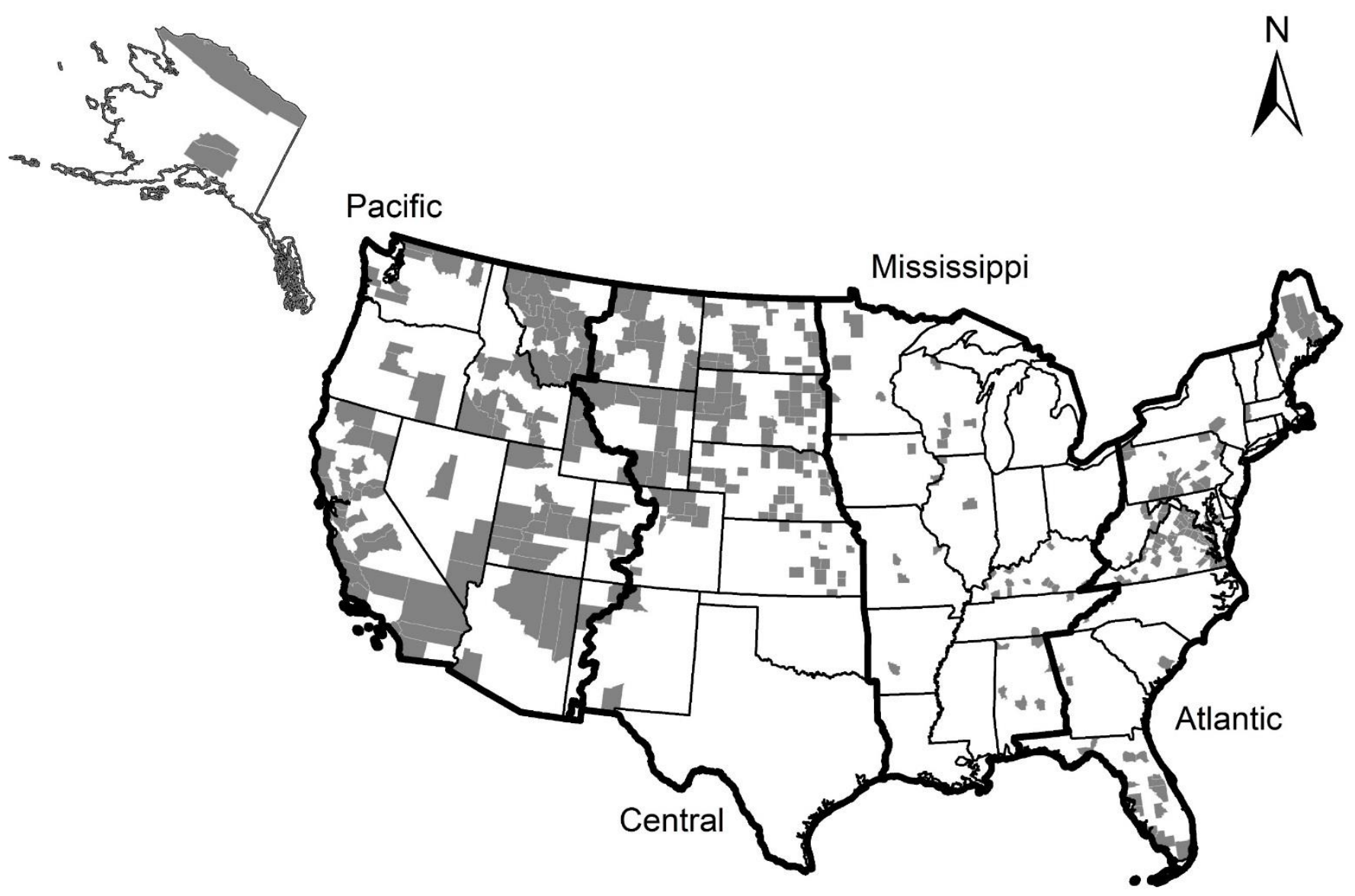

Sample Locations by County

Flyway Boundaries

$0 \quad 500 \quad 1,000$ Kilometers 
Fig. 2a

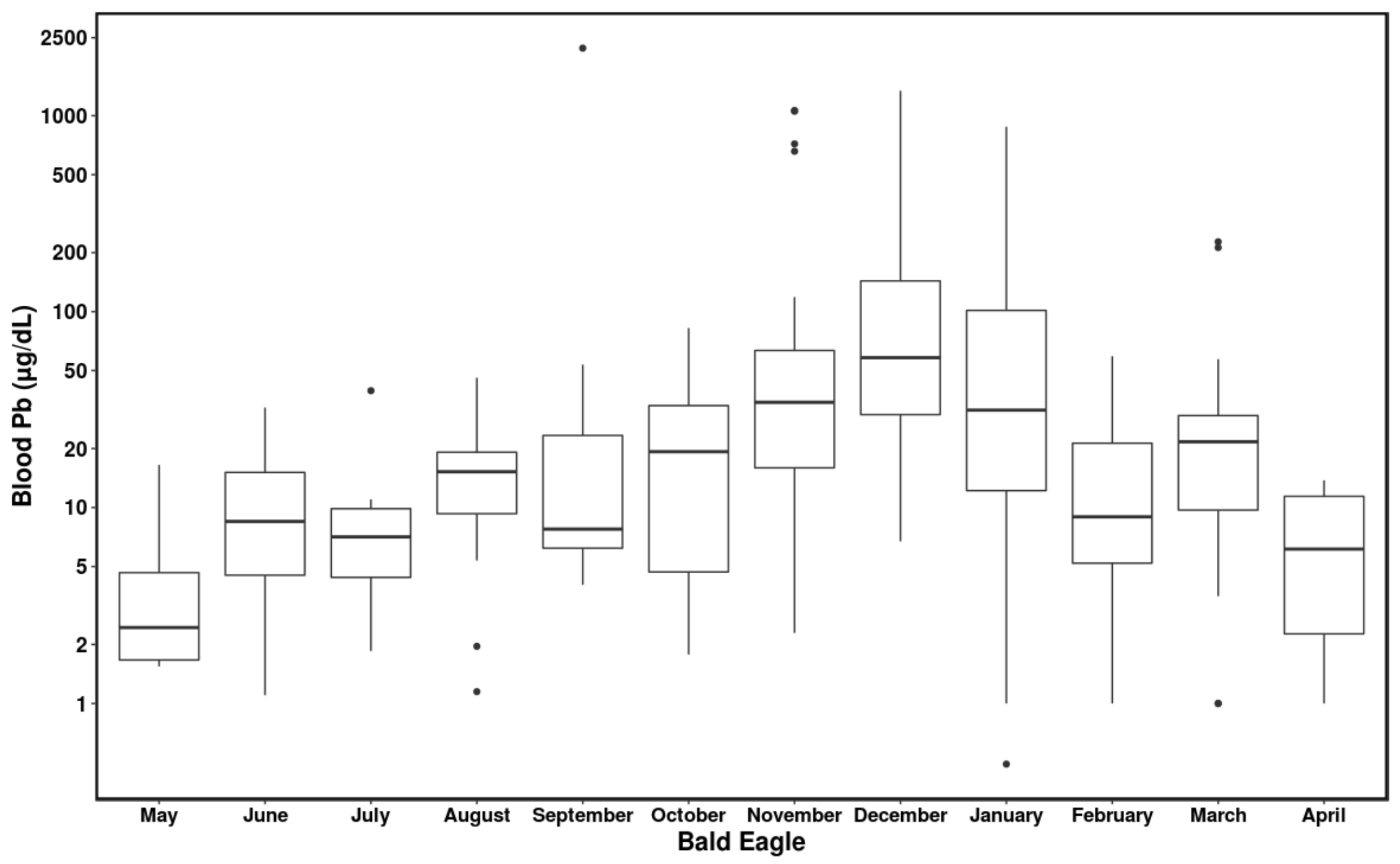


Fig. 2b

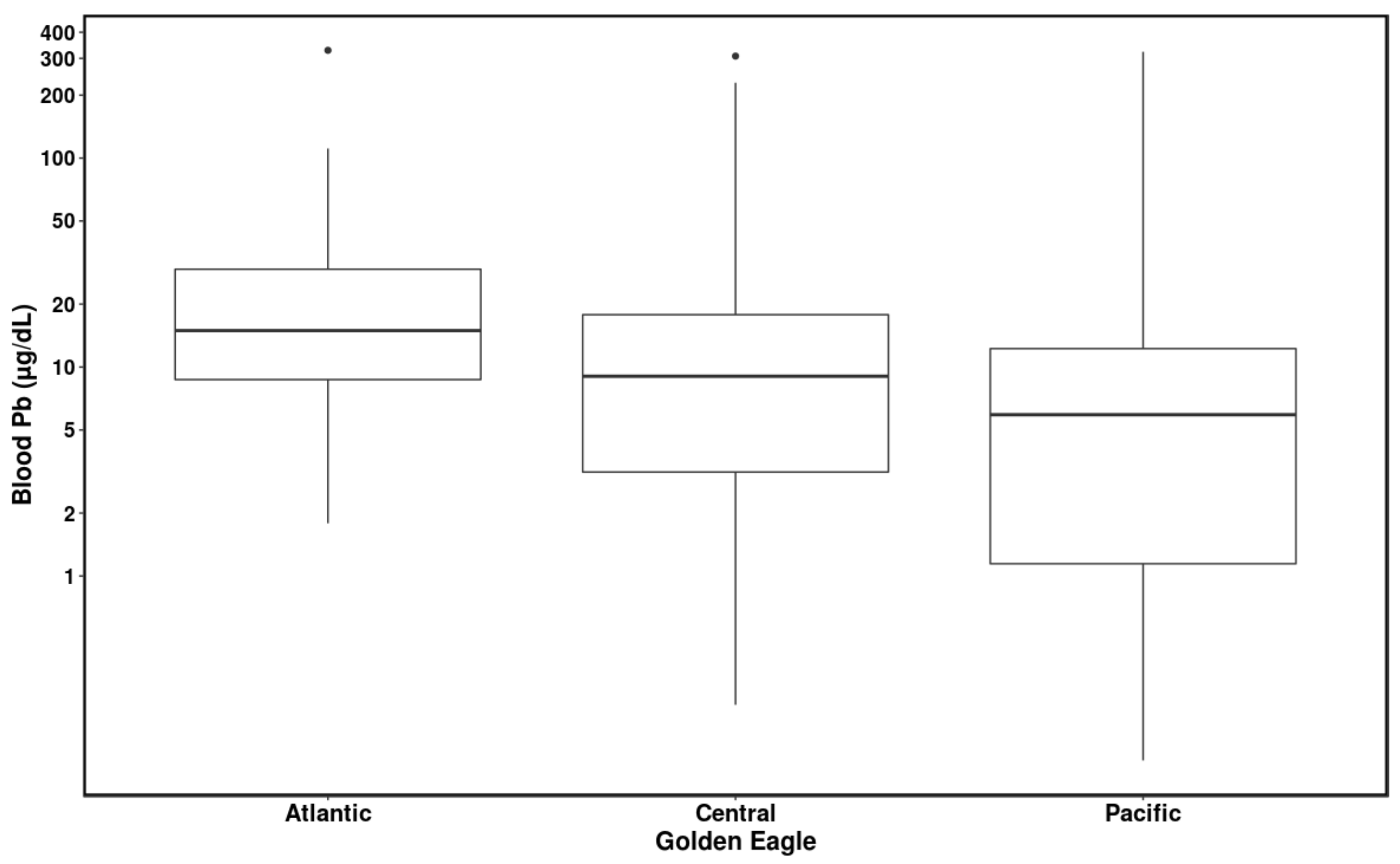


Fig. 3

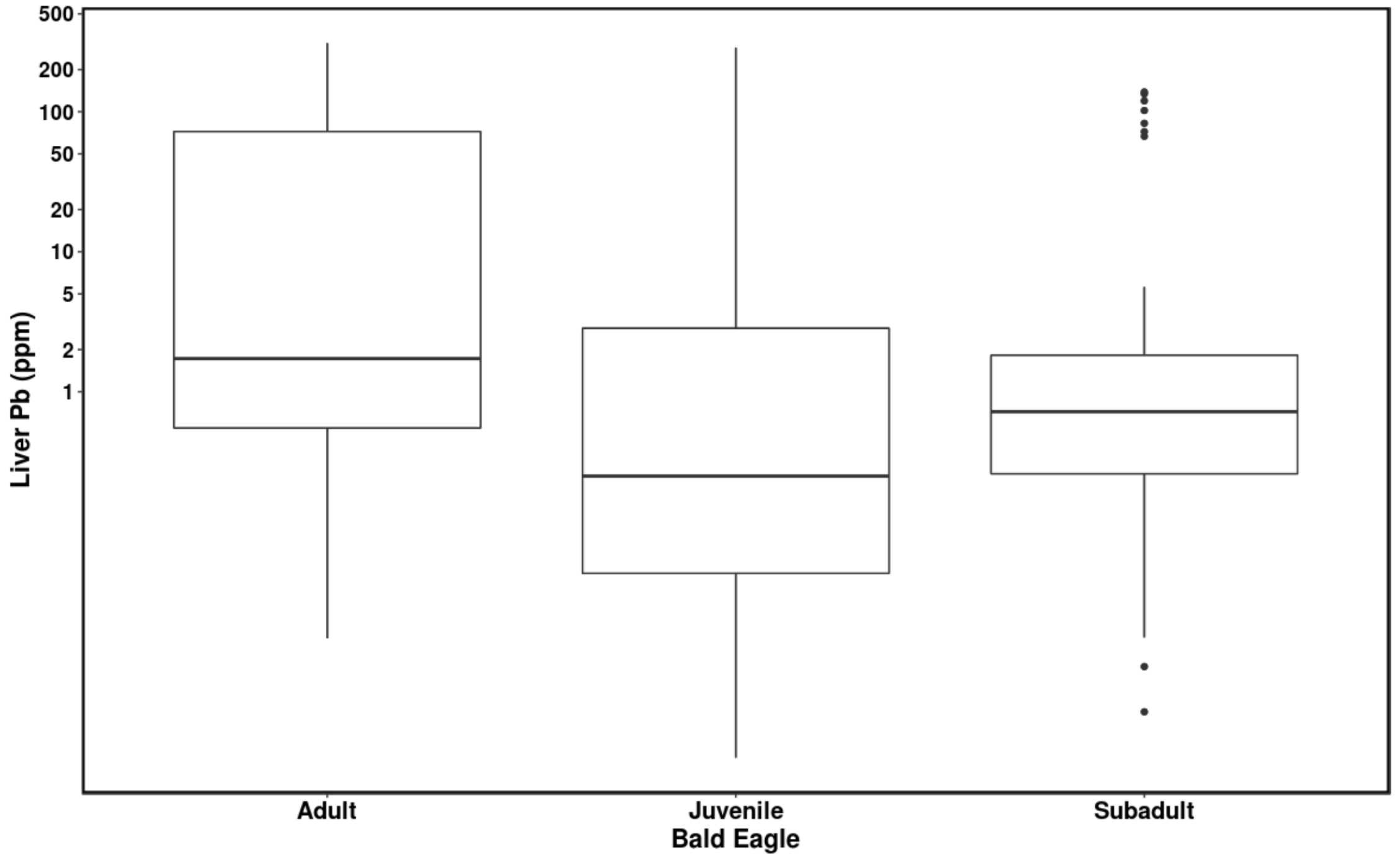


Fig. 4a

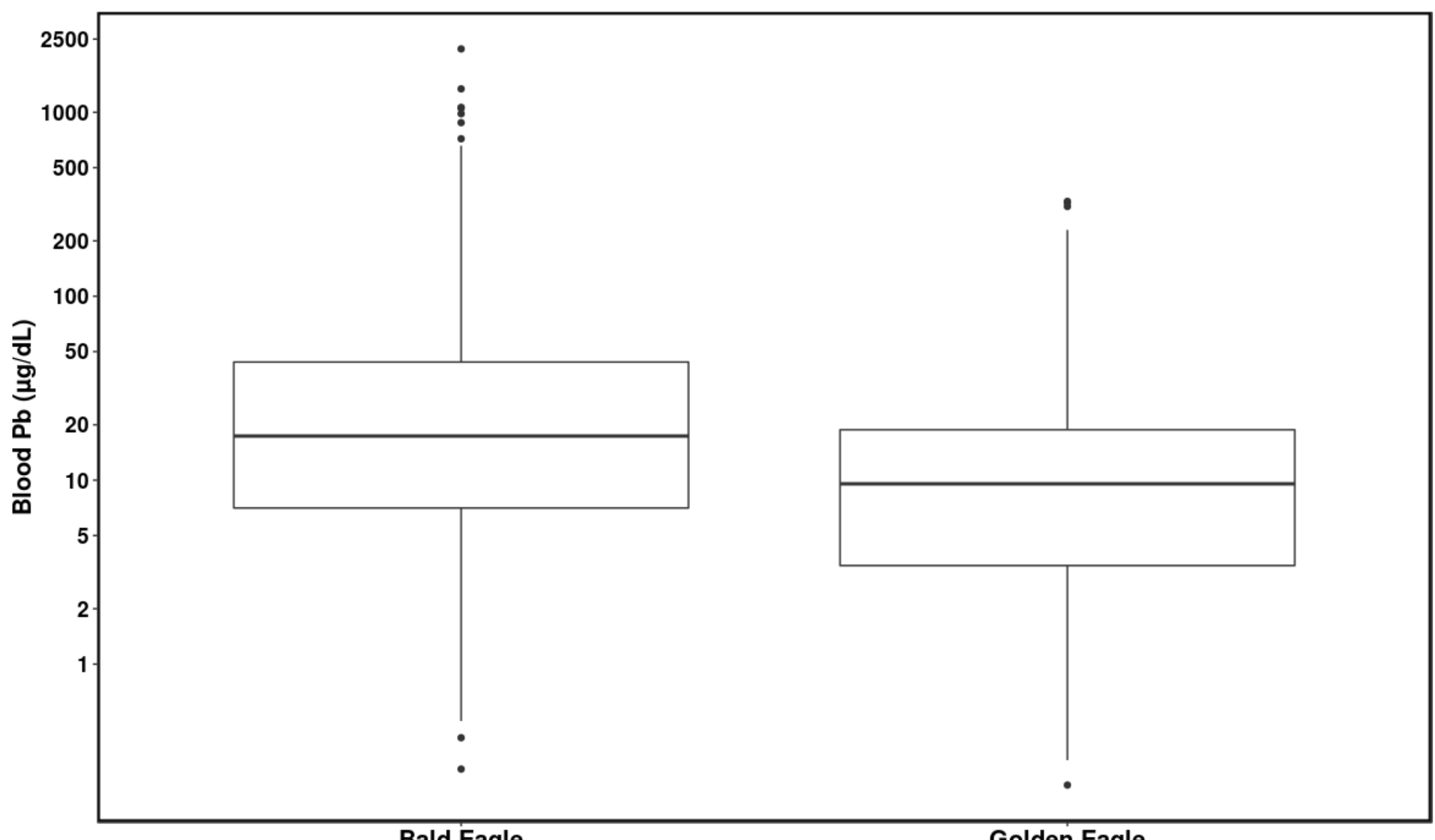

Bald Eagle

Golden Eagle 
Fig.4b

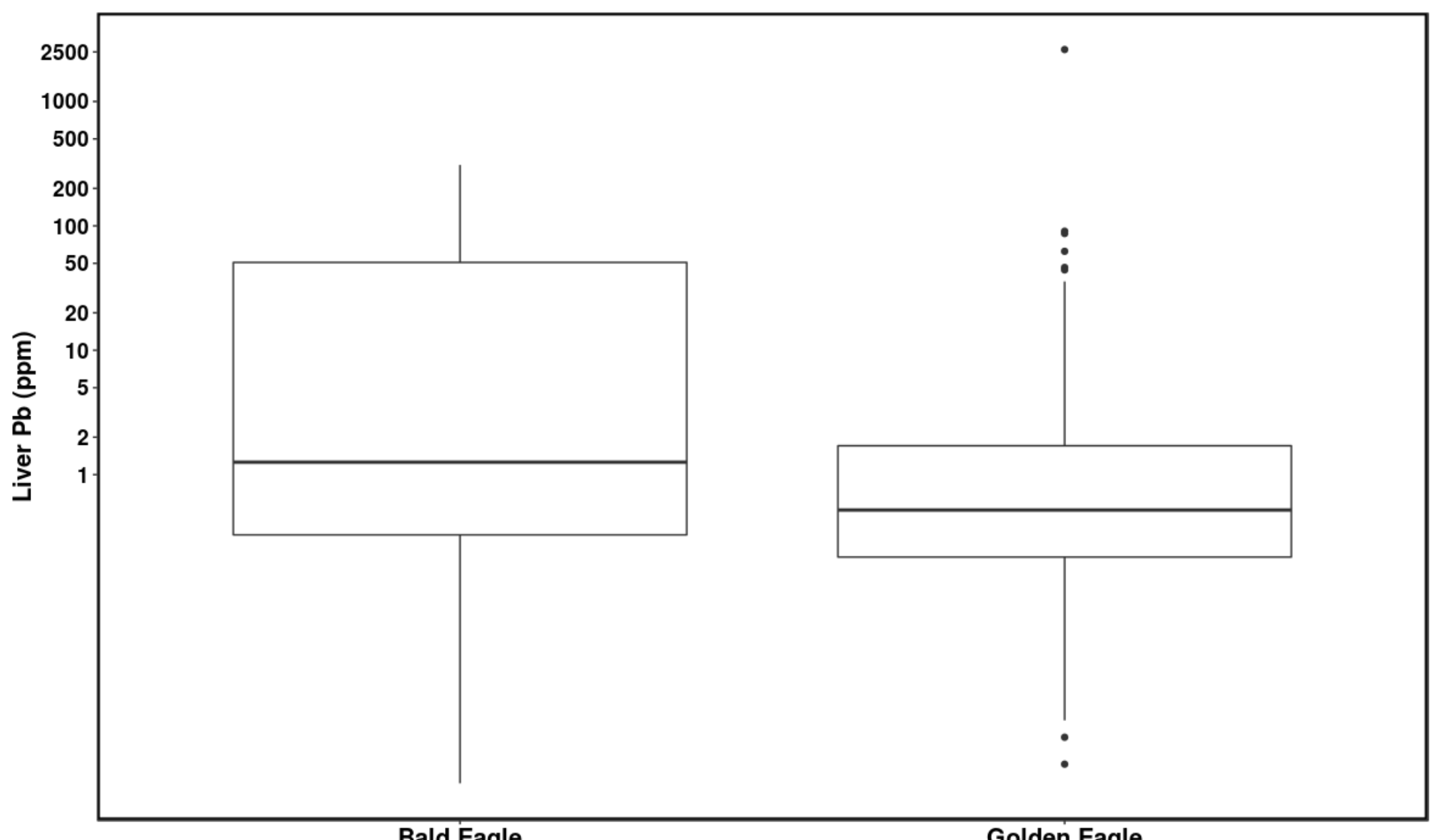

Bald Eagle

Golden Eagle 


\section{CHAPTER 6}

\section{Concluding Remarks}

Vincent A. Slabe ${ }^{1}$

1 Division of Forestry and Natural Resources, West Virginia University, Morgantown WV 26506 U.S.A. 
To further understand the sources and pathways of lead exposure of raptors, I studied this problem by investigating its toxicology in novel species, regions, seasons and spatial scales. The lack of age-related differences in the lead exposure of osprey bring to light a previously undocumented pattern in a previously understudied non-scavenging piscivorous raptor. Seasonal avian scavengers in this study including bald eagles and previously unstudied red-shouldered hawks exhibited age-related differences in lead exposure. This finding illustrates the cumulative nature of lead accumulation in raptors that scavenge seasonally and the absence of this pattern in a raptor that does not scavenge.

Prior to this study, there were little data available in the eastern US and at a nationwide scale describing lead concentration patterns in raptor species. This study provides year-round lead concentration data for the eastern US in multiple facultative scavenging birds. These data suggest that the degree to which an individual species scavenges is a determinant of lead exposure. Additionally, this study provides detailed nationwide patterns of lead concentrations in bald and golden eagles. These nationwide patterns mirror findings presented in previous regional studies that describe lead exposure of eagle species within smaller geographic regions of North America.

\section{RECOMMENDATIONS FOR FUTURE RESEARCH}

There is a large body of work documenting lead concentrations in wildlife and this catalogue continues to grow. Moving forward, I recommend studies that will use these data to assist in the understanding of the population level effects of this toxicant on specific species. Lead poisoning is currently one of the leading causes of mortality in bald and golden eagles in the US. More work needs to be accomplished in the interpretation of lead concentrations and correlated effects on population parameters such as mortality and fecundity rates. 
Due to the tight relationship of this research topic to the hunting community, I

recommend additional studies that can further describe the human dimensions of this issue, and more specifically, describe hunter's attitudes toward the lead poisoning of wildlife. The more we understand the attitudes and belief systems of the hunting community, the easier it will be to recommend pathways forward.

\section{MANAGEMENT RECOMMENDATIONS}

This study illustrates that lead exposure occurs commonly in multiple raptor species at multiple spatial scales in the US. The pathway by which this exposure occurs has broad-scale health implications for all scavenging wildlife. In addition to the incidental ingestion of fragmented ammunition by scavenging wildlife, lead can easily end up in harvested game consumed by humans. There is no health benefit that results from consuming lead. In fact, lead is a neurotoxin, can damage almost every system in the body and is particularly dangerous for children. For this reason, it seems prudent to recommend preventing this pathway of lead poisoning in humans and wildlife.

Since the industrial revolution, legislation and changing cultural practices have removed lead from multiple common applications in our society. Due to the current political environment in the US, many citizens, lobbyists and stakeholders will strongly resist any legislation that restricts the application and use of guns in our society. For this reason, I do not support legislation preventing the use of lead ammunition for hunting. As an alternative, I challenge myself and others who are knowledgeable on this issue to continue to speak in public settings in an effort to educate the general public and licensed hunters about lead poisoning, the pathways by which humans and wildlife are poisoned, and mechanisms to preserve the tradition of hunting while reducing the frequency of lead exposure of humans and wildlife. The easiest way for 
hunters to avoid leaving a contaminated food source on the landscape is the use of non-toxic ammunition. Many non-lead alternatives are readily available for use and with the implementation of a statewide ban of lead ammunition in California, the ammunition industry has responded with affordable and widely distributed alternatives to lead.

As a hunter myself, I identify with the majority of the hunting population in this country - we are conservationists and do not want to knowingly leave a contaminated food source on the landscape for scavenging wildlife species such as raptors. Furthermore, we enjoy providing our families with wild game as a healthy alternative to store-bought meat without the possibility of lead poisoning. 